Florida International University FIU Digital Commons

11-12-2009

\title{
A Methodological Framework for Modeling Pavement Maintenance Costs for Projects with Performance-based Contracts
}

Kamalesh Panthi

Florida International University, kpant003@fiu.edu

DOI: $10.25148 /$ etd.FI09120824

Follow this and additional works at: https://digitalcommons.fiu.edu/etd

Part of the Civil Engineering Commons, and the Construction Engineering and Management Commons

\section{Recommended Citation}

Panthi, Kamalesh, "A Methodological Framework for Modeling Pavement Maintenance Costs for Projects with Performance-based Contracts" (2009). FIU Electronic Theses and Dissertations. 120.

https://digitalcommons.fiu.edu/etd/120 


\title{
UUFLORIDA INTERNATIONAL UNIVERSITY
}

Miami, Florida

\section{A METHODOLOGICAL FRAMEWORK FOR MODELING PAVEMENT MAINTENANCE COSTS FOR PROJECTS WITH PERFORMANCE-BASED CONTRACTS}

A dissertation submitted in partial fulfillment of the requirements for the degree of DOCTOR OF PHILOSPHY

\author{
in \\ CIVIL ENGINEERING
}

by

Kamalesh Panthi 
To: Dean Amir Mirmiran

College of Engineering and Computing

This dissertation, written by Kamalesh Panthi, and entitled A Methodological Framework for Modeling Pavement Maintenance Costs for Projects with Performance-based Contracts, having been approved in respect to style and intellectual content, is referred to you for judgment.

We have read this dissertation and recommend that it be approved.

M. Emre Bayraktar

Arindam G. Chowdhury

Luis Prieto-Portar

Caesar Abi Shdid

Syed M. Ahmed, Major Professor

Date of Defense: November 12, 2009

The dissertation of Kamalesh Panthi is approved.

\begin{tabular}{r} 
Dean Amir Mirmiran \\
College of Engineering and Computing \\
\hline Dean George Walker \\
University Graduate School
\end{tabular}

Florida International University, 2009 


\section{ACKNOWLEDGMENTS}

A dissertation like this requires a great amount of sacrifice, effort, and patience by both the researcher and those around him/her. This dissertation is no different. I would therefore, like to thank everyone who directly or indirectly contributed in shaping up this dissertation work.

I would like to thank my advisory and examining committee members, Dr. M. Emre Bayraktar, Dr. Arindam G. Chowdhury, Dr. Luis Prieto-Portar, and Dr. Caesar Abi Shdid for their support and guidance throughout this research.

I wish to extend special thanks to Dr. Syed M. Ahmed, my major professor, for providing me with the opportunity to study under his guidance, and for his extra effort in helping me develop as a Ph.D. candidate. His continuous instruction, supervision and encouragement are greatly appreciated, and I shall forever remain indebted.

A special note of thanks is due to Mr. Mike Smith, Manager of Maintenance and Operations of Miami Dade Expressways Authority; Mr. Jose Quintana, Maintenance Engineer of Florida's Turnpike Enterprise; and Mr. Jose Darsin, Senior Operations Manager of Transfield Services, for kindly agreeing to provide expert opinion on my research work.

During my time as a graduate student in the Department of Construction Management at Florida International University, I had the privilege of receiving guidance and support from Dr. Irtishad Ahmad, Chair of Construction Management Department and other faculty members for which I'm very appreciative. I'm also thankful to Dr. Salman Azhar, Mrs. Bernadette Chung, Mr. Rizwan Farooqui, and Mr. Umut Artuk for their continual support. Finally, I thank god for having given me such a wonderful and loving family 
whose continual support and motivation encouraged me to achieve this highest level of education degree. I owe a lot to my wife, Rakshya, without whose patience and moral support, it would have been extremely difficult to complete this research.

Special gratitude is expressed to University Graduate School of Florida International University for providing me with the financial support in the form of a Dissertation Year Fellowship. 


\section{ABSTRACT OF THE DISSERTATION \\ A METHODOLOGICAL FRAMEWORK FOR MODELING PAVEMENT \\ MAINTENANCE COSTS FOR PROJECTS WITH PERFORMANCE-BASED \\ CONTRACTS \\ by}

Kamalesh Panthi

Florida International University, 2009

Miami, Florida

Professor Syed M. Ahmed, Major Professor

Performance-based maintenance contracts differ significantly from material and method-based contracts that have been traditionally used to maintain roads. Road agencies around the world have moved towards a performance-based contract approach because it offers several advantages like cost saving, better budgeting certainty, better customer satisfaction with better road services and conditions. Payments for the maintenance of road are explicitly linked to the contractor successfully meeting certain clearly defined minimum performance indicators in these contracts. Quantitative evaluation of the cost of performance-based contracts has several difficulties due to the complexity of the pavement deterioration process. Based on a probabilistic analysis of failures of achieving multiple performance criteria over the length of the contract period, an effort has been made to develop a model that is capable of estimating the cost of these performance-based contracts. One of the essential functions of such model is to predict performance of the pavement as accurately as possible. Prediction of future degradation of pavement is done using Markov Chain Process, which requires estimating transition 
probabilities from previous deterioration rate for similar pavements. Transition probabilities were derived using historical pavement condition rating data, both for predicting pavement deterioration when there is no maintenance, and for predicting pavement improvement when maintenance activities are performed.

A methodological framework has been developed to estimate the cost of maintaining road based on multiple performance criteria such as crack, rut and, roughness. The application of the developed model has been demonstrated via a real case study of Miami Dade Expressways (MDX) using pavement condition rating data from Florida Department of Transportation (FDOT) for a typical performance-based asphalt pavement maintenance contract. Results indicated that the pavement performance model developed could predict the pavement deterioration quite accurately. Sensitivity analysis performed shows that the model is very responsive to even slight changes in pavement deterioration rate and performance constraints. It is expected that the use of this model will assist the highway agencies and contractors in arriving at a fair contract value for executing long term performance-based pavement maintenance works. 


\section{TABLE OF CONTENTS}

CHAPTER

PAGE

1. INTRODUCTION

1.1 Background and Motivation

1.2 Problem Statement

1.3 Research Thesis

1.4 Research Goals and Objectives 6

1.5 Scope

1.6 Summary of Methodology 8

1.6.1 Define Number of Condition States/Categories 8

1.6.2 Determine Pavement Deterioration Rate 8

1.6.3 Generate Maintenance Transition Probability Matrix 9

1.6.4 Determine Current Distribution of Pavement in Different Condition $\quad 10$ States

1.6.5 Identify Treatment Costs for Each Maintenance Action 10

1.6.6 Iterate M\&R Actions Using Performance Triggers 10

1.6.7 Estimate Cost Associated With a Long Term Maintenance Contract $\quad 10$

1.7 Organization of Dissertation 11

1.7.1 Introduction 11

1.7.2 Literature Review 11

1.7.3 Using Historical Performance Data to Predict Pavement 12

Deterioration and Improvement

1.7.4 Framework for Cost Estimation Model 12

1.7.5 Applying Methodological Framework to a Case Study 12

1.7.6 Sensitivity Analysis and Model Validation 13

1.7.7 Research Summary, Research Limitations, and Recommendations 13 for Future Research

2. LITERATURE REVIEW 14

2.1 Introduction 14

2.2 Performance-based Maintenance Contracts in Construction Industry 14

2.3 Risks in Performance-based Maintenance Contracts 19

2.4 Pavement Performance Models 24

2.5 Maintenance Strategies for Multiple Performance Criteria 32

2.6 Assessing and Estimating Costs of Maintaining Pavements within 34

Specified Performance Criteria

2.7 Conclusion

3. USING HISTORICAL PERFORMANCE DATA TO PREDICT 43

PAVEMENT DETERIORATION AND IMPROVEMENT

3.1 Introduction 43

3.2 Markov Transition Probability Matrices 43 
3.3 Generating Transition Probability Matrices from Pavement Condition Data $\quad 46$

3.3.1 Data Types and Sources for Methodology Development 46

3.3.2 Pavement Condition Data 46

3.3.3 Number of Pavement Condition States 48

3.3.4 Current Pavement Condition State Vector 48

3.3.5 Transition Probabilities Estimation Using Count Proportions $\quad 50$

3.3.6 Transition Probability Matrices for M\&R Activities 59

3.4 Conclusion $\quad 71$

4. FRAMEWORK FOR THE COST ESTIMATION MODEL 73

$\begin{array}{ll}4.1 \text { Introduction } & 73\end{array}$

$\begin{array}{ll}\text { 4.2 Model Inputs } & 74\end{array}$

$\begin{array}{ll}\text { 4.2.1 Performance Specifications } & 74\end{array}$

$\begin{array}{ll}\text { 4.2.2 Pavement Condition } & 77\end{array}$

4.2.3 Maintenance and Repair Strategies, and Their Unit Costs 78

$\begin{array}{ll}\text { 4.3 Pavement Deterioration Model } & 78\end{array}$

4.4 Pavement Repair Model $\quad 79$

4.5 Iteration of Deterioration-Repair Process up to Analysis Period 80

4.6 Total Estimated Performance Cost 83

4.7 Conclusion $\quad 83$

5. APPLYING THE METHODOLOGICAL FRAMEWORK TO A CASE 84 STUDY: MIAMI DADE EXPRESSWAY

5.1 Introduction $\quad 84$

5.2 Miami Dade Expressway Asset Management Contract 85

5.3 Model Inputs $\quad 88$

$\begin{array}{lr}\text { 5.3.1 Performance Specifications } & 88\end{array}$

$\begin{array}{ll}\text { 5.3.2 Pavement Condition } & 93\end{array}$

5.3.3 Maintenance and Repair Strategies, and Their Unit Cost 97

5.4 Pavement Deterioration Model 99

$\begin{array}{ll}\text { 5.5 Pavement Repair Model } & 100\end{array}$

$\begin{array}{ll}5.6 \text { Iteration of Deterioration-Repair Process } & 102\end{array}$

5.7 Total Expected Costs 113

5.8 Unit Cost Variability in Estimating Total Cost 115

5.9 Conclusion 118

6. SENSITIVITY ANALYSIS AND MODEL VALIDATION 119

$\begin{array}{ll}6.1 \text { Introduction } & 119\end{array}$

$\begin{array}{lr}6.2 \text { Models } & 120\end{array}$

$\begin{array}{ll}\text { 6.2.1 Base Case } & 120\end{array}$

6.2.2 Sensitivity for Improved Pavement Performance 121

$\begin{array}{lr}\text { 6.2.3 Reduced Pavement Performance } & 123\end{array}$

$\begin{array}{ll}\text { 6.2.4 Relaxing a Performance Constraint } & 125\end{array}$

$\begin{array}{ll}\text { 6.2.5 Restricting a Performance Constraint } & 126\end{array}$

6.2.6 Relaxing Proportion of Pavement under Threshold Limit 126 
6.2.7 Restricting Proportion of Pavement under Threshold Limit

6.3 Model Validation

6.3.1 Component Model Validation

128

6.3.2 Overall Model Validation

130

6.4 Conclusion

7. RESEARCH SUMMARY, RESEARCH LIMITATIONS AND

133

RECOMMENDATIONS FOR FUTURE RESEARCH

7.1 Research Summary and Conclusions

133

7.2 Research Contributions

136

7.3 Research Limitations and Future Research

REFERENCES

APPENDICES

146

VITA

175 


\section{LIST OF TABLES}

TABLE

PAGE

$\begin{array}{lll}2.1 & \text { Warranty Provisions in the U.S } & 17\end{array}$

2.2 Types of Pavement Performance Model 26

2.3 Advantages and Disadvantages of Using Different Pavement Performance 30 Models

2.4 Performance Indicators and Their Measures for Different State DOTs 34

2.5 Matrix of Failures, Probabilities, Extent, and Repairs 36

2.6 Warranty Costing 36

3.1 Transition Probability Matrix 44

3.2 Data Types and Sources 46

3.3 Five-step Classification for Crack Condition States 48

3.4 Condition State Vector Using Probability Distribution of Pavement 49

3.5 Crack Condition Rating Distribution 52

3.6 Intermediate Transition Probability Matrix for Crack 52

3.7 Transition Probability Matrix for Deterioration-Crack 53

3.8 Ride Condition Rating Distribution 53

3.9 Intermediate Transition Probability Matrix for Ride $\quad 54$

3.10 Transition Probability Matrix for Deterioration-Ride $\quad 54$

3.11 Rut Condition Rating Distribution 54

3.12 Intermediate Transition Probability Matrix for Rut 55

3.13 Transition Probability Matrix for Deterioration-Rut 55 
3.14 Standards for Low and High Volume Highways in Annual Average Daily

Traffic Volumes for Freeway-Urban

3.15 Transition Probability Matrix for Different Distresses for Low AADT

3.16 An Identity Matrix

3.17 Crack Condition Distribution After Resurfacing

3.18 Intermediate Transition Probability Matrix for Crack After Resurfacing

3.19 Transition Probability Matrix for Resurfacing-Crack

3.20 Transition Probability Matrix for Reconstruction-Crack

3.21 Transition Probability Matrix for Resurfacing-Ride

3.22 Transition Probability Matrix for Reconstruction-Ride

3.23 Transition Probability Matrix for Resurfacing-Rut

3.24 Transition Probability Matrix for Reconstruction-Rut

3.25 Pavement Service Index (PSI) Range for Indiana DOT Pavement Condition Rating

3.26 Deriving Transition Probability Matrix for Minor Maintenance

3.27 Transition Probability Matrix for Minor Maintenance

3.28 Transition Probability Matrix for Pavement Maintenance Strategies for Crack 68

3.29 Transition Probability Matrix for Pavement Maintenance Strategies for Ride

3.30 Transition Probability Matrix for Maintenance Strategies for Rut

4.1 Standard Maintenance Strategies $\quad 82$

5.1 Maintenance Elements Covered Under the Asset Management Contract 87

5.2 Distress Threshold Values and Remedial Work Specified in the FDOT 90 Contractor Guaranteed Asphalt Pavement (CGAP)

5.3 Five-step Classification of the Condition States 
5.4 Distress Condition Rating of SR-836 (Dolphin Expressway) for Year $2008 \quad 94$

5.5 Condition State Distribution for Crack 95

5.6 Condition State Distribution for Ride 95

5.7 Condition State Distribution for Rut 95

5.8 Unit Cost of Different Maintenance Treatments 99

5.9 Transition Probability Matrix for Distresses Under Pavement Deterioration 100 (High AADT Volume)

5.10 Transition Probability Matrix for Pavement Repair 101

5.11 Percentage Distribution of Condition State for Year One with Routine 106 Maintenance

5.12 Percentage Distribution of Condition State for Year One with Minor 108 Maintenance

5.13 Percentage Distribution of Condition State for Year Two with Routine 110 Maintenance

5.14 Program of Maintenance Works and Their Cost 113

5.15 Program of Maintenance Works and Their Cost When Major Maintenance is 114 Scheduled in the First Year

5.16 Summary Statistics of Monte Carlo Simulation on Total Cost 116

6.1 Variables and Their Range for Sensitivity Analysis 120

6.2 Variables for Sensitivity and the Base Case $\quad 121$

6.3 Transition Probabilities Generated for Improved Performance (5\% Less 122 Deterioration)

6.4 Transition Probabilities Generated for Reduced Performance (5\% More $\quad 124$ Deterioration) 


\section{LIST OF FIGURES}

FIGURE

PAGE

2.1 Short-term Performance Warranty Contracts 18

2.2 Long-term Performance Warranty Contracts 19

2.3 Maintenance Performance Warranty Contracts 19

2.4 Variation in Pavement Life 22

2.5 Financial Risk Due to Prediction Error of Pavement Life 23

2.6 Deterioration Curve for Past and Future Pavement Condition 25

2.7 Typical Survivor Curve 29

2.8 Timing Criteria for Formulation of Pavement M\&R Strategies 32

3.1 The Transition between Two States 44

3.2 A Schematic Diagram Describing the State Transitions for a Three State 45 Model

3.3 The Possible Transitions Over Two Epochs 45

3.4 Definition of Condition States for a Flexible Pavement 48

4.1 A Methodological Framework to Estimate Cost of Performance-based 74 Pavement Maintenance Contracts

4.2 Pavement Failures and Repairs 79

4.3 Flowchart for Selecting Pavement Maintenance Strategies 81

$5.1 \quad$ Focus Area of Case Study $\quad 85$

5.2 Miami Dade Expressways Pavement Network 86

5.3 Condition Distribution of Pavement in Various Condition Ratings in Year 96 2008

5.4 An Example of Application of the Methodology to a Case Study Using Excel Spreadsheet 
5.5 Multiplication Process to Obtain Condition State Vector for Crack in Year

105

One with Routine Maintenance

5.6 Multiplication Process to Obtain Condition State Vector for Ride in Year

105

One with Routine Maintenance

5.7 Multiplication Process to Obtain Condition State Vector for Rut in Year

106

One with Routine Maintenance

5.8 Multiplication Process to Obtain Condition State Vector for Crack in Year

107

One with Minor Maintenance

5.9 Multiplication Process to Obtain Condition State Vector for Ride in Year One with Minor Maintenance

107

5.10 Multiplication Process to Obtain Condition State Vector for Rut in Year One with Minor Maintenance

108

5.11 Multiplication Process to Obtain Condition State Vector for Crack in Year

Two with Routine Maintenance

5.12 Multiplication Process to Obtain Condition State Vector for Ride in Year

Two with Routine Maintenance

5.13 Multiplication Process to Obtain Condition State Vector for Rut in Year

Two with Routine Maintenance

5.14 Condition Distribution of Crack

5.15 Condition Distribution of Ride

5.16 Condition Distribution of Rut

5.17 Frequency Chart from Monte Carlo Simulation

5.18 Cumulative Frequency Chart

6.1 Sensitivity for Improved Performance

6.2 Sensitivity for Reduced Performance

6.3 Comparison of Predicted Crack Condition Rating

6.4 Comparison of Predicted Ride Condition Rating

6.5 Comparison of Predicted Rut Condition Rating 


\section{LIST OF ACRONYMS}

AADT Average Annual Daily Traffic

AASHTO American Association of State Highway and Transportation Officials

ASCE American Society of Civil Engineers

BOT Build Operate Transfer

CGAP Contractor Guaranteed Asphalt Pavement

CR Crack

DOT Department of Transportation

FDOT Florida Department of Transportation

FHWA Federal Highway Administration

IRI International Roughness Index

KPI Key Performance Indicator

LOS Level of Service

LTPP Long Term Pavement Performance

MAC Managing Agent Contract

M\&R Maintenance and Rehabilitation

MDX Miami Dade Expressways

MRP Maintenance Rating Program

OPCR Output and Performance-based Road Contracts

PBC Performance Based Contacts

PCI Pavement Condition Index

PDF Probability Density function

PCS Pavement Condition State 


$\begin{array}{ll}\text { PJ } & \text { Performance Jump } \\ \text { PMMR } & \text { Performance Based Management and Maintenance of Roads } \\ \text { PMS } & \text { Pavement Management System } \\ \text { PSI } & \text { Pavement Serviceability Index } \\ \text { PSMC } & \text { Performance Specified Maintenance Contracts } \\ \text { RN } & \text { Ride Number } \\ \text { ROCOF } & \text { Rate of Occurrence of Failure } \\ \text { RU } & \text { Rut } \\ \text { SHA } & \text { State Highway Agency } \\ \text { SR } & \text { State Road } \\ \text { TPM } & \text { Transition Probability Matrix } \\ \text { USDOT } & \text { United States Department of Transportation } \\ \text { WB } & \text { World Bank }\end{array}$




\section{CHAPTER 1}

\section{INTRODUCTION}

\subsection{Background and Motivation}

American Society of Civil Engineers (ASCE) issued its latest Report Card for America's Infrastructure, the fourth since 1998. In its 2009 report card, the ASCE has awarded an overall grade of D for the nation's infrastructure, and stated that the cost to bring it up to good condition has risen to \$2.2 trillion (ASCE, 2009). Roadways, which comprise an essential component of the national infrastructure, received a grade of " $\mathrm{D}$ minus." There is an overwhelming amount of maintenance and rehabilitation work to be done but the resources available to achieve a better standard of infrastructure facilities are too limited. In such a scenario, Department of Transportation (DOT) in many states of the US have had to take drastic cost reduction measures by increasing the efficiency and effectiveness of the way the maintenance works of roads are carried out. For example, the Florida DOT (FDOT) has been mandated to execute an employee reduction plan and examine privatization as a means of cost reduction. The percentage of FDOT maintenance work performed by private contractors was estimated to be $74 \%$ in 2003 (TRC, 2006). Department managers compared the unit costs for services such as mowing, embankment repairs, and shoulder repairs performed by employees to prices bid by private contractors and determined that in many cases private contractors were providing services at a lower unit cost than in-house employees. This allowed the FDOT to reduce its budget request for highway maintenance by $\$ 5.9$ million in FY 2002-2003 (TRC, 2006). 
A majority of the maintenance of the state and federal highways network currently involve material and method type specification. These specifications are based on the prescriptions of the state highway agencies as regard to type of materials and construction procedures. The construction procedure is closely supervised by client representative engineers followed by a short maintenance period. Payment to the contractor is done once the majority of the construction is completed with a certain percentage retention held pending successful completion of the construction with no defects at the end of the maintenance period. Any defects or a failure after the maintenance period is the responsibility of the agency. So, in this type of contract, a major share of risk still remains with the agency, whereas the contractors do not have to carry the burden of performance risks after the short maintenance period. With the conventional material-and method-based specification, there is a limitation on the use of new materials and innovative, unproven design and construction technologies because of the fact that there exists the risk of not achieving the required performance level. In order to transfer this risk to the contractors who have a better control over the risk of fulfilling the performance criteria in such new and unproven technologies, agencies extend this short maintenance period to a longer period so that the performance levels can be satisfactorily measured over a longer duration. These are performance-based contracts, and may also be viewed as warranty contracts that specify the output or outcome required from the finished product. When the output or outcome required from such product extends over a number of years, or when the performance is observed over an extended period of time, they become long term warranties or long term performance-based contracts. For infrastructure projects, for instance, highway projects, performance warranties for the 
procurement and management of transportation infrastructure can be classified into three categories (FHWA, 2003): short term warranties, long term warranties, and maintenance warranties. Short term warranties are usually implemented to safeguard against any defects shortly after construction. Contractors are liable to rectify any damage or defect within this short period without imposing any extra cost to the highway agencies. The other form of warranty, the long term warranty, on the other hand, covers the design, construction and maintenance period even after several years post construction. This form of warranty is also known as the performance-based contract or performance-specified maintenance contract. A very similar form of warranty as that of long term warranty but that covers only the maintenance part of the constructed transportation infrastructure in use is the maintenance performance warranties. Maintenance performance warranties consider the application of preventive maintenance as well as rehabilitations and are also sometimes referred to as performance-specified maintenance contracts or performancebased contracts (Damnjanovic, 2006). It is the intention of this study to explore this form of maintenance warranties which is often referred to as the performance-based maintenance contracts.

Performance-based contracts differ significantly from traditionally used methodbased contracts for maintaining roads. In performance-based contracts, payments for maintaining the roads over a time period is clearly linked to the contractor successfully meeting or exceeding certain clearly defined minimum performance indicators. In traditional method-based contracts for road maintenance, highway agencies usually specify techniques, technologies, materials, and quantities of materials to be used, together with the time period for which the maintenance works should be executed. The 
payments to the contractor is based on the amount of inputs (e.g. cubic meters of asphalt concrete, number of working hours) and, therefore, the cost estimation is rather straight forward. However, in performance-based contracts, evaluation of payment amount to the contractor is difficult because payments are not based on the amount of inputs. Rather, a different approach of evaluating the amount of payment for the work scheduled or done by the contractor in the performance-based contracting is necessary. When these contract values are agreed in lump sum, which is often the case, it also becomes a burden for the contractor to evaluate the fair value of these contracts so that their bid price is competitive without putting them in a peril of losing money once they get the contracts.

\subsection{Problem Statement}

Eventual transition from in-house maintenance practice to off-shoring of the maintenance work has in turn necessitated and brought about various contracting practices around the world and also in the United States. As evident from the discussion in the previous paragraphs, one such form of contracting is the warranty contracting. A special form of warranty contracting is the performance-based contract which is usually awarded on a long term basis, often exceeding ten years. Agreements of these contracts are complex not only because of the length of the contract durations but also because of the multiple performance criteria that these contracts have to meet. Unlike the cost estimation process in method-based contracts where the quantity of work is defined, it becomes the burden of the contracting party to estimate the cost of maintaining the road to a specified level of condition by predicting the future condition of the road. Linking performance to cost is often difficult, and it is this difficulty and uncertainty that makes the contractors more concerned about using the performance-based contracting in their 
future work. One of the biggest concerns of the construction industry is the risks and liabilities posed by the use of long-term warranties. The contractor must maintain the warranted highway facilities above the required performance. Research by Bayraktar et al. (2004) indicated that the increase of bid price for such performance based contracts, or warranty projects in particular, is a function of project type and the warranty period. Short term warranties, with duration of one to three years, do not have significant impact on the cost. For warranties longer than five years, the resulting increase in the bid price varies dramatically. On average, a 5-year-warranty takes $10 \%$ of the total budget, and a 20-year warranty takes over 30\% (Bayraktar et al., 2004). Contractors in many states are thus skeptical of warranty contracting. Cui et al. (2007) reported that warranty cost estimating ranked third among the main concerns in construction industry regarding warranty contracting.

Experience confirms that the only credible means of managing pavement performance is through the use of pavement modeling techniques like the pavement deterioration models (Parkman et al., 2003). However, many of the existing pavement deterioration models are mechanistic and do not take uncertainty associated with the input variables in their modeling process. A comprehensive list of controllable variables and uncontrollable factors that impact the performance of the road has been listed by Ozbek for developing a framework for measuring the efficiency of highway maintenance strategies (Ozbek, 2007) but there has been no attempt to quantify the effect of these risks on the total cost of these maintenance projects. Since the agencies specify multiple performance indicators (such as crack, rut, roughness, etc.) rather than a single performance measure, such as the pavement condition index for the pavement, it is 
essential to predict the future road conditions in terms of all of these performance indicators or criteria. In its annual research needs statements, Transportation Research Board (TRB) pointed out that the maintenance level-of-service (LOS) and the budget requirements of road maintenance need more investigation. It mentions that the relationship between observed LOS and the cost necessary to achieve that LOS has been based largely on professional judgment drawn from practical experience (TRB, 2008). Given the discussion above, there is therefore a need to develop a model that can take into account the risk of achieving multiple performance criteria over an extended period of time as specified in the contract.

\subsection{Research Thesis}

Developing a cost estimation model for bidding purposes for long term pavement maintenance projects is quite different from developing a model for asset management purposes. When bidding, one is required to make a financial commitment on the outcomes of the model for a longer period of time, often exceeding ten years, whereas when modeling for asset management purpose the ten-year program of works is not usually required, and is often updated annually. Therefore, when modeling pavements for bidding, a different approach is required than modeling for asset management.

Research thesis: "Modeling for bidding of long-term performance-based pavement maintenance contract requires a far greater understanding of the risks associated with the bid, both financial and pavement condition related. For these reasons, a far more in-depth analysis is often required than if developing a model for purely asset management purposes. For performance-based pavement maintenance contracts, it is important to develop a model that takes into account the risk of achieving multiple performance 
targets specified, which are normally not considered by the traditional methodologies for developing program of works.”

\subsection{Research Goals and Objectives}

The purpose of this research is to develop a model that can assist contractors and highway agencies to estimate the cost of performance-based pavement maintenance contracts, depending on the risks transferred to them by the highway agencies so that a fair value for executing the contract is obtained. Under varying contract specifications and contract durations, the risk transferred to the contractor also varies and to accurately model the cost associated with major contract risks is the primary purpose of this research. Specific objectives that will be met to achieve the research goals are:

Traditional methodologies for developing program of works to meet the condition drivers are limited to a single performance criterion. This research is however, geared towards developing a model to estimate cost while meeting multiple performance criteria.

When trying to quantify risks associated with such contracts it is essential to consider what-if scenarios. The second objective is to develop a model that considers what-if-scenarios for bidding purposes of these long term contracts.

\subsection{Scope}

The scope of this study is limited to the development of a cost estimation model. Florida Department of Transportation provided the pavement condition data used for this research. In this research, focus is directed only towards flexible pavement as rigid 
pavements have different sets of performance specifications and distresses. However, the methodology used for flexible pavements can easily be adapted to suit rigid pavements and also pavements in other states with little modification.

\subsection{Summary of Methodology}

\subsubsection{Define Number of Condition States/Categories}

Although condition states defined by the Florida Department of Transportation (FDOT) is rated on a scale of 0 to 10 , for simplification purpose the condition of the distresses are reclassified into five condition states. This is done so because pavement condition ratings are spread mostly from 6 to 10. Since this research applied a five state condition model, FDOT condition rating on a scale of $1-10$ is modified suitably to conform to a five-step classification of the condition states adopted in this research.

\subsubsection{Determine Pavement Deterioration Rate}

Pavement deterioration rate is represented by a transition matrix, the elements of which denote the change in proportion of pavement in one particular condition state to the next poor condition state in one year. Estimation of the transition matrix is a relatively straight forward process, if we can observe the sequence of states for each of the individual unit of observation. For example, if we observe the condition state of the pavement at the beginning of the year and again at end of the year, then we can estimate the probability of any pavement section moving from one condition state to another. The probability of a pavement having a particular condition state at the end of the year, (e.g. Good) given their condition state at the beginning of the year (e.g. Very Good) is given by the simple ratio of the number of pavement sections that began the year with the same condition state (Very Good) and ended with Good condition state to the total number of 
pavement sections that began with a Very Good condition state. Suppose there are 100 pavement sections with a Very Good condition state at the beginning of the year, of which only 70 remain in the Very Good condition state and the remaining 30 sections degrade to next condition state Good at the end of the year, then the transition probability can be estimated using the ratio as follows:

Transition probability from Very Good (VG) to Very Good (VG) condition state is given by the proportion:

$$
\text { pVG,VG }=70 / 100=0.7
$$

Transition probability from Very Good (VG) to Good (G) condition state is given by the proportion:

$$
\mathrm{pVG}, \mathrm{G}=30 / 100=0.3 \text {. }
$$

Transition probabilities for all other possible combinations of deterioration can be estimated in a similar manner using the count proportions obtained from historical record of condition states. Transition probability matrices are derived for three different distress indicators from the available pavement condition surveys.

\subsubsection{Generate Maintenance Transition Probability Matrix}

Deterioration matrix is determined by studying the transition of pavement sections going from better to worse condition state in the absence of maintenance activities. In contrast to this, transition matrix for maintenance activities is obtained by studying the transition of pavement from a worse condition state to a better condition state when different maintenance activities are applied. When performance data are available for pavements just before and after the maintenance activity, transition probability matrices for each of these maintenance actions can be determined. 


\subsubsection{Determine Current Distribution of Pavement in Different Condition States}

Distribution of actual condition states for the entire length of the pavement under performance-based contract gives the condition state vector. The condition state vector is estimated by finding the proportion of the roadway in Very Good, Good, Fair, Bad, and Very Bad condition states. Once this initial condition state vector is determined, condition state vectors for pavement after $t$ years can be easily calculated by multiplying this condition state vector with the deterioration matrix.

\subsubsection{Identify Treatment Costs for Each Maintenance Action}

In order to estimate the total cost of the performance-based contracts, it is essential to collect the unit cost of maintenance activities that are considered to be feasible for the pavement section under contract. Broad categories of pavement maintenance strategies considered in this research are routine maintenance, minor maintenance, major maintenance, and reconstruction. Cost of application of these maintenance activities per lane-mile are taken from historical maintenance cost data where available and from other related literatures for those that do not have unit cost data.

\subsubsection{Iterate M\&R Actions Using Performance Triggers}

Depending on the initial condition of the pavement at the time of contract award, different maintenance treatments may be needed to bring the condition of the pavement to an accepted level of performance. In the iteration process, maintenance activity that requires the least overall cost to keep the pavement at the specified performance level is selected first. If this maintenance activity is unable to achieve an acceptable level of pavement performance, maintenance treatment of the next higher level is chosen. The 
iteration process ensures that the pavements are at least maintained at the specified threshold level of performance.

\subsubsection{Estimate Cost Associated with a Long Term Maintenance Contract}

Once the overall program of maintenance actions is determined using the above steps, it then becomes easy to quantify the cost associated with these maintenance activities from the unit cost data available. These costs, which are determined for annual maintenance, are added up for the entire contract duration and for the entire pavement length under performance-based contracts. This cost should be the least among the cost obtained from different combinations of maintenance operations during iterations. This cost is then the cost of executing the pavement maintenance under performance-based contracts.

\subsection{Organization of Dissertation}

\subsubsection{Introduction}

The first chapter introduces the topic of performance-based maintenance contracts in transportation infrastructure and the need for a cost estimation methodology in the light of increasing use of this innovative contract.

\subsubsection{Literature Review}

The second chapter, which is the literature review, delves on the increasing use of this new contracting method and the limitations of the existing methodology to estimate the cost of these long term maintenance contracts. The literature review further investigates how the progression of body of knowledge in this research area led to the proposed methodology so as to address the problem associated with estimating the cost of performance-based contracts more systematically than the existing methodologies. 


\subsubsection{Using Historical Performance Data to Predict Pavement Deterioration and Improvement}

The third chapter discusses how pavement performance data recorded and kept by state highway agencies can be used to predict future condition of the transportation infrastructure. In this chapter, the concept of Markov chain and transition probabilities discussed in the literature review is used to represent the change in condition distribution of the pavement as transition probability matrices. These transition probability matrices are multiplied with the condition state vector of the pavement in any one year to obtain the condition state vector of the pavement in the consecutive years. Transition probability matrices are also derived for different maintenance activities that will be used in improving the condition state of the pavement.

\subsubsection{Framework for Cost Estimation Model}

The fourth chapter discusses on how the methodology is developed to estimate the cost associated with performance-based maintenance contracts. The pavement is either let to deteriorate on its own (with only minimal routine maintenance) until the threshold levels of pavement performance indicators are reached and then different maintenance activities are simulated at different years so that the pavement condition never reaches below the threshold specified in the contract. Cost of providing maintenance services each year as required, is then added up to determine the total cost of the contract.

\subsubsection{Applying Methodological Framework to a Case Study}

The fifth chapter describes how the proposed framework can be applied to real case study problems. When pavement deterioration model and pavement improvement model are developed (Chapter 3), performance specifications from performance-based contracts 
are used as inputs to determine the level of maintenance effort to meet the performance requirements. In order to achieve the performance requirements with the least maintenance effort, iteration is done for each maintenance activity until such criteria are met. This is repeated for all the years until the end of the analysis period is reached so as to obtain the program of maintenance works from which the total cost is estimated. Asphalt pavements from Miami Dade Expressways are used in the analysis to build the methodology and SR-836 (Dolphin Expressway) is used for the application purpose.

\subsubsection{Sensitivity Analysis and Model Validation}

The sixth chapter provides a concept of sensitivity analysis as a way of determining the risk associated with uncertainty of deterioration process, and the uncertainty of effect of changing the threshold levels. The impacts of these changes in the input of the model have on the output, which is the cost, will be demonstrated using sensitivity analysis. Quantitative and qualitative validation of the model is also performed in this chapter.

\subsubsection{Research Summary, Research Limitations, and Recommendations for Future Research}

The last chapter will provide a summary of the findings with conclusions derived from the findings. Based on the feedback received from the experts on the usefulness, accuracy, and flexibility of the model to estimate the long term maintenance contracts recommendations are made for future research. 


\section{CHAPTER 2}

\section{LITERATURE REVIEW}

\subsection{Introduction}

Research in the area of long term maintenance contract is recent. The emergence of this research is attributed mainly to the increasing involvement of private sector firms in the management of these long term pavement maintenance. Body of knowledge that is present in this area is mostly focused on asset management. Available asset management models invariably revolve around life cycle maintenance cost which may not be appropriate for use by contractors who are increasingly being involved in these long term pavement maintenance works. There have been few studies and research in the area of long term maintenance contracts but much of this research is of qualitative in nature. The discussion in this chapter leads us to realize how the existing body of knowledge in this area lacks relevant literatures to quantify cost associated with long term pavement maintenance contracts with multiple performance indicators. The literature discussed in this chapter also provides foundation for the proposed methodology.

\subsection{Performance-based Maintenance Contracts in Construction Industry}

Performance-based contracts (PBC) differ significantly from method-based contracts that have been traditionally used to maintain roads. PBC is a type of contract in which payments for the management and maintenance of road assets are explicitly linked to the contractor successfully meeting or exceeding certain clearly defined minimum performance indicators. In traditional method-based contracts, the road agency as a client normally specifies techniques, technologies, materials and quantities of materials to be 
used, together with the time period during which the maintenance works should be executed. The payment to the contractor is based on the amount of inputs (e.g., cubic meters of asphalt concrete, number of working hours). In performance-based contracting the client does not specify any method or material requirements. Instead the client specifies performance indicators that the contractor is required to meet when delivering maintenance services. For example, the contractor is not paid for the number of potholes he has patched, but for the output of his work: no pothole remaining open (or 100\% patched). Failure to comply with the performance indicators or to promptly rectify revealed deficiencies adversely affects the contractor's payment through a series of clearly defined penalties. In case of compliance, the payment is regularly made, usually in equal monthly installments. PBC within the road sector can be "pure" or "hybrid". The latter combines feature of both method and performance-based contracts. Some services are paid on a unit rate basis, while others are linked to meeting performance indicators (Stankevich et al., 2005).

In some literatures PBCs are also referred to as output-based or outcome-based contracts. In the World Bank sample bidding document (World Bank, 2005), it is referred to as performance-based contract for management and maintenance of roads (PMMR). In the very latest version of the Bank's document (World Bank, 2005) the title has been changed from PMMR to OPCR - Output-and-Performance-based Road Contracts. Performance specifications are often called "levels of service" (LOS) in some countries.

British Columbia, Canada, pioneered the use of $\mathrm{PBC}$ of road maintenance in 1988 which was then followed by other Canadian Provinces, Alberta and Ontario. In 1995 Australia launched its first PBC to maintain urban roads in Sydney. Since then New 
South Wales, Tasmania, and Southern and Western Australia have started using performance-based and "hybrid" approaches. In 1998 a PBC was introduced in New Zealand to maintain $405 \mathrm{~km}$ of national roads (Zietlow, 2004). In the developing world Latin America was the pioneer in developing and adopting its own performance-based contracting model. In 1995, Argentina introduced performance-based contracts, which at present cover $44 \%$ of its national network (Liautaud, 2004). In the mid nineties Uruguay also piloted PBC, first on a small portion of its national network and then on the main urban roads of Montevideo. Shortly thereafter, other Latin American countries, such as Brazil, Chile, Colombia, Ecuador, Guatemala, Mexico and Peru, also started adopting a performance-based approach. Gradually, this trend has spread to other developed and developing countries in Europe, Africa and Asia, e.g., UK, Sweden, Finland, Netherlands, Norway, France, Estonia (63\% of national roads), Serbia and Montenegro ( $8 \%$ of national roads), South Africa (100\% of national roads), Zambia, Chad (17\% of all season roads), the Philippines (231 km of national roads). At present, a PBC is referred to as a 'performance-specified maintenance contract' (PSMC) in Australia and New Zealand. A PBC is referred to as an 'Asset management contract' in the USA. PBC is referred to as a 'Managing agent contract' (MAC) in the UK, and as "Area maintenance contracts" in Finland. Preparations for launching PBC programs are underway in Albania, Cape Verde, Chad, Madagascar, Tanzania, Burkina Faso, India, Cambodia, Thailand, Indonesia, Vietnam and Yemen. Some of the above countries use "pure" performance based contracts, while others (e.g., Finland, South Africa, Serbia and Montenegro) use "hybrid" contracts (World Bank, 2005). 
In 1999, the U.S. Department of Transportation (USDOT) requested highway agencies to come up with plans to convert their traditional contracts to Performancebased contracts (Tomanelli, as cited in Ozbek, 2004). DOTs within Virginia (in 1996), Florida (in 1998), Texas (in 1999), and the District of Columbia (in 2000) have been the first ones to implement performance-based contracts for the maintenance of their road and highway systems (Ozbek, 2004).

Warranty is also a form of performance-based contract that has been popularly used in the United States in the recent years (Queiroz, 1999). In warranty contracting, contractor is responsible for the post-construction risk in addition to that assumed during the construction process. In warranty contracting contractor has to ensure that the constructed infrastructure should provide the level of service (LOS) specified in the contract by the agency within the warranty period. Table 2.1 shows the states that have used warranty contracting in road construction in the US.

Table 2.1: Warranty Provisions in the U.S (Adapted from Garza et al., 2008)

\begin{tabular}{|l|l|l|l|l|l|l|l|}
\hline \multicolumn{2}{|l|}{ North Atlantic } & \multicolumn{2}{l|}{ North Central } & \multicolumn{2}{l|}{ Southern Region } & \multicolumn{2}{l|}{ Western Region } \\
\hline State & $\begin{array}{l}\text { Warranty } \\
\text { Length } \\
\text { (years) }\end{array}$ & State & $\begin{array}{l}\text { Warranty } \\
\text { Length } \\
\text { (years) }\end{array}$ & State & $\begin{array}{l}\text { Warranty } \\
\text { Length } \\
\text { (years) }\end{array}$ & $\begin{array}{l}\text { Sarranty } \\
\text { Length } \\
\text { (years) }\end{array}$ \\
\hline $\begin{array}{l}\text { North } \\
\text { Carolina }\end{array}$ & 5 & Illinois & 5 & Florida & 3 & Colorado & 3,5 \\
\hline Virginia & 3,5 & Indiana & 5 & Mississippi & 5,7 & California & 5 \\
\hline & & Michigan & 5 & Louisiana & 3 & & \\
\hline & & Ohio & $3,5,7$ & & & & \\
\hline & & Wisconsin & 5 & & & & \\
\hline
\end{tabular}


Performance warranties for the procurement and management of transportation infrastructure can be classified into three categories (FHWA, 2003): short term warranties, long-term warranties, and maintenance warranties.

Short term performance warranties are warranties that are implemented as a safeguard against the risk of latent flaws and defects, hidden in the design and construction phases. Typically they range from two to ten years after construction is completed and consider only the application of preventive maintenance actions during the coverage of the warranty. Figure 2.1 illustrates the life-cycle phases included in shortterm performance warranties.

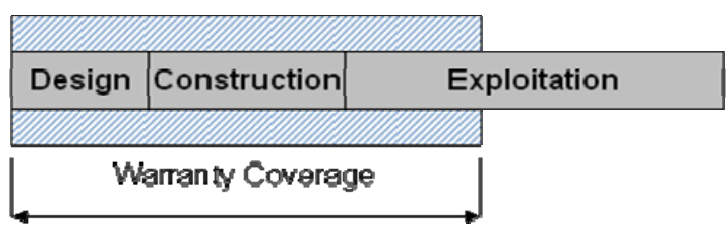

Short-term Performance Warranty Contracts

Figure 2.1: Short-term Performance Warranty Contracts

Even though short term performance warranties provide some degree of protection against poor performance, they cover only a short period of the facility's life-cycle. To shift all the performance-related risks to the contractors, state highway agencies (SHA) can implement long term performance warranties. These warranties cover the entire lifecycle and allow for the application of both preventive maintenance and rehabilitations.

The life cycle phases involved with long term performance warranties are illustrated in Figure 2.2. 


\begin{tabular}{|c|c|c|}
\hline Design & Construction & Exploitation \\
\hline \multicolumn{3}{|c|}{ Warranty Coverage } \\
\hline
\end{tabular}

Figure 2.2: Long-term Performance Warranty Contracts

In contrast to the previously discussed performance warranties that involve design and construction phases, maintenance performance warranties cover only the exploitation phase of the infrastructure life-cycle. Maintenance performance warranties consider the application of both preventive maintenance and rehabilitations and are also sometimes referred to as performance-specified maintenance contracts. Figure 2.3 shows involvement of the life-cycle phases for maintenance performance warranties.

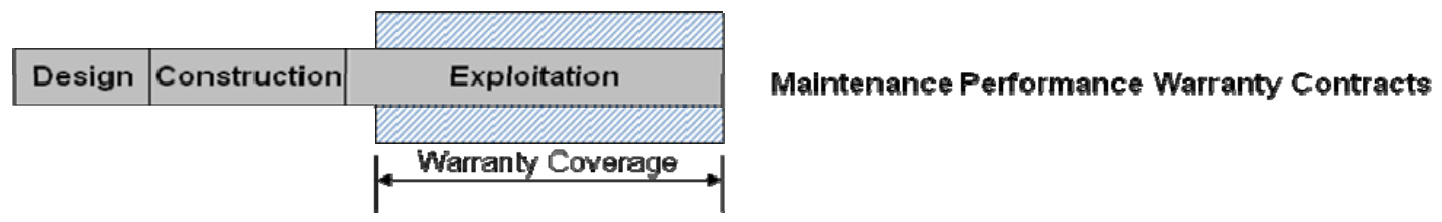

Figure 2.3: Maintenance Performance Warranty Contracts

\subsection{Risks in Performance-based Maintenance Contracts}

Within the context of projects, risk is commonly associated with uncertain events or conditions that, if they occur, have positive or negative effects on the objectives of a project (Ayyub, 2003). There may be several risk areas in a construction project. For example, Zayed et al. (2002) identified eight risk areas for build-operate-transfer (BOT) projects such as financial, procurement, construction completion, and operating risks. In performance based projects, there are additional risks that a contractor may not have been exposed under standard method type contracts. These are enlisted by Owen (2000) as follows: 
1. Extended maintenance periods

2. Unrealistic or too tight tolerances

3. Unproven confidence limits on specified performance values

4. Use of unproven/untried materials

5. Condition of the base layer of the road

6. Poor Quality control producing variable results

7. Communication between parties and clear understanding of the philosophy and principles of a performance specification

8. Method of measurement, variability between testing agencies

9. Assessment of failure and resultant proportional payment

Sensitivity analysis can be used to test the effects of these risks on the overall cost of the project. However, a major risk in the performance-based maintenance contract is the risk associated with the failure of the product to meet the performance requirements during the performance period. Once the economic consequence of failure, for which the contractor is liable, is quantified it then allows the owner and the contractor to trade-off the product performance risk with the contract price.

In understanding the risks in the performance-based long term pavement maintenance contracts it becomes essential to identify and understand the factors that affect pavement performance and service life. This is because whatever the extra cost is associated with unforeseen maintenance and rehabilitation of pavement projects comes from inaccuracies in estimation of the service life of the pavement. If for some reason one of the critical variables impacting pavement deterioration rate is not considered in estimating the pavement service life, the consequence would be that the pavement would deteriorate at a 
faster rate than what was designed and expected by the contractor. Ultimately the contractor has to absorb the cost of maintaining the prematurely deteriorated pavement because of the lack of foresightedness in identifying the risk variable.

Not only is it important to identify all the risk variables impacting the deterioration rate of the pavement, it is also very important to understand the key performance indicators or level of service (LOS) that are required by the highway agencies. Pavement modeling on long term contracts is critical in terms of understanding the financial cost of maintaining key performance indicators (KPI's) at a particular level and it is a very high risk area if the modeling predictions are not right (Keir \& Blerk, 2006). Ozbek (2004) emphasizes this fact and has developed a warranty clause template for the performancebased road maintenance contract with an aim to reduce the risk imposed on the contractors.

In performance-based maintenance contracts risk is shifted to the party who has more control over the project. Since a contractor has more control over the project and, therefore, the risks, the contractor has to bear the risk of failure of the project. There is a wealth of research in the area of risk management for new projects but there are very few for the maintenance projects under the performance-based environment. The risks that were earlier assumed by the agencies in pavement maintenance projects under traditional contracts now fall under contractors' responsibility in the performance-based contracts. There is a dearth of literature in the area of performance-based maintenance risks borne by the contractors. Most of the literatures discussing risks in performance-based maintenance contracts are subjective in nature focusing largely on the opportunities and importance of managing risk. Kostuk (2003) points this shortcoming and states that 
Gallagher and Mangan (1998) were the first to directly address risk in the context of long term maintenance contracts but that too without any methodology to quantify the risk. Gallagher and Mangan (1998) identified that the key to success in managing the risk associated with long term maintenance contracts, is to be able to measure the condition state of the asset at the time the contract is awarded and in the future.

Cost estimation of pavement maintenance for long term contracts involves the evaluation of future funding requirements that will maintain the highway system at a desirable level meeting the performance criteria. The development of appropriate program of works relies heavily on the ability to accurately predict future needs and then to select effective courses of action to meet these needs. A vast majority of the models developed for financial planning have focused on the expected or average future performance of pavements. Risk associated with the expected performance is often ignored. This risk component can be captured in the form of variation in pavement life. Actual remaining life of the pavement is random and may be close to or far from the average as shown in Figure 2.4 and Figure 2.5.

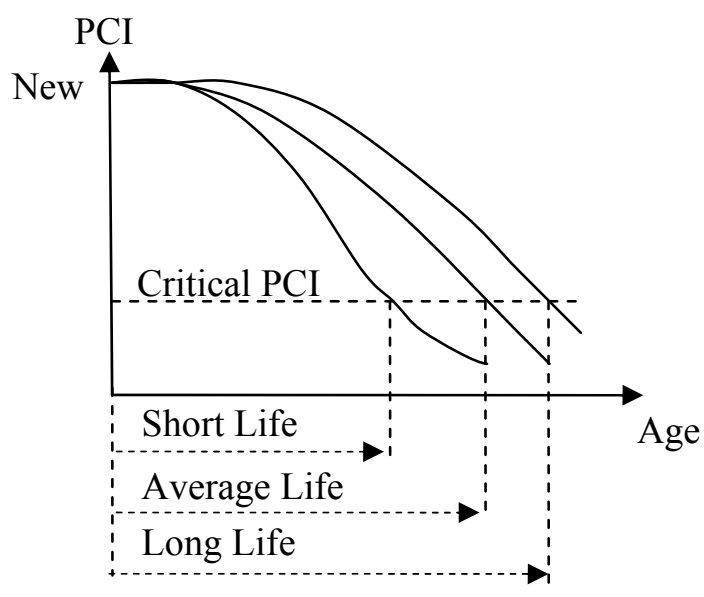

Figure 2.4: Variation in Pavement Life 
The impact of such variations is demonstrated by a simple example as pointed out by Kazakov and Cook (1988). If for example, cost of rehabilitation of total pavement network is $\$ 1$ Billion with a predicted life expectancy of the network to be 14 years. Then within this period, $1 / 14^{\text {th }}$ of network will be maintained each year at cost of $\$ 71.4$ Million. However, if the actual life of the pavement is 15 years, then $1 / 15^{\text {th }}$ of network is maintained each year at cost of $\$ 66.7$ Million. There is a prediction error of $\$ 4.7$ Million/year.

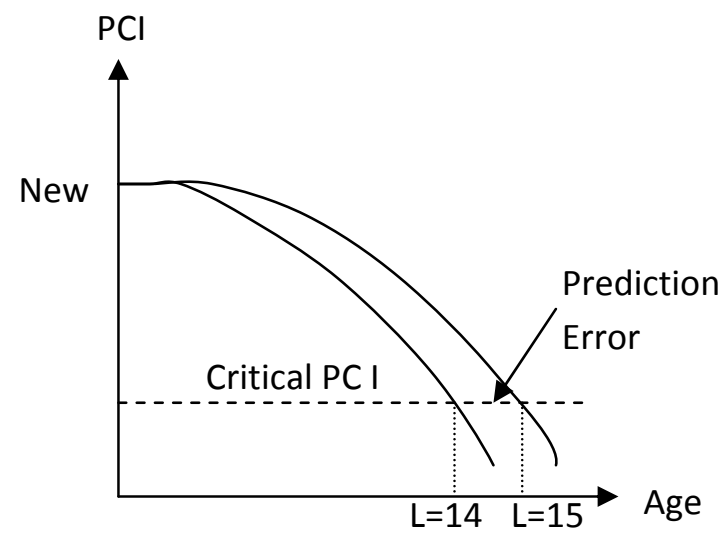

Figure 2.5: Financial Risk Due to Prediction Error of Pavement Life

As discussed, life cycle of a pavement is a random variable and, therefore, contains risk elements. Risk is introduced not only due to the fact that the life of the pavement is random and, therefore, an uncertain event, risk is also introduced because of the threshold level of performance criteria specified in the contract. For instance, if the critical PCI level in Figure 2.5 is raised or lowered the life of the pavement is consequently reduced or increased respectively. Therefore, the tolerance level of performance specification, critical PCI level in this case, also introduces risk in the estimation of maintenance cost of 
pavement. Although, theoretically, the entire network of pavement may be maintained to meet the critical PCI level, this will create an extra financial burden on the highway agency. Therefore, it may be assumed that a nominal proportion of the entire pavement network may be allowed below the accepted level of PCI without significantly impacting the LOS. This nominal percentage may vary with different highway agencies and for different categories of road. This also introduces another risk component in the estimation of performance-based pavement maintenance contracts.

\subsection{Pavement Performance Models}

It has been emphasized in the previous section that the best way of managing the risk associated with long term maintenance contracts is to be able to measure the present and the future condition state of the asset. The main purpose of pavement performance models is to predict future condition state when its present condition state is known. Various types of distresses, such as roughness, rut, crack, etc, or indices based on combinations of such distresses, can be used as input for these models. Pavement Management Systems (PMS) require accurate and efficient pavement performance prediction models. Pavement performance analysis is a primary form of engineering application of PMS database to determine the effects on pavement deterioration. Engineering analysis is performed to quantify these effects and develop mathematical models that predict pavement performance over time. These performance models are required in order to estimate the needs and timing of maintenance of the sections in a pavement network. Figure 2.6 below is an illustration of how deterioration prediction would be applied to an existing pavement section to estimate the rate of future 
deterioration, and the "needs year". Additionally, it illustrates the application of the deterioration model to rehabilitation alternatives applied in the needs year.

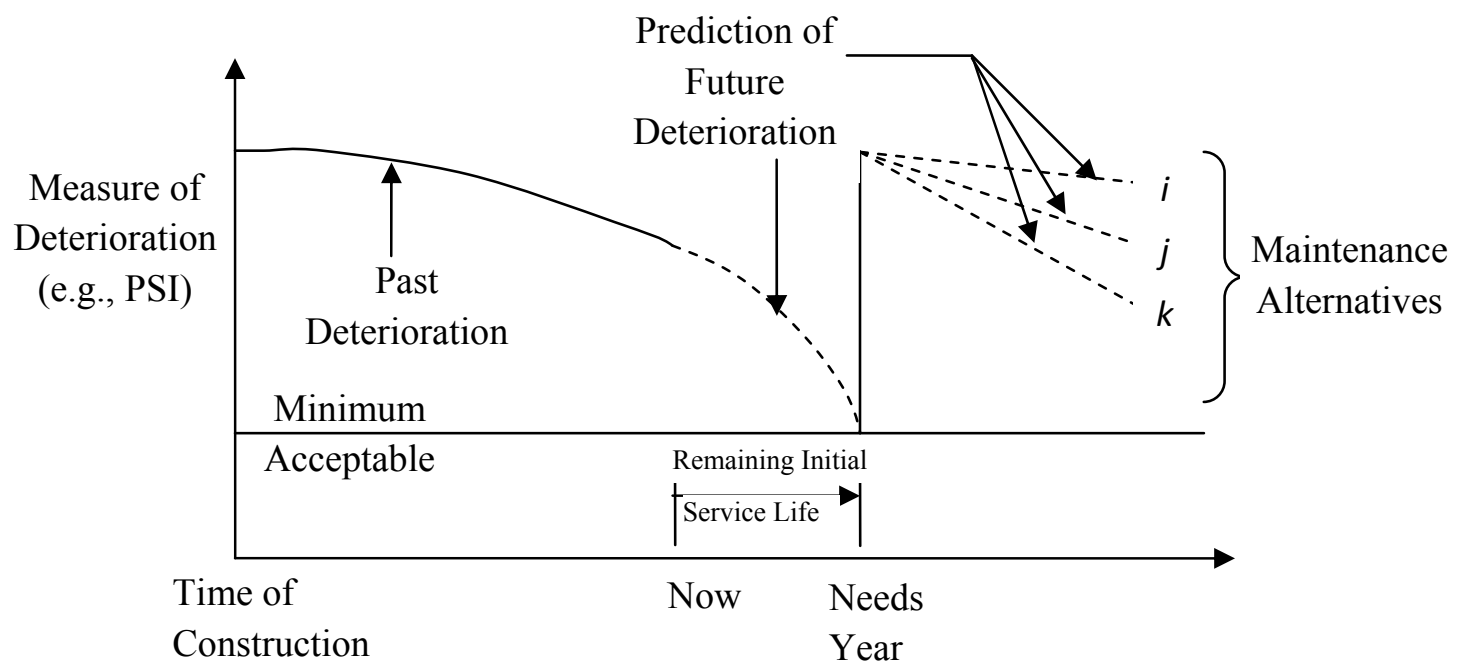

Figure 2.6: Deterioration Curve for Past and Future Pavement Condition (Adapted from Federal Highway Administration, 2002)

A classification of prediction models has been suggested by Mahoney (1990), based on earlier work by Lytton (1987). Pavement performance models can either be deterministic or probabilistic. Deterministic models predict average values of pavement performance measures. In contrast, probabilistic models can predict averages as well as distributions of these measures. Most deterministic models are mechanistic or empirical. They include primary response, structural performance, functional performance, and damage models (FHWA, 2002; Mbwana, 1996; Mahoney, 1990). Examples of stochastic models include survival curves and Markov process models. Different types of performance models are summarized in Table 2.2. 
Table 2.2: Types of Pavement Performance Model (Adapted from Mahoney, 1990)

\begin{tabular}{|c|c|c|c|c|c|c|}
\hline \multicolumn{4}{|c|}{ Deterministic } & \multicolumn{3}{|c|}{ Probabilistic } \\
\hline $\begin{array}{l}\text { Primary } \\
\text { Response }\end{array}$ & Structural & Functional & Damage & $\begin{array}{l}\text { Survivor } \\
\text { Curves }\end{array}$ & $\begin{array}{l}\text { Transition } \\
\text { Models }\end{array}$ & rocess \\
\hline $\begin{array}{l}\text { - Deflection } \\
\text { - Stress } \\
\text { - Strain } \\
\text { - Etc. }\end{array}$ & $\begin{array}{l}\text { - Distress } \\
\text { - Pavement } \\
\text { - Condition }\end{array}$ & $\begin{array}{l}\text { - PSI } \\
\text { - Safety } \\
\text { - Etc. }\end{array}$ & $\begin{array}{l}\text { - Load } \\
\text { Equivalent }\end{array}$ & & - Markov & $\begin{array}{l}\text { - Semi- } \\
\text { Markov }\end{array}$ \\
\hline
\end{tabular}

The following paragraphs discuss stochastic or probabilistic models as they are more suited to model the uncertain behavior of pavements. Stochastic modeling of pavement performance is the most appropriate one because many factors responsible for pavement deterioration such as traffic loading, pavement materials, construction methods, and weather, are not deterministic (Mbwana, 1993). Many probabilistic or stochastic models have been developed in order to characterize the uncertain behavior of pavement deterioration processes. These previously-developed probabilistic models can be summarized into two categories: state-based Markov Chain models, and time-based reliability analysis (Haas et al., 1994; Cook and Lytton, 1987). Most state DOTs keep a record of historical database of condition state of pavements. These condition states are usually expressed in discrete scale, e.g., 1 to $5,1-10,1-100$, and so on. This discrete representation favors the use of discrete state Markov models to characterize pavement deterioration process. Such models are based on transition probabilities that capture the nature of the evolution of condition states from one discrete time point to the next. Transition probabilities can be obtained by observing the performance of a large number of pavements over a long period of time. Following Markovian chain method, pavement 
condition state at time $t$, PCS ( $t$ ), of the pavement at any stage, $t$, can be calculated from the initial condition state vector PCS (0) as:

$\operatorname{PCS}(1)=\operatorname{P} 1 \times \operatorname{PCS}(0)$

$\operatorname{PCS}(2)=\mathrm{P} 2 \times \operatorname{PCS}(1)=\mathrm{P} 2 \times \mathrm{P} 1 \times \mathrm{PCS}(0)$

$\operatorname{PCS}(\mathrm{t})=\operatorname{Pt} \times \operatorname{PCS}(\mathrm{t}-1)=\operatorname{Pt} \times \mathrm{Pt}-1 \ldots . \mathrm{P} 1 \times \operatorname{PCS}(0)$

where, Pt is the transition probability matrix at stage $t$ and PCS ( $t)$ is the condition vector at stage t. PCS refers to the pavement condition states, such as serviceability index, pavement condition index, etc., suitably scaled for quantitative analysis. If a scale of 1-5 is used where 5 and 1 represent the best and the worst condition respectively, PCS (2) which is the condition vector at stage 2 can be typically expressed as $\{0.4,0.3,0.2,0.1$, $0.0\}$, where the elements of the vector represent the percentage of pavement section in five condition states ( 1 to 5) for PCS level from 1 to 5. Generally, stages are considered as series of consecutive periods of one year. A Markov transition process can be either homogeneous or non homogeneous. In homogeneous transition, variables such as, traffic load, environmental conditions, sub-grade strength, etc., are considered constant over the entire analysis period, and for this reason the probability matrix $(\mathrm{P})$ remains unchanged at all stages. For all practical applications in pavement management, non-homogeneous models are commonly used. Golabi et al. (1982) proved the effectiveness of applying a homogeneous Markov Chain process. Markov-Chain models are used for predicting the performance deterioration of infrastructure facilities because of their ability to capture the time dependence and uncertainty of the deterioration process, maintenance operations, and initial condition as well as their practicality for network level analysis (Morcous and Lounis, 2005). 
Semi-Markov models on the other hand are developed using available data and judgment/experience of the pavement experts. The main advantage of this type of model is the use of subjective inputs which reduce large requirement of field data.

Survivor curves (also known as mortality curves), another method of performance modeling, were developed in the actuarial process. They have been used extensively in the utility industry. Insurance companies use these curves to determine insurance premium values. The use of survivor curves in assessing pavement service life started in 1934. A survivor curve as defined by Winfrey is "the curve that shows the number of units of a given group which are surviving in service at given ages (Winfrey, 1967). The ordinates of the curve give at any particular age the percentage (or the actual number) of the original number which are yet surviving in service. The abscissa is measured in years or other suitable service unit" (Winfrey, 1967). The number of units surviving is generally expressed in percentage. The area under the curve divided by 100 (if units are expressed in percentage) gives the average service life of the units. Survivor curve gives the probable life of units at any particular age. The area under the curve to the right of the vertical line drawn at any age gives the service remaining at that age. The expectancy of remaining life at any age can be computed by dividing the service remaining by the number of units surviving at that age. The probable average life at any age can be obtained by adding the expectancy to the age for which the expectancy is computed. Considerable error may be found in the estimate of life expectancy if retirement data of small group of units are used. However, the probability of error can be reduced if adequate representative data is used and service conditions are evaluated by the experts. A typical survivor curve is shown in Figure 2.7. 


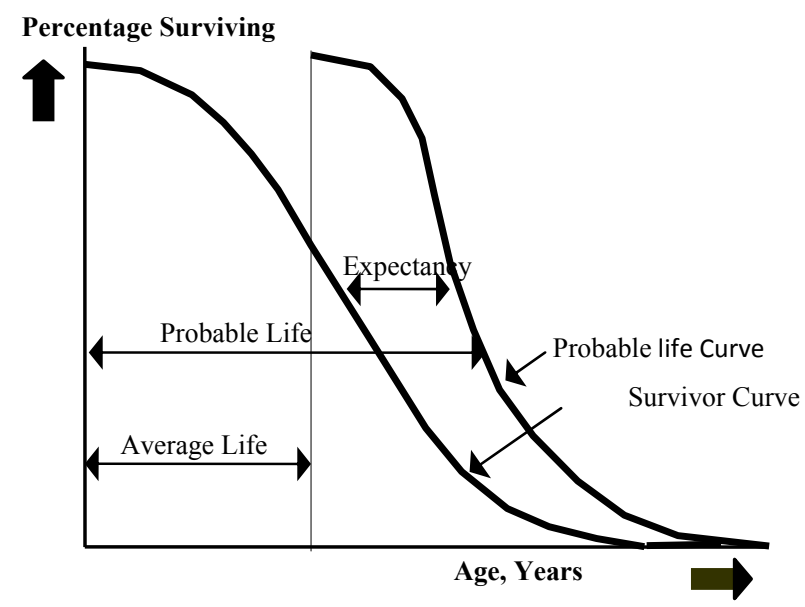

Figure 2.7 : Typical Survivor Curve

An application of survivor curves for the determination of pavement service life is explained by Gharibeh and Darter (2003). Prozzi and Madanat (2000) applied survival analysis to reanalyze the AASHTO road test data and stated that the survival model is more appealing than the original AASHTO formulations. Wang et al. (1994) conducted survival analysis on the development patterns of fatigue crack using flexible pavement test data of the Long-Term Pavement Performance (LTPP) program.

A survivor curve can be modeled using the following mathematical form:

$$
\begin{aligned}
& \text { PS =1-e }\left[\frac{\rho}{\text { AGE }}\right]_{\text {where, }}^{\beta} \\
& \text { PS = probability of surviving } \\
& \text { e = base of natural logarithm } \\
& \rho=\text { a coefficient to control life of the curve } \\
& \text { AGE = age of pavement }
\end{aligned}
$$


$\beta=a$ coefficient to control the shape of the curve

Types of performance models which may be used at different level of pavement management are summarized in Table 2.3.

Table 2.3: Advantages and Disadvantages of Using Different Pavement Performance Models (Adapted from FHWA, 1990)

\begin{tabular}{|c|c|c|}
\hline Models & Advantage & Disadvantage \\
\hline Regression & $\begin{array}{l}\text { Microcomputer software } \\
\text { packages are now widely } \\
\text { available for analysis which } \\
\text { makes modeling easy and } \\
\text { less time consuming. } \\
\text { - These models can be easily } \\
\text { installed in a PMS. } \\
\text { - Models take less time and } \\
\text { storage to run. }\end{array}$ & $\begin{array}{l}\text { - Needs large database for a } \\
\text { better model. } \\
\text { - Works only within the range } \\
\text { of input data. } \\
\text { - Faulty data sometimes get } \\
\text { mixed up and induces poor } \\
\text { prediction. Needs data } \\
\text { censorship. } \\
\text { - Selection of proper form is } \\
\text { difficult and time taking. }\end{array}$ \\
\hline $\begin{array}{l}\text { Survivor } \\
\text { Curve }\end{array}$ & $\begin{array}{l}\text { Comparatively easy to } \\
\text { develop. } \\
\text { - It is simpler as it gives only } \\
\text { the probability of failure } \\
\text { corresponding to pavement } \\
\text { age. }\end{array}$ & $\begin{array}{l}\text { Considerable error may be } \\
\text { expected if small group of } \\
\text { units are used. }\end{array}$ \\
\hline Markov & $\begin{array}{ll}\text { - } & \text { Provides a convenient way } \\
\text { to incorporate data feedback. } \\
\text { - } \\
\text { reflects performance trends } \\
\text { regardless of non-linear } \\
\text { trends }\end{array}$ & $\begin{array}{l}\text { - No ready made software is } \\
\text { available. } \\
\text { - Past performance has no } \\
\text { influence } \\
\text { - It does not provide guidance } \\
\text { on physical factors which } \\
\text { contribute to change. } \\
\text { - Needs large computer storage } \\
\text { and time. }\end{array}$ \\
\hline $\begin{array}{l}\text { Semi- } \\
\text { Markov }\end{array}$ & $\begin{array}{l}\text { - } \quad \text { Can be developed solely on } \\
\text { subjective inputs. } \\
\text { - } \quad \text { Needs much less field data. }\end{array}$ & $\begin{array}{l}\text { - No ready made software is } \\
\text { available. } \\
\text { - Needs large computer storage }\end{array}$ \\
\hline
\end{tabular}




\begin{tabular}{|c|c|c|}
\hline & $\begin{array}{l}\text { - Provides a convenient way } \\
\text { to incorporate data feedback. } \\
\text { - } \\
\text { Past performance can be } \\
\text { used }\end{array}$ & \\
\hline Mechanistic & $\begin{array}{l}\text { Prediction is based on cause- } \\
\text { and-effect relationship, } \\
\text { hence gives the best result. }\end{array}$ & $\begin{array}{l}\text { Needs maximum computer } \\
\text { power, storage and time. } \\
\text { - Uses large number of } \\
\text { variables (e.g. material } \\
\text { properties, environment } \\
\text { conditions, geometric } \\
\text { elements, loading } \\
\text { characteristics etc.). } \\
\text { - Predicts only basic material } \\
\text { responses }\end{array}$ \\
\hline $\begin{array}{l}\text { Mechanistic- } \\
\text { empirical }\end{array}$ & $\begin{array}{l}\text { Primarily based on cause- } \\
\text { and-effect relationship, } \\
\text { hence its prediction is better. } \\
\text { - Easy to work with the final } \\
\text { empirical model. } \\
\text { - Needs less computer power } \\
\text { and time. }\end{array}$ & $\begin{array}{l}\text { - } \begin{array}{l}\text { Depends on field data for the } \\
\text { development of empirical } \\
\text { model. }\end{array} \\
\text { - } \begin{array}{l}\text { Does not lend itself to } \\
\text { subjective inputs. }\end{array} \\
\text { - Works within a fixed domain } \\
\text { of independent variable. } \\
\text { - Generally works with large } \\
\text { number of input variables } \\
\text { (material properties, } \\
\text { environment conditions, } \\
\text { geometric elements, etc.) } \\
\text { which are often not available } \\
\text { in a PMS. }\end{array}$ \\
\hline Bayesian & $\begin{array}{l}\text { - Can be developed from past } \\
\text { experience and limited field } \\
\text { data. } \\
\text { - Simpler than Markov and } \\
\text { Semi-Markov models. } \\
\text { - Can be suitably enhanced } \\
\text { using feedback data. }\end{array}$ & $\begin{array}{l}\text { - May not consider mechanistic } \\
\text { behavior. } \\
\text { - Improper judgment can lead to } \\
\text { erroneous model. }\end{array}$ \\
\hline
\end{tabular}




\subsection{Maintenance Strategies for Multiple Performance Criteria}

Maintenance strategies may consist of activities whose timings can be based on predefined intervals of time or usage, or condition triggers as shown in Figure 2.8.

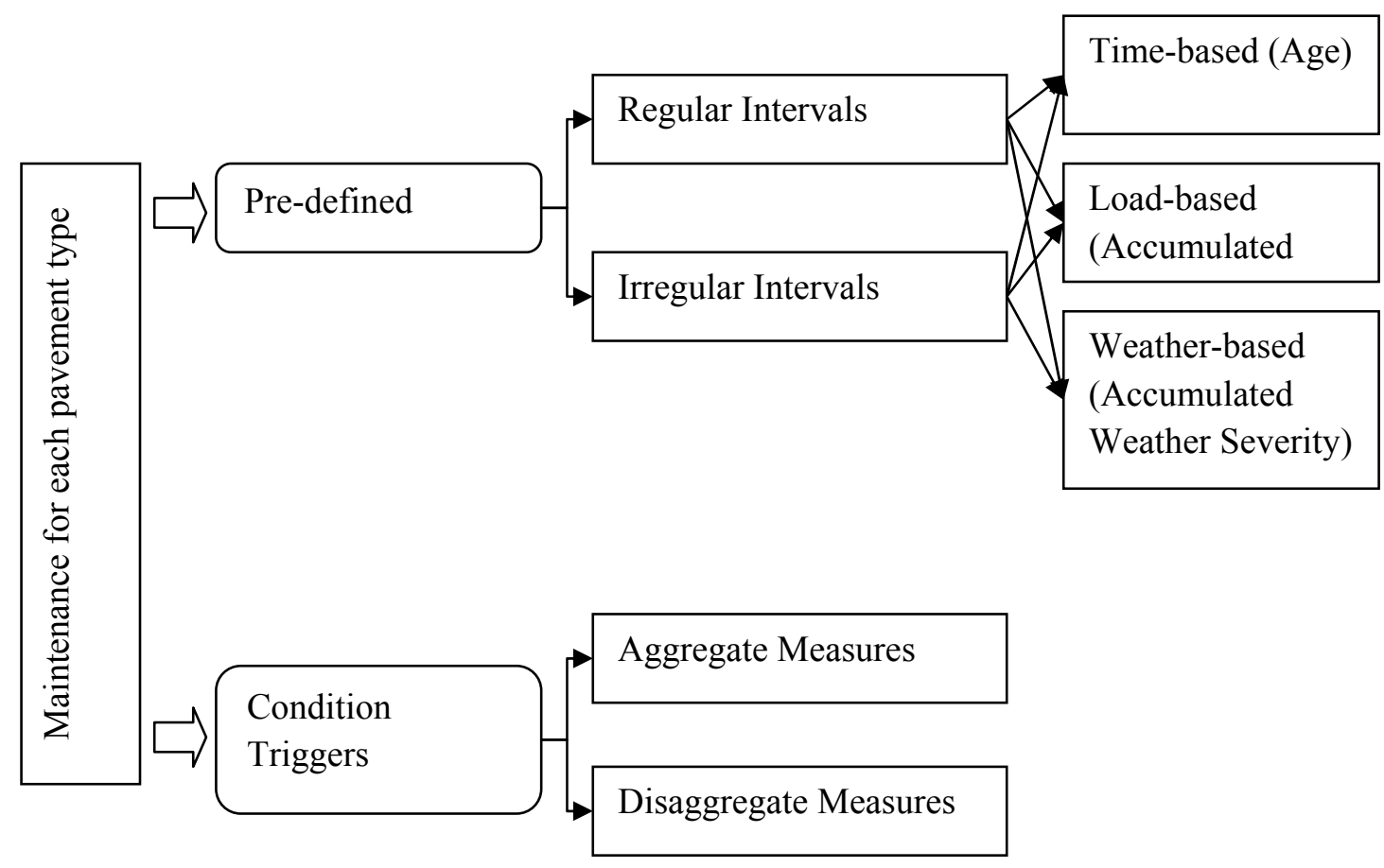

Figure 2.8: Timing Criteria for Formulation of Pavement M\&R Strategies (Adapted from Lamptey et al., 2005)

Maintenance activities planned at predefined intervals may be regular or irregular. These intervals may further be based on time, accumulated load, and accumulated weather. On the other hand, maintenance activities based on condition triggers, a specific treatment activity is undertaken anytime a selected measure of pavement condition reaches a certain threshold value. The measure of pavement condition may be aggregate or disaggregate, meaning that either a single composite performance index may be used, 
or a multiple performance indicators (distress indicators) may be used for maintenance decision making.

Most of the asset management models use optimization techniques to find the optimal maintenance strategies, and therefore the life cycle cost. Invariably most of these models have single performance criterion (aggregate measures) which is maximized against the total or annual maintenance expenditure (Lamptey et al., 2005). This performance criterion is usually the pavement condition index (PCI) or other forms of indices such as the international roughness index (IRI). An advantage of using a single composite performance criterion (over multiple distress indicators) lies in their economy: there is no need to carry out separate field monitoring of each indicator of pavement distress. However, a disadvantage is that aggregate measures only give an indication of overall pavement condition and fail to provide the distribution of various distresses. For the purpose of performance-based contracts, there usually are more than one pavement performance criteria that the contractor has to fulfill. Performance indicators based on multiple distress indicators are found in many state DOT's pavement survey database, and can easily be obtained for analysis. In this scenario, formulation of maintenance strategies based on multiple performance criteria is recommended and is deemed appropriate.

Table 2.4 shows the performance indices used by various state DOTs for measuring the condition state of the pavement. Based on the current state of condition rating, pavement treatments are then selected. It is apparent that ride, rut, and crack are three measures of pavement performance popularly adopted by the highway agencies. 
Table 2.4: Performance Indicators and Their Measures for Different State DOTs (Adapted from FHWA, 2003)

\begin{tabular}{|l|l|l|l|}
\hline Maryland & Ride & Rut & Crack \\
\hline $\begin{array}{l}\text { IRI(inch/mile) } \\
\text { Condition limits: } \\
\text { Very Good, Good, } \\
\text { Fair, Mediocre, } \\
\text { Poor }\end{array}$ & $\begin{array}{l}\text { Max depth for both } \\
\text { wheel paths } \\
\text { recorded in inch }\end{array}$ & Not reported \\
\hline Indiana & $\begin{array}{l}\text { IRI(inch/mile) } \\
\text { Condition limits: } \\
\text { Excellent, Good, } \\
\text { Fair, Poor }\end{array}$ & $\begin{array}{l}\text { Average depth in } \\
\text { wheel paths } \\
\text { recorded in inch. } \\
>0.25 \text { " is poor }\end{array}$ & $\begin{array}{l}\text { PCR includes all } \\
\text { crack types, } \\
\text { Condition Limits: } \\
\text { Excellent, Good, } \\
\text { Fair, Poor }\end{array}$ \\
\hline Florida & $\begin{array}{l}\text { IRI(inch/mile) } \\
\text { Converted to RN } \\
\text { with 0-10 scale }(10 \\
\text { is the best possible } \\
\text { condition) }\end{array}$ & $\begin{array}{l}\text { Average depth in } \\
\text { both wheel paths, } \\
\text { converted to 0-10 } \\
\text { scale. }\end{array}$ & $\begin{array}{l}\text { Crack rating in \& } \\
\text { outside wheel path } \\
\text { converted to 0-10 } \\
\text { scale. }\end{array}$ \\
\hline Arizona & $\begin{array}{l}\text { Roughness } \\
\text { (inch/mile), } \\
\text { Condition limits: } \\
\text { Very Good, Good, } \\
\text { Poor, Very Poor }\end{array}$ & $\begin{array}{l}\text { Average depth in } \\
\text { both wheel paths, } \\
\text { Medium, High }\end{array}$ & $\begin{array}{l}\text { \% crack of 1000 ft. } \\
\text { area at mile point, } \\
\text { Limits: Low, } \\
\text { Medium, High }\end{array}$ \\
\hline Washington & $\begin{array}{l}\text { PRC, average } \\
\text { depth in both wheel } \\
\text { paths. Limits: Very } \\
\text { Good, Good, Poor, } \\
\text { Very Poor. }\end{array}$ & $\begin{array}{l}\text { PSC includes all } \\
\text { crack type and } \\
\text { patching } \\
\text { Limits: Very Good, } \\
\text { Good, Poor, Very } \\
\text { Poor. }\end{array}$ \\
\hline
\end{tabular}

\subsection{Assessing and Estimating Costs of Maintaining Pavements within Specified Performance Criteria}

An extensive literature review reveals that there are only very limited research done on the cost analysis of performance-based pavement maintenance contracts, particularly with regard to pavement performance/warranty cost estimation. Moynihan et al. point to the fact that neither state agencies nor contractors can precisely calculate the real cost of a 
warranty obligation (Moynihan et al., 2009). They attribute the lack of such methodology primarily to the fact that the warranty programs of many states are relatively recent, and sufficient historical data are not available for a reliable prediction of future costs. However, all the states of the US have some form of pavement management system in place and there are plenty of avenues to get historical pavement condition data. LTPP is a fine example of the pavement performance data which can be used to analyze pavement maintenance cost. Most states, which perform life cycle cost analysis of assets, use the historical pavement performance data in one way or the other. The same historical pavement performance data can be utilized to estimate the cost of these warranty provision and performance-based pavement maintenance contracts. However, in practice highway agencies and contractors have been estimating the cost by the rule of thumb (Moynihan et al., 2009). Some of the important literatures dwelling on the subject of cost estimation of performance-based contracts/warranty contracts are discussed in detail in the following sections.

Emery (2000), in his paper, "Improved Construction Practices: Pavement Performance Evaluation as an Input to Stochastic Asset Management," provides a quantitative model that can be used for pricing the risk and cost of asset management. The paper outlines a technique to price the cost of repairs and maintenance work to meet the performance guarantee over the term of the contract. This stochastic asset management technique, used commonly by the highway agencies in asset management, considers more than one significant failure occurring during the warranty period. The calculation of the new generation warranty costing, as it is called in the paper, starts with the matrix of failures, probabilities, extent, and repairs, shown in Table 2.5. The cost of 
repairs and the warranty costing is given in Table 2.6. Poisson distribution was applied using data from commercial practice in South Africa to estimate the number of failures per year. The probabilities of $0,1,2,3,4$, etc., significant failures per year per project was then found by evaluating the Poisson distribution. The total cost of warranty is $\$ 7043$, when all the possible modes of failure are considered.

Table 2.5: Matrix of Failures, Probabilities, Extent, and Repairs (Adapted from Emery, 2000)

\begin{tabular}{|c|c|c|c|}
\hline Failure & Probability & Extent & Repair \\
\hline $\begin{array}{l}\text { Roughness and } \\
\text { structural crack }\end{array}$ & $5 \%$ & $5000 \mathrm{~m} 2$ & Slurry \\
\hline Rut & $5 \%$ & Full & Micro-surfacing \\
\hline Surface crack & $1 \%$ & Full & $\begin{array}{l}\text { Modified Single } \\
\text { seal }\end{array}$ \\
\hline Raveling/dry & $5 \%$ & Full & Single seal \\
\hline $\begin{array}{l}\text { Bleeding/skid } \\
\text { resistance }\end{array}$ & $5 \%$ & Full & $\begin{array}{l}\text { Modified single } \\
\text { seal }\end{array}$ \\
\hline
\end{tabular}

Table 2.6 : Warranty Costing (Adapted from Emery, 2000)

\begin{tabular}{|l|l|l|l|l|l|}
\hline Failure & Probability & Extent & $\begin{array}{l}\text { Rate } \\
\mathbf{( \$ ) / \text { unit }}\end{array}$ & $\begin{array}{l}\text { Cost } \\
\mathbf{\$}\end{array}$ & $\begin{array}{l}\text { P X Cost } \\
\mathbf{\$}\end{array}$ \\
\hline $\begin{array}{l}\text { Roughness } \\
\text { and structural } \\
\text { crack }\end{array}$ & $5 \%$ & $5000 \mathrm{~m} 2$ & 0.6 & 2976.2 & 148.9 \\
\hline Rut & $5 \%$ & Full & 0.87 & $42,603.2$ & 2130.2 \\
\hline Surface crack & $1 \%$ & Full & 1.03 & 50349.2 & 503.5 \\
\hline Raveling/dry & $5 \%$ & Full & 0.71 & $34,857.1$ & 1742.9 \\
\hline $\begin{array}{l}\text { Bleeding/skid } \\
\text { resistance }\end{array}$ & $5 \%$ & Full & 1.03 & $50,349.2$ & 2517.5 \\
\hline & & & & Total & 7043.0 \\
\hline
\end{tabular}


This method of costing warranty of pavement maintenance contracts is a better approach because it considers several modes of pavement failure. The traditional way of budgeting asset management may no longer be applicable to the new performance-based maintenance contracts which require multiple performance criteria such as roughness, rut, crack, etc., to be satisfied. Although this paper successfully addresses the costing of warranty to meet multiple performance criteria, it merely estimates the likelihood of pavement failure over the warranty period using the Poisson distribution. However, in reality there are several repair and deterioration cycles within the warranty period which have not been accounted in this paper.

Damnjanovic and Zhang (2006) applied a structured reliability-based method for short-term pavement warranty cost estimation. A system analysis methodology was developed for quantifying the warranty cost. The methodology considers the characterization of the warranty system and mathematical modeling of the system for the quantitative analysis. They also discussed the random characteristics of pavement failures, and pointed out that the appropriate approach for performance modeling should be a stochastic framework. The research focused on short-term warranties, where repair and rehabilitation are ignored, and possible multiple failures are not considered. It only evaluated the cost of risk before the first claim, which may be an underestimation of total warranty costs when in fact there may be more than one claims. Warranty cost of products in manufacturing industry is a well established concept. The authors have tried to develop an analogous methodology for pavement (considered as a product) using reliability method. Structural reliability, which has been used in the analysis, is the stressstrength inference method that compares a random variable which defines the level of 
strength and another random variable that specifies the applied loads or stress. A failure occurs when the level of stress exceeds that of strength. Although the approach of this paper is quite different to the one described in the previous paper, this methodology is an improvement over the previous method in a sense that it takes into account the effect of preventive maintenance and rehabilitation actions on the rate of occurrence of failure function (ROCOF). A major drawback of this methodology is that it considers structural number of pavement as the only criteria by which pavement performance is measured. However, in actual performance-based pavement maintenance contracts, there are several performance measurement criteria that have to be fulfilled in order for the pavement to have passed the performance test.

Moynihan et al. (2009) assume in their paper titled "Stochastic Modeling for Pavement Warranty Cost Estimation" that the time to failure of pavement is a random variable. Failure of pavement occurs when any of the distress indicators exceeds its threshold value. The probability distribution that assigns a probability to each value of a time-to-failure can be described in terms of a probability density function (PDF). The probability that the distress deterioration exceeds the threshold is

$\operatorname{Pr}\{\mathrm{d} \geq \mathrm{H}\}=1-\Phi\left(\frac{H-\mu}{\sigma}\right)$

where, $\Phi$ is the standard normal cumulative distribution, $\mu$ and $\sigma$ are expected value and standard deviation respectively of distress $i$ level. $\mathrm{H}$ is the threshold value for a distress denoted by $\mathrm{d}$.

However, when the pavement is treated it brings the condition of the pavement to a new condition level under the "good as new" assumption. This renewal process is an 
ordinary renewal process and the authors derive a mathematical function for expected number of renewals in the performance analysis period. When the expected number of renewals is known using the historical data on pavements for several distress indicators, the expected cost associated with such renewals over the time period of the performance contract is determined. The authors have applied mathematical formulation derived to estimate the cost of highway warranty by using Long Term Pavement Performance (LTPP) data. Two distress indicators, rut and transverse crack, have been used in the analysis. This paper is quite successful in achieving its objective of estimating cost of pavement warranty contracts but falls short on two issues: i) this methodology does not take into account the effectiveness of different maintenance and repair strategies to bring about the pavement to its new condition. Rather, a black box type of approach is used whereby the pavement is brought to a new condition no matter what repair strategies are used, ii) only two distress indicators are used whereas in actual warranty contracts, there are usually more than two performance criteria to fulfill. Although extension of the mathematical formulation to more than two distress indicators is possible, it is a very complex process and the resulting mathematical formulae are not easy to decipher.

Pinero (2003), in his dissertation, “A Framework for Monitoring Performance-Based Road Maintenance," tries to relate cost to performance requirement by evaluating the performance level of service that can be achieved by the allocated budget. Although one objective of the dissertation among several others, is to compare the cost effectiveness of traditional maintenance contracts with the performance-based maintenance contracts, this study is able to relate cost to performance by evaluating the impact in level of service (i.e., the condition of the assets) if the implementing agency spent in traditional 
maintenance at least the same amount under performance-based work. Markovian chains or condition state transition probabilities are used to relate cost to performance. Markovian chains have been used successfully in many state highway agencies to predict the pavement and bridge condition and estimate the cost of such maintenance requirements during the life cycle of the asset. Two nationwide projects in the United States, PONTIS and BRIDGIT, have implemented the Markovian approach to model the impact in the condition of bridge elements as a result of implementing different maintenance policies. A Markov chain is basically a square matrix that has a set of mutually exclusive states whose objective in the context of pavement management is to predict the future condition or future state of the system based on the current condition or current state. Hypothetical deterioration rate of the pavement is considered in the form of transitional probabilities represented in a matrix called transition probability matrix. When the probability distribution of the pavement in different condition state is known for the current period, it is easy to determine the condition of the pavement (which again is represented by probability distribution of different condition states) at any time step in the future. When such condition of the pavement in the future is determined it becomes easy to estimate the cost required to bring the pavement to the required level of service at different time intervals. This is done so in the dissertation by choosing different maintenance activities such that the minimum level of service of the pavement is achieved at the minimum cost possible. Analysis of maintenance work required for each year up to the completion of the contract period is performed, and at the same time cost to maintain the road at the required level of service for each year is estimated. This methodology is quite straight forward and takes into account the uncertainties of 
pavement deterioration in the cost estimation methodology. However, as pointed out with the other research works described earlier, only a single performance criterion is used. Moreover, one of the objectives was to relate cost to performance whereas, in estimating the cost of performance-based maintenance contract in reality, relating performance level to cost is necessary.

\subsection{Conclusion}

Performance-based maintenance contracts have been used in various parts of the world, albeit with a different terminology and different contract periods. In FHWA's terminology, these are nothing but maintenance performance warranty contracts. There are many risks inherent in such contracts. Risks with these contracts arise because of the uncertainty in accurately estimating the service life of the pavement. Predictions of service life get even more complex when a contractor maintaining the pavement has to meet multiple performance requirements throughout the contract period. The best way of managing risk associated with long term pavement maintenance contract, as mentioned in many literatures, is to be able to measure the present and future condition state of the pavement. One way of doing so is by modeling to predict future condition state of the pavement when it's past condition data are available. Probabilistic models, such as the one proposed in this research, are preferred over the deterministic models when there are many uncertainties in the input of the model. An inherent difficulty of using asset management models that are widely available is that these models invariably optimize maintenance cost using single (aggregate) performance criteria as opposed to multiple performance criteria that are usually present in the long-term performance-based maintenance contracts. For this very reason, a need for a different methodology is called 
for. Some of the literatures that are very relevant to the case discussed in this dissertation are highlighted, and their deficiencies in developing the methodology proposed in this dissertation are pointed out in this chapter. 


\section{CHAPTER 3}

\section{USING HISTORICAL PERFORMANCE DATA TO PREDICT PAVEMENT DETERIORATION AND IMPROVEMENT}

\subsection{Introduction}

This chapter will elucidate on the use of historical record of actual pavement condition to predict future condition of the pavement so that proper management of the asset can be planned well in advance. As previously mentioned, there are two basic methods of predicting pavement deterioration, namely deterministic, and probabilistic methods. Since deterministic methods lack the ability to accurately predict the deterioration of a pavement owing to the uncertainties of its explanatory factors, probabilistic models are more popular and widely used. One such widely used probabilistic method is the Markov Chain Theory. In this method, transition probability matrix (TPM) is used in order to predict future pavement conditions. Essential to the establishment of the TPM are the pavement conditions from previous years. This chapter will introduce to the generation of TPMs from historical data, the results from which will be used in the forthcoming chapters to develop a methodological framework to estimate the cost of performance-based pavement maintenance contracts.

\subsection{Markov Transition Probability Matrices}

Markov transition probability matrices are useful in representing the change in condition of the system from one state to another over time. Change in condition is nothing but the transition from one state to another over time. So, essentially, the key elements of any Markov transition matrices are states and transitions. To clarify this, an 
interesting example of how a Markov transition matrix may be constructed is quoted from Kostuk (2003).

The classic example for a Markov process is a frog sitting in a pond filled with lily pads. In this example, each pad in the pond represents a state of the system. If there is a finite number of pads in the pond, the system we are describing is a finite state system. If we were to check the pond every five minutes to observe the frog's location each epoch in the model would be equivalent to five minutes in real time. The likelihood of the frog making a transition from pad $i$ to $j$ is $p_{i j}$. Figure 3.1 shows a simple schematic describing the transition from one state to the next.

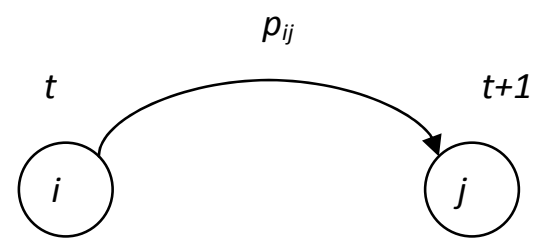

Figure 3.1: The Transition between Two States (Adapted from Kostuk, 2003)

The transition probabilities $p_{i j}$ are stored in a matrix where the rows represent the present state and the columns the future state. In the matrix shown in Table 3.1, the probability of making a transition from state 1 to state 2 is 0.3 (row 1, column 2).

Table 3.1: Transition Probability Matrix (Adapted from Kostuk, 2003)

\begin{tabular}{|c|c|c|c|c|}
\hline & \multicolumn{3}{|c|}{$\mathrm{TO}$} \\
\hline & & 1 & 2 & 3 \\
\hline \multirow{3}{*}{ FROM } & 1 & 0.7 & 0.3 & 0 \\
\hline & 2 & 0 & 0.6 & 0.4 \\
\hline & 3 & 0 & 0 & 1 \\
\hline
\end{tabular}

Typically the transition probability matrix is denoted as $P$ and the individual elements of the matrix are referenced via the notation $p_{i j}$ where $i$ indicates the row and $j$ indicates the column of the matrix element. The schematic equivalent to the transition matrix shown above can be found in Figure 3.2. 


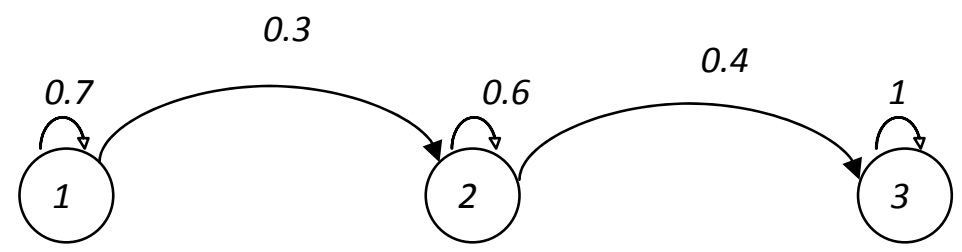

Figure 3.2: A Schematic Diagram Describing the State Transitions for a Three State Model (Adapted from Kostuk, 2003)

A slightly more complex state transition schematic is illustrated in Figure 3.3. In this figure it can be seen that the possible transitions the frog could make over two epochs (time steps). The schematic starts with the frog on some pad $i$. This schematic illustrates the frog's potential location after one and two time epochs.

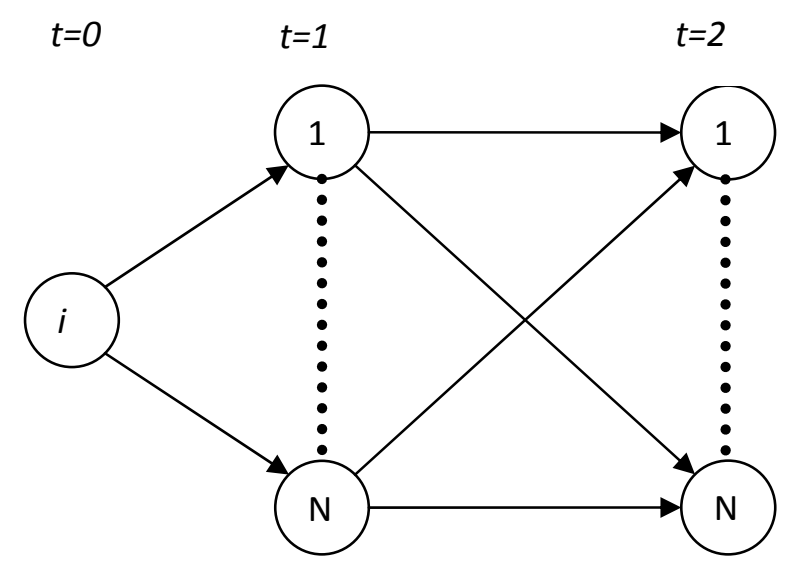

Figure 3.3: The Possible Transitions Over Two Epochs (Adapted from Kostuk, 2003)

The above description provides a classic example of how transition probabilities may be estimated. Chapter 2 discussed some of the literatures that made use of Markov transition probability matrices in asset management modeling. Markov transition probability matrices have been popularly and successfully used in the optimization of pavement maintenance, bridge maintenance, sewer infrastructure maintenance, building maintenance, and in many other areas. Next section describes how transition 
probabilities, which are the elements of the transition probability matrix, are estimated when a series of pavement performance data are available over a long period of time.

\subsection{Generating Transition Probability Matrices from Pavement Condition Data}

\subsubsection{Data Types and Sources for Methodology Development}

Table 3.2 shows the details of the data type and the sources used for this dissertation.

Table 3.2: Data Types and Sources

\begin{tabular}{|c|c|c|}
\hline Data Type & Details & Source \\
\hline $\begin{array}{l}\text { Pavement condition rating } \\
\text { data }\end{array}$ & Crack, ride, and rut & $\begin{array}{l}\text { FDOT pavement condition } \\
\text { rating survey }\end{array}$ \\
\hline $\begin{array}{l}\text { Operating characteristics } \\
\text { data (traffic volumes, } \\
\text { vehicle classification, } \\
\text { speed limit, etc.) }\end{array}$ & $\begin{array}{l}\text { AADT, } \% \text { trucks, speed } \\
\text { limit }\end{array}$ & $\begin{array}{l}\text { FDOT pavement condition } \\
\text { rating survey }\end{array}$ \\
\hline $\begin{array}{l}\text { Major maintenance and } \\
\text { reconstruction records data }\end{array}$ & $\begin{array}{l}\text { Resurfacing, and } \\
\text { reconstruction dates }\end{array}$ & $\begin{array}{l}\text { FDOT pavement condition } \\
\text { rating survey }\end{array}$ \\
\hline $\begin{array}{l}\text { Routine and minor } \\
\text { maintenance cost }\end{array}$ & $\begin{array}{l}\text { Historical average } \\
\text { maintenance costs per lane- } \\
\text { mile }\end{array}$ & LTPP data \\
\hline $\begin{array}{l}\text { Major maintenance and } \\
\text { reconstruction cost }\end{array}$ & Average cost per lane-mile & Other literatures \\
\hline Performance specifications & $\begin{array}{l}\text { Performance thresholds, } \\
\text { maintenance requirements, } \\
\text { etc. }\end{array}$ & $\begin{array}{l}\text { Contractor Guaranteed } \\
\text { Asphalt Pavement } \\
\text { (FDOT), Miami Dade } \\
\text { Expressways Authority }\end{array}$ \\
\hline
\end{tabular}

\subsubsection{Pavement Condition Data}

Most countries keep a database of the road condition recorded each year as part of their pavement management system (PMS). A majority of these countries have a pavement management mechanism. In the US, only five states Arizona, California, Idaho, Utah, and Washington were reported to have been in various stages of developing pavement system management in 1980 (FHWA, 2003). Since then, all states of the US 
have some form of pavement management programs in place. The major work of these pavement management systems is to devise pavement management strategies based on the condition state of the pavement.

Apart from the state DOTs, FHWA has carried out a Long Term Pavement Performance (LTPP) 20 year-research program as part of the Strategic Highway Research Program. LTPP collects information on pavement performance and the elements that may influence pavement performance. Since 1987, the LTPP program has been monitoring more than 2,400 pavement test sections across the United States and Canada. Several distress characteristics such as rut depth, transverse crack, longitudinal crack, alligator crack, potholes, etc., along with pavement structures, material characteristics, climatic conditions, pavement loading, maintenance activities and other pieces of information are recorded as part of the LTPP program (FHWA, 2003).

In the case of state of Florida, Condition Survey Unit conducts annual surveys of the entire state highway system in support of the department's pavement management program. The data collected (in terms of crack, ride, and rut measurements) over a long period of time is used to evaluate the existing condition of the state's roadways as well as to predict future rehabilitation needs. These predictions are used in preparing the budget requirement and subsequent distribution of funds to the districts. The following sections describe how transition probabilities can be generated when historical performance data are available. 


\subsubsection{Number of Pavement Condition States}

Pavement can be first discretized into "n" states in terms of its condition index. Pavement distress ratings for crack, rut, roughness, etc. may be used as the criterion to discretize pavements into different states, as illustrated in Figure 3.4.

\begin{tabular}{lllllllll}
\hline & \multicolumn{1}{l}{} & \multicolumn{1}{l}{} & \multicolumn{1}{l}{} \\
\hline 10 & State 1 & $\alpha_{1}$ & State 2 & $\alpha_{2}$ & $\alpha_{n}$ State $n-1$ & $\alpha_{n-1}$ & State $n$ & 1
\end{tabular}

Figure 3.4: Definition of Condition States for a Flexible Pavement

where, $\alpha_{\mathrm{i}}=$ the thresholds that are used to discretize pavement into different states in terms of distress ratings. For example, if the crack condition rating of the pavement is discretized into five different states with ratings ranging from 1 to 10 , the following categorization as shown in Table 3.3 is be obtained.

Table 3.3: Five-step Classification for Crack Condition States

\begin{tabular}{|l|l|}
\hline Crack Rating Ranges & Condition State \\
\hline $9.1-10$ & Very Good \\
\hline $8.1-9$ & Good \\
\hline $7.1-8$ & Fair \\
\hline $6.1-7$ & Bad \\
\hline$<6$ & Very Bad \\
\hline
\end{tabular}

\subsubsection{Current Pavement Condition State Vector}

In order to determine the future pavement condition after $n$ number of years, it is essential to determine the present pavement condition. Having determined the range for different states of pavement condition, it is a simple task to determine how many sections (or length) of the road fall into each of these condition states in any one year. The 
derivation of condition state vector is illustrated for a pavement length from the crack condition rating data as of SR-836 (Dolphin Expressway) for year 2008 as shown in Table 3.4.

Table 3.4: Condition State Vector Using Probability Distribution of Pavement

\begin{tabular}{|l|l|l|l|}
\hline $\begin{array}{l}\text { Condition } \\
\text { State }\end{array}$ & $\begin{array}{l}\text { Corresponding } \\
\text { Crack Rating }\end{array}$ & Miles & $\begin{array}{l}\text { Probability } \\
\text { Distribution }\end{array}$ \\
\hline Very good & $9.1-10$ & 9.023 & $68.7 \%$ \\
\hline Good & $8.1-9$ & 0 & $0 \%$ \\
\hline Fair & $7.1-8$ & 0.445 & $3.3 \%$ \\
\hline Bad & $6.1-7$ & 3.752 & $28 \%$ \\
\hline Very bad & $<6$ & 0 & $0 \%$ \\
\hline Total miles & & 13.4 & $100 \%$ \\
\hline
\end{tabular}

This condition probability in year 2008 can be represented by a condition state vector $X=\left[\begin{array}{lllll}0.687 & 0.000 & 0.033 & 0.280 & 0.000\end{array}\right]$. This is a vector of probabilities that a pavement section will be in that state at the beginning of year 2008. When the condition state of the pavement in year $t+1$ is to be found, then vector $X_{t}$ is simply multiplied by the Markovian transition probability matrix $\mathrm{P}$. Thus,

$$
\begin{aligned}
& \mathrm{X}(1)=\mathrm{X}(0) * \mathrm{P} \\
& \mathrm{X}(2)=\mathrm{X}(1) * \mathrm{P}=\mathrm{X}(0) * \mathrm{P}^{2} \\
& : \quad: \quad: \quad: \\
& : \quad: \quad: \quad: \\
& \mathrm{X}(t)=\mathrm{X}(t-1) * \mathrm{P}=\mathrm{X}(0) * \mathrm{P}^{\mathrm{t}}
\end{aligned}
$$

Using the current condition state vector and the Markov transition probabilities, the future condition of the pavement at any time $t$ can be predicted. 


\subsubsection{Transition Probabilities Estimation Using Count Proportions}

Different techniques have been used in the past to develop transition probability matrices from condition data. The regression-based optimization method is the mostcommonly used approach in estimating the elements of these matrices for different types of facilities, such as pavements and bridges (Bulusu and Sinha 1997). This method uses a non-linear optimization function to minimize the sum of absolute differences between the regression curve that best fits the condition data and the conditions predicted using the adopted Markov chain model. The objective function and the constraints of this optimization problem can be formulated as (Butt et al., 1987, 1994; Jiang et al., 1988; Madanat et al. 1995; Wirahadikusumah et al., 2003):

Minimize $\sum_{t=1}^{N}[Y(t)-E[Y(t, P)]]$ where,

$\mathrm{N}=$ the total number of transition periods

$\mathrm{Y}(\mathrm{t})=$ the condition at period $t$ on the regression curve

$\mathrm{E}[\mathrm{Y}(\mathrm{t}, \mathrm{P})]=$ expected value of condition at period $t$ as predicted by the Markov chain model using probability matrix $P$.

Because the regression model used in this method is affected significantly by any prior MR\&R actions, whose records are not readily available in the Pavement Management System database, the count proportions method, which is more suitable, is used instead. In this method, the probability $p_{i j}$ of transition in pavement condition from state $i$ to state $j$ can be estimated using the following equation (Jiang et al., 1988; Morcous et al., 2002; Garcia et al., 2006): 
$p_{i, j}=n_{i, j} / n_{i}$

where, $n_{i j}=$ number of road sections transitioning from state $i$ to state $j$ within a given time period.

$n_{i}=$ the total number of road sections in state $i$ before the transition.

Estimating transition probability is a relatively straight forward process if one is able to observe the sequence of states for each individual unit of observation. For instance, if we observe the condition ratings of a number of pavement sections at the beginning of a year and then again at the end of the year, then we can estimate the probability of pavement condition moving from one state to another. The probability of a section having a particular condition rating at the end of the year (e.g., Good) given their condition states at the beginning of the year (e.g. Very Good) is given by the simple ratio of the number of sections that began the year with the same rating (Very Good) and ended with a Good rating to the total number of sections that began with a Very Good rating. This can be illustrated by presenting the transition of condition states for crack in Table 3.5 as shown. Out of the total 652 sections considered for the analysis, 433 sections remained in the Very Good condition state from one year to the next consecutive year. Only 18 of those pavement sections in Very Good condition state deteriorated to Good condition state in the consecutive year. The transition of pavement from one year to the next is observed for all other condition states.

Table 3.5 can be presented in its intermediate transition probability matrix as shown in Table 3.6, and final transition matrix in Table 3.7. 
Table 3.5: Crack Condition Rating Distribution

\begin{tabular}{|l|l|l|}
\hline $\begin{array}{l}\text { Condition State } \\
\text { Transition }\end{array}$ & $\begin{array}{l}\text { Corresponding Crack } \\
\text { Rating }\end{array}$ & No. of Sections \\
\hline Very Good $\rightarrow$ Very Good & $9.1-10 \rightarrow 9.1-10$ & 433 \\
\hline Very Good $\rightarrow$ Good & $9.1-10 \rightarrow 8.1-9$ & 18 \\
\hline Good $\rightarrow$ Good & $8.1-9 \rightarrow 8.1-9$ & 19 \\
\hline Good $\rightarrow$ Fair & $8.1-9 \rightarrow 7.1-8$ & 12 \\
\hline Fair $\rightarrow$ Fair & $7.1-8 \rightarrow 7.1-8$ & 72 \\
\hline Fair $\rightarrow$ Bad & $7.1-8 \rightarrow 6.1-7$ & 18 \\
\hline Bad $\rightarrow$ Bad & $6.1-7 \rightarrow 6.1-7$ & 32 \\
\hline Bad $\rightarrow$ Very Bad & $6.1-7 \rightarrow<6$ & 10 \\
\hline Very Bad $\rightarrow$ Very Bad & $<6 \rightarrow<6$ & 38 \\
\hline Total No. of Sections & & 652 \\
\hline
\end{tabular}

Table 3.6: Intermediate Transition Probability Matrix for Crack

\begin{tabular}{|c|c|c|c|c|c|c|c|}
\hline \multirow{7}{*}{ 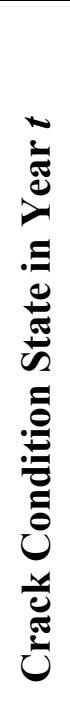 } & \multicolumn{6}{|c|}{ Crack Condition State in Year $t+1$} & \multirow[b]{2}{*}{$\begin{array}{l}\text { Total } \\
\text { No. of } \\
\text { Sections }\end{array}$} \\
\hline & & $\begin{array}{l}\overrightarrow{0} \\
\dot{0} \\
0 \\
\overrightarrow{0} \\
>\end{array}$ & $\begin{array}{l}\text { : } \\
\dot{0}\end{array}$ & 寻 & $\ddot{\mathscr{m}}$ & $\begin{array}{l}\vec{Z} \\
\stackrel{0}{0} \\
\vec{D} \\
>\end{array}$ & \\
\hline & $\begin{array}{l}\text { Very } \\
\text { Good }\end{array}$ & 433 & 18 & 0 & 0 & 0 & 451 \\
\hline & Good & 0 & 19 & 12 & 0 & 0 & 31 \\
\hline & Fair & 0 & 0 & 72 & 18 & 0 & 90 \\
\hline & $\mathrm{Bad}$ & 0 & 0 & 0 & 32 & 10 & 42 \\
\hline & Very Bad & 0 & 0 & 0 & 0 & 38 & 38 \\
\hline & & & & & & & 652 \\
\hline
\end{tabular}


Table 3.7: Transition Probability Matrix for Deterioration-Crack

\begin{tabular}{|l|l|l|l|l|l|}
\hline \multirow{2}{*}{$\begin{array}{l}\text { Pavement } \\
\text { Condition } \\
\text { Before }\end{array}$} & \multicolumn{5}{|c|}{ Pavement Condition After } \\
\cline { 2 - 6 } & $\begin{array}{l}\text { Very } \\
\text { Good }\end{array}$ & Good & Fair & Bad & $\begin{array}{l}\text { Very } \\
\text { Bad }\end{array}$ \\
\hline Very Good & 0.960 & 0.040 & 0 & 0 & 0 \\
\hline Good & 0 & 0.613 & 0.387 & 0 & 0 \\
\hline Fair & 0 & 0 & 0.8 & 0.2 & 0 \\
\hline Bad & 0 & 0 & 0 & 0.762 & 0.238 \\
\hline Very Bad & 0 & 0 & 0 & 0 & 1 \\
\hline
\end{tabular}

Similarly, for ride, transition probability matrix can be derived as illustrated through Table 3.8 to Table 3.10 .

Table 3.8: Ride Condition Rating Distribution

\begin{tabular}{|l|l|l|}
\hline $\begin{array}{l}\text { Condition State } \\
\text { Transition }\end{array}$ & $\begin{array}{l}\text { Corresponding Ride } \\
\text { Rating }\end{array}$ & No. of Sections \\
\hline Very good $\rightarrow$ Very Good & $9.1-10 \rightarrow 9.1-10$ & 8 \\
\hline Very Good $\rightarrow$ Good & $9.1-10 \rightarrow 8.1-9$ & 20 \\
\hline Good $\rightarrow$ Good & $8.1-9 \rightarrow 8.1-9$ & 416 \\
\hline Good $\rightarrow$ Fair & $8.1-9 \rightarrow 7.1-8$ & 51 \\
\hline Fair $\rightarrow$ Fair & $7.1-8 \rightarrow 7.1-8$ & 117 \\
\hline Fair $\rightarrow$ Bad & $7.1-8 \rightarrow 6.1-7$ & 7 \\
\hline Bad $\rightarrow$ Bad & $6.1-7 \rightarrow 6.1-7$ & 13 \\
\hline Bad $\rightarrow$ Very Bad & $6.1-7 \rightarrow<6$ & 0 \\
\hline Very Bad $\rightarrow$ Very Bad & $<6 \rightarrow<6$ & 5 \\
\hline Total No. of Sections & & 637 \\
\hline
\end{tabular}

Table 3.8 can be presented in its intermediate transition matrix form as shown in Table 3.9, and to final transition matrix form as shown in Table 3.10. 
Table 3.9: Intermediate Transition Probability Matrix for Ride

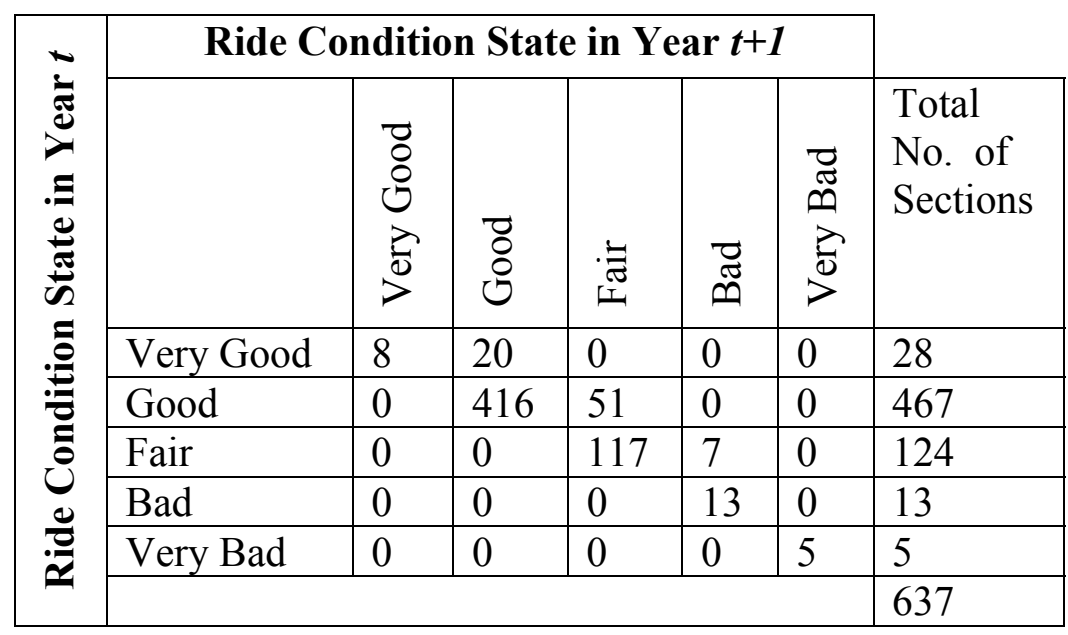

Table 3.10: Transition Probability Matrix for Deterioration-Ride

\begin{tabular}{|l|l|l|l|l|l|}
\hline Pavement & \multicolumn{5}{|c|}{ Pavement Condition After } \\
$\begin{array}{l}\text { Condition } \\
\text { Before }\end{array}$ & $\begin{array}{l}\text { Very } \\
\text { Good }\end{array}$ & Good & Fair & Bad & $\begin{array}{l}\text { Very } \\
\text { Bad }\end{array}$ \\
\hline Very Good & 0.286 & 0.714 & 0 & 0 & 0 \\
\hline Good & 0 & 0.891 & 0.109 & 0 & 0 \\
\hline Fair & 0 & 0 & 0.944 & 0.056 & 0 \\
\hline Bad & 0 & 0 & 0 & 1 & 0 \\
\hline Very Bad & 0 & 0 & 0 & 0 & 1 \\
\hline
\end{tabular}

And finally for rut, transition probability matrix can be developed similarly, and is illustrated through Table 3.11 to 3.13 .

Table 3.11: Rut Condition Rating Distribution

\begin{tabular}{|l|l|l|}
\hline Condition State Transition & Corresponding Rut Rating & No. of Sections \\
\hline Very good $\rightarrow$ Very Good & $9.1-10 \rightarrow 9.1-10$ & 8 \\
\hline Very Good $\rightarrow$ Good & $9.1-10 \rightarrow 8.1-9$ & 21 \\
\hline Good $\rightarrow$ Good & $8.1-9 \rightarrow 8.1-9$ & 237 \\
\hline Good $\rightarrow$ Fair & $8.1-9 \rightarrow 7.1-8$ & 48 \\
\hline Fair $\rightarrow$ Fair & $7.1-8 \rightarrow 7.1-8$ & 190 \\
\hline Fair $\rightarrow$ Bad & $7.1-8 \rightarrow 6.1-7$ & 25 \\
\hline Bad $\rightarrow$ Bad & $6.1-7 \rightarrow 6.1-7$ & 46 \\
\hline Bad $\rightarrow$ Very Bad & $6.1-7 \rightarrow<6$ & 11 \\
\hline Very Bad $\rightarrow$ Very Bad & $<6 \rightarrow<6$ & 2 \\
\hline Total No. of Sections & & 588 \\
\hline
\end{tabular}


Table 3.11 can be presented in its intermediate transition probability matrix form as shown in Table 3.12, and final transition probability matrix form as shown in Table 3.13.

Table 3.12: Intermediate Transition Probability Matrix for Rut

\begin{tabular}{|c|c|c|c|c|c|c|c|}
\hline \multirow{7}{*}{ 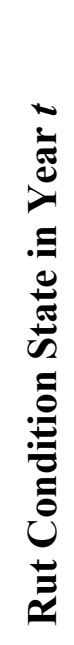 } & \multicolumn{6}{|c|}{ Rut Condition State in Year $t+1$} & \multirow[b]{2}{*}{$\begin{array}{l}\text { Total } \\
\text { No. of } \\
\text { Sections }\end{array}$} \\
\hline & & $\begin{array}{l}\overrightarrow{8} \\
8 \\
0 \\
\overrightarrow{0} \\
>\end{array}$ & $\begin{array}{l}\ddot{8} \\
\dot{8} \\
\end{array}$ & 离 & $\stackrel{\vec{Z}}{\mathscr{D}}$ & 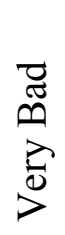 & \\
\hline & Very Good & 8 & 21 & 0 & 0 & 0 & 29 \\
\hline & Good & 0 & 237 & 48 & 0 & 0 & 285 \\
\hline & Fair & 0 & 0 & 190 & 25 & 0 & 215 \\
\hline & $\mathrm{Bad}$ & 0 & 0 & 0 & 46 & 11 & 57 \\
\hline & Very Bad & 0 & 0 & 0 & 0 & 2 & 2 \\
\hline & & & & & & & 588 \\
\hline
\end{tabular}

Table 3.13: Transition Probability Matrix for Deterioration-Rut

\begin{tabular}{|l|l|l|l|l|l|}
\hline $\begin{array}{l}\text { Pavement } \\
\text { Condition } \\
\text { Before }\end{array}$ & \multicolumn{5}{|c|}{ Pavement Condition After } \\
\cline { 2 - 6 } & $\begin{array}{l}\text { Very } \\
\text { Good }\end{array}$ & Good & Fair & Bad & $\begin{array}{l}\text { Very } \\
\text { Bad }\end{array}$ \\
\hline Very Good & 0.276 & 0.724 & 0 & 0 & 0 \\
\hline Good & 0 & 0.832 & 0.168 & 0 & 0 \\
\hline Fair & 0 & 0 & 0.884 & 0.116 & 0 \\
\hline Bad & 0 & 0 & 0 & 0.807 & 0.193 \\
\hline Very Bad & 0 & 0 & 0 & 0 & 1 \\
\hline
\end{tabular}

It can be seen that pavement deterioration rate due to crack is less severe for pavement in very good condition. Only $4 \%$ of the pavement deteriorates from Very Good condition to Good condition in one year. This is, however, not the same with ride and rut 
distresses. For ride, $71.4 \%$ of the pavement degrades to Good condition from Very Good condition, and $72.4 \%$ of the pavement degrades to Good condition from Very Good condition for rut. These results may be quite contrary to what is actually expected. This unexpected result for ride and rut may be explained by the availability of only few pavement sections in Very Good condition with respect to ride and rut. As a result of this, transition probability, which is determined by count proportion of pavement section moving from one state to the next, may not be represented accurately. To offset this problem, a large sample of pavement sections is required such that there are sufficient numbers of pavement sections in each condition category.

It should be noted here that transition probabilities that characterize the pavement deterioration process are dependent on many factors. Some of these factors may include weather conditions, pavement sub-grade, geological conditions, volume of traffic, and composition of traffic, among many others. In order to obtain the actual deterioration process as accurately as possible, these factors have to be taken into account when developing their corresponding transition probability matrices. A good way of doing so is to classify the pavements based on these factors and then find the transition probabilities for pavements in each of these different classifications. However, when pavement sections that are to be analyzed have similar characteristics and are exposed to similar conditions, a single set of transition probability matrix may be used to describe the deterioration process for pavements falling in that category. Pavement sections that are analyzed in this dissertation are all from a similar geographical location having similar weather patterns. Only categorizations that had to be made were with regards to the speed limits, annual average daily traffic (AADT) volume, and percentage of trucks. The speed 
limits for all these pavements were above $50 \mathrm{mph}$. Annual percentage of trucks using the Miami Dade Expressways ranged from $1.5 \%$ to $13.7 \%$. Only for a small stretch of asphalt pavement of SR 112 had a high percentage of trucks. The weighted average percentage of trucks for the entire network was $5.7 \%$. A better approach would have been to generate transitional probability matrix to represent deterioration based on the different level of percentage of trucks. However, categorization of pavement based on annual percentage of trucks resulted in very few usable pavement performance data in some categories for model development, and therefore, the average value of percentage of truck was used to generate transition probability matrix. Categorization of road was finally based only on the AADT volume. Standards based on Plans Preparation Manual for FDOT were used to categorize pavements into low volume AADT and high volume AADT as shown in Table 3.14

Table 3.14: Standards for Low and High Volume Highways in Annual Average Daily Traffic Volumes- Freeway-Urban (Adapted from FDOT, 2009)

\begin{tabular}{|l|l|l|}
\hline Highway Type & Low AADT Volume & High AADT Volume \\
\hline 4-lane facility & 57,000 & 69,000 \\
\hline 6-lane facility & 86,000 & 103,000 \\
\hline 8-lane facility & 114,000 & 138,000 \\
\hline
\end{tabular}

Transition probabilities are generated for pavements with low AADT volume separately in a similar way as it was done for the high AADT volume pavements earlier. Since the methodology adopted is the same, only the results of the transition probability estimation process for low volume AADT are summarized as shown in Table 3.15 without further elaborating on the methodology. 
Table 3.15:Transition Probability Matrix for Different Distresses for Low AADT

\begin{tabular}{|c|c|c|c|c|c|}
\hline \multirow{2}{*}{$\begin{array}{l}\text { Distress Indicator } \\
\text { Crack }\end{array}$} & \multicolumn{5}{|c|}{ Transition Probability Matrix } \\
\hline & 0.909 & 0.091 & 0 & 0 & 0 \\
\hline & 0 & 0.871 & 0.129 & 0 & 0 \\
\hline & 0 & 0 & 0.591 & 0.410 & 0 \\
\hline & 0 & 0 & 0 & 0.682 & 0.318 \\
\hline & 0 & 0 & 0 & 0 & 1 \\
\hline \multirow[t]{5}{*}{ Ride } & 0 & 0 & 0 & 0 & 0 \\
\hline & 0 & 0.832 & 0.168 & 0 & 0 \\
\hline & 0 & 0 & 0.92 & 0.08 & 0 \\
\hline & 0 & 0 & 0 & 0.579 & 0.421 \\
\hline & 0 & 0 & 0 & 0 & 1 \\
\hline \multirow[t]{5}{*}{ Rut } & 0.667 & 0.333 & 0 & 0 & 0 \\
\hline & 0 & 0.808 & 0.192 & 0 & 0 \\
\hline & 0 & 0 & 0.921 & 0.079 & 0 \\
\hline & 0 & 0 & 0 & 0.889 & 0.111 \\
\hline & 0 & 0 & 0 & 0 & 1 \\
\hline
\end{tabular}

There were certain assumptions made in generating transition probability matrix for the pavements which are as follows:

- Pavement conditions are expressed in a finite number of states, i.e., distress rating is discretized into five different states.

- The transition probabilities depend only on the present condition state.

- The transition process is stationary, that is, the probability of transition from one condition state to another is independent of time.

- Condition ratings will always remain constant or decrease with time. Increase in condition rating is not taken into account for pavement that is leftt to deteriorate on its own. 
- The pavement condition cannot deteriorate by more than a single state in one year.

- Transition probability matrix assumed here is homogenous meaning that the transition probability for deterioration from one year to the next is always the same.

\subsubsection{Transition Probability Matrices for M\&R Activities}

It was assumed in the previous section that the condition rating will always remain constant or decrease with the passage of time when the pavement is left to deteriorate. However, when repair and maintenance activities are performed, condition of the pavement improves and, therefore, the condition rating may remain constant or increase as the maintenance is carried out. Since it is the intention of this research to quantify the maintenance cost for a period for which the pavement is to be maintained at pre-specified levels of services, it is necessary to develop transition probability matrices for maintenance and rehabilitation activities as well.

For this dissertation, a set of four standardized pavement M\&R treatment strategies have been considered. These four M\&R strategies are: (1) Routine maintenance, (2) Minor maintenance, (3) Major maintenance, and (4) Reconstruction. Each of these four maintenance strategies is defined based on pavement maintenance action, work content, unit cost, and treatment effect on the existing pavement.

When a routine maintenance strategy is applied, pavement is treated with light maintenance works that does not have substantial improvement in pavement performance. Some of these routine maintenance works could be sealing cracks, patching of few potholes, etc. Since the historical pavement condition rating survey data available 
does not distinguish the pavement performance rating after the application of these routine maintenance, it is assumed that the effect of routine maintenance are already included in the deterioration matrix developed. So, the deterioration transition probability matrix that was derived earlier is actually the transition probability matrix for pavement deterioration under routine maintenance. For other maintenance strategies, knowledge of the effects of the treatment actions on the improvement of the road condition is essential to derive transition probability matrices. Transition probability matrix represented by an identity matrix provides a good basis to develop and compare the transition probability matrix for treatment actions. An identity matrix or unit matrix of size $n$ is the $n$-by- $n$ square matrix with ones on the main diagonal and zeros elsewhere. An important property of a unit matrix is that whatever matrix is multiplied with a unit matrix, that product (output matrix) remains unchanged after the multiplication. Since we have defined our condition categories into five steps, the identity matrix will be as shown in Table 3.16 for a size of $5 X 5$ :

Table 3.16: An Identity Matrix

$$
\left|\begin{array}{lllll}
1 & 0 & 0 & 0 & 0 \\
0 & 1 & 0 & 0 & 0 \\
0 & 0 & 1 & 0 & 0 \\
0 & 0 & 0 & 1 & 0 \\
0 & 0 & 0 & 0 & 1
\end{array}\right|
$$

Elements that are above the diagonal of this matrix represent the deterioration transitions where as the elements below the diagonal represent the improvement transitions of the pavement to a better condition. When a treatment action is represented 
by such an identity transition matrix, it means that there is no change in the condition of the pavement, i.e., it restores the pavement condition to where it was before the treatment. For example, if the condition of the pavement this year is represented by condition state vector $\left[\begin{array}{lllll}0.5 & 0.25 & 0.1 & 0.1 & 0.05\end{array}\right]$, then the pavement condition next year will be given by the product of this condition state vector and the deterioration transition probability matrix, which in this case is an identity matrix. The product is nothing but the same condition state vector, i.e., $\left[\begin{array}{lllll}0.5 & 0.25 & 0.1 & 0.1 & 0.05\end{array}\right]$ This condition state vector shows that $50 \%$ of the pavement is in Very Good condition state, $25 \%$ in Good condition state, $10 \%$ in Fair condition state, $10 \%$ in Bad condition state, and 5\% in Very Bad condition state before and after the treatment. So, if any condition state vector is multiplied with an identity matrix, there is no change in the state vector. To derive transition probability matrices for other maintenance activities, performance jump concept is introduced in the following paragraph.

\section{Performance Jump}

The concept of performance jump, which is the instantaneous elevation in performance upon maintenance, has been discussed by Lytton (1987), Colucci-Rios and Sinha (1985), Rajagopal and George (1991), Smith et al. (1993) and Labi and Sinha (2004). Smith et al.(1993) and Labi and Sinha (2004) have proposed a mathematical form for an immediate improvement model for maintenance effectiveness. Transition probability matrices may be derived from a similar concept of performance jump by calculating the proportion of pavement in certain condition state just before the treatment to a better condition state after the treatment. For this, pavement condition rating data for a large number of pavement sections just before and after the maintenance activity should 
be available. Pavement condition survey conducted by FDOT includes pavement condition rating for rehabilitation work such as resurfacing and reconstruction. In the Flexible Pavement Condition Survey of FDOT, the year in which such rehabilitative works were carried out are recorded. By observing the pavement conditions rating just before and after the rehabilitation treatment, transition probabilities are estimated for resurfacing and reconstruction. A step-by-step process of calculating these transition probabilities for resurfacing activity that improved the condition of the pavement with respect to crack distress are shown in Table 3.17, Table 3.18, and Table 3.19.

Table 3.17: Crack Condition Distribution After Resurfacing

\begin{tabular}{|l|l|l|}
\hline $\begin{array}{l}\text { Condition State } \\
\text { Transition }\end{array}$ & $\begin{array}{l}\text { Corresponding Crack } \\
\text { Rating }\end{array}$ & No. of Sections \\
\hline Very good $\rightarrow$ Very Good & $9.1-10 \rightarrow 9.1-10$ & 9 \\
\hline Good $\rightarrow$ Very Good & $8.1-9 \rightarrow 9.1-10$ & 23 \\
\hline Good $\rightarrow$ Good & $8.1-9 \rightarrow 8.1-9$ & 13 \\
\hline Fair $\rightarrow$ Very Good & $7.1-8 \rightarrow 9.1-10$ & 14 \\
\hline Fair $\rightarrow$ Good & $7.1-8 \rightarrow 8.1-9$ & 3 \\
\hline Fair $\rightarrow$ Fair & $7.1-8 \rightarrow 7.1-8$ & 0 \\
\hline Bad $\rightarrow$ Very Good & $6.1-7 \rightarrow 9.1-10$ & 41 \\
\hline Bad $\rightarrow$ Good & $6.1-7 \rightarrow 8.1-9$ & 3 \\
\hline Bad $\rightarrow$ Fair & $6.1-7 \rightarrow 7.1-8$ & 0 \\
\hline Bad $\rightarrow$ Bad & $6.1-7 \rightarrow 6.1-7$ & 0 \\
\hline Very Bad $\rightarrow$ Very Good & $<6 \rightarrow 9.1-10$ & 26 \\
\hline Very Bad $\rightarrow$ Good & $<6 \rightarrow 8.1-10$ & 2 \\
\hline Very Bad $\rightarrow$ Fair & $<6 \rightarrow 7.1-8$ & 0 \\
\hline Very Bad $\rightarrow$ Bad & $<6 \rightarrow 6.1-7$ & 0 \\
\hline Very Bad $\rightarrow$ Very Bad & $<6 \rightarrow<6$ & 0 \\
\hline Total No. of Sections & & 134 \\
\hline
\end{tabular}


Table 3.17 can be expressed in the form of intermediate transition probability matrix as shown in Table 3.18 and finally into transition probability matrix as shown in Table 3.19 .

Table 3.18: Intermediate Transition Probability Matrix for Crack After Resurfacing

\begin{tabular}{|c|c|c|c|c|c|c|c|}
\hline \multirow{7}{*}{ 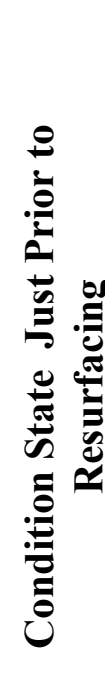 } & \multicolumn{6}{|c|}{$\begin{array}{c}\text { Condition State Just After } \\
\text { Resurfacing }\end{array}$} & \multirow[b]{2}{*}{$\begin{array}{l}\text { Total } \\
\text { No. of } \\
\text { Sections }\end{array}$} \\
\hline & & $\begin{array}{l}\overrightarrow{8} \\
0 \\
0 \\
\overrightarrow{0} \\
>\end{array}$ & $\begin{array}{l}\overline{0} \\
\dot{0} \\
0\end{array}$ & : & $\stackrel{\ddot{\mathscr{I}}}{\mathscr{\varphi}}$ & 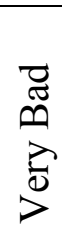 & \\
\hline & Very Good & 9 & 9 & 0 & 0 & 0 & 9 \\
\hline & Good & 23 & 13 & 0 & 0 & 0 & 36 \\
\hline & Fair & 14 & 3 & 0 & 0 & 0 & 17 \\
\hline & Bad & 41 & 3 & 0 & 0 & 0 & 44 \\
\hline & Very Bad & 26 & 2 & 0 & 0 & 0 & 28 \\
\hline & & & & & & & 134 \\
\hline
\end{tabular}

Table 3.19: Transition Probability Matrix for Resurfacing-Crack

\begin{tabular}{|l|l|l|l|l|l|}
\hline $\begin{array}{l}\text { Pavement } \\
\begin{array}{l}\text { Condition } \\
\text { Before }\end{array}\end{array}$ & \multicolumn{5}{|c|}{ Pavement Condition After } \\
\cline { 2 - 6 } & Very Good & Good & Fair & Bad & Very Bad \\
\hline Very Good & 1 & 0 & 0 & 0 & 0 \\
\hline Good & 0.639 & 0.361 & 0 & 0 & 0 \\
\hline Fair & 0.824 & 0.176 & 0 & 0 & 0 \\
\hline Bad & 0.932 & 0.068 & 0 & 0 & 0 \\
\hline Very Bad & 0.929 & 0.071 & 0 & 0 & 0 \\
\hline
\end{tabular}

For reconstruction of pavement, transition probability matrix is similarly derived and the final transition matrix for reconstruction is shown in Table 3.20. 
Table 3.20: Transition Probability Matrix for Reconstruction-Crack

\begin{tabular}{|l|l|l|l|l|l|}
\hline $\begin{array}{l}\text { Pavement } \\
\text { Condition } \\
\text { Before }\end{array}$ & \multicolumn{5}{|c|}{ Pavement Condition After } \\
\cline { 2 - 6 } & Very Good & Good & Fair & Bad & Very Bad \\
\hline Very Good & 1 & 0 & 0 & 0 & 0 \\
\hline Good & 0.8 & 0.2 & 0 & 0 & 0 \\
\hline Fair & 1 & 0 & 0 & 0 & 0 \\
\hline Bad & 1 & 0 & 0 & 0 & 0 \\
\hline Very Bad & 1 & 0 & 0 & 0 & 0 \\
\hline
\end{tabular}

Until now, the tabular results provided transition probability matrices for resurfacing and reconstruction works with respect to improving the crack condition of the pavement. Since, this research also considers ride and rut distresses besides crack, transition probability matrices for both resurfacing and reconstruction with respect to these two distresses are also evaluated similarly, and the results are shown in Table 3.21 and Table 3.22 for ride, and Table 3.23 and Table 3.24 for rut.

Table 3.21: Transition Probability Matrix for Resurfacing-Ride

\begin{tabular}{|l|l|l|l|l|l|}
\hline $\begin{array}{l}\text { Pavement } \\
\text { Condition } \\
\text { Before }\end{array}$ & \multicolumn{5}{|c|}{ Pavement Condition After } \\
\cline { 2 - 6 } & Very Good & Good & Fair & Bad & Very Bad \\
\hline Very Good & 1 & 0 & 0 & 0 & 0 \\
\hline Good & 0.071 & 0.929 & 0 & 0 & 0 \\
\hline Fair & 0.025 & 0.675 & 0.3 & 0 & 0 \\
\hline Bad & 0 & 0.519 & 0.37 & 0.111 & 0 \\
\hline Very Bad & 0 & 0.059 & 0.618 & 0.323 & 0 \\
\hline
\end{tabular}


Table 3.22: Transition Probability Matrix for Reconstruction-Ride

\begin{tabular}{|l|l|l|l|l|l|}
\hline \multirow{2}{*}{$\begin{array}{l}\text { Pavement } \\
\text { Condition } \\
\text { Before }\end{array}$} & \multicolumn{5}{|c|}{ Pavement Condition After } \\
\cline { 2 - 6 } & Very Good & Good & Fair & Bad & Very Bad \\
\hline Very Good & 1 & 0 & 0 & 0 & 0 \\
\hline Good & 1 & 0 & 0 & 0 & 0 \\
\hline Fair & 0.72 & 0.28 & 0 & 0 & 0 \\
\hline Bad & 0.059 & 0.412 & 0.353 & 0.176 & 0 \\
\hline Very Bad & 0.261 & 0.565 & 0.174 & 0 & 0 \\
\hline
\end{tabular}

Table 3.23: Transition Probability Matrix for Resurfacing-Rut

\begin{tabular}{|l|l|l|l|l|l|}
\hline $\begin{array}{l}\text { Pavement } \\
\text { Condition } \\
\text { Before }\end{array}$ & \multicolumn{5}{|c|}{ Pavement Condition After } \\
\cline { 2 - 6 } & Very Good & Good & Fair & Bad & Very Bad \\
\hline Very Good & 1 & 0 & 0 & 0 & 0 \\
\hline Good & 0.814 & 0.186 & 0 & 0 & 0 \\
\hline Fair & 0.767 & 0.067 & 0.166 & 0 & 0 \\
\hline Bad & 1 & 0 & 0 & 0 & 0 \\
\hline Very Bad & 0.666 & 0.167 & 0 & 0.167 & 0 \\
\hline
\end{tabular}

Table 3.24: Transition Probability Matrix for Reconstruction-Rut

\begin{tabular}{|l|l|l|l|l|l|}
\hline $\begin{array}{l}\text { Pavement } \\
\text { Condition } \\
\text { Before }\end{array}$ & \multicolumn{5}{|c|}{ Pavement Condition After } \\
\cline { 2 - 7 } & Very Good & Good & Fair & Bad & Very Bad \\
\hline Very Good & 1 & 0 & 0 & 0 & 0 \\
\hline Good & 0.895 & 0.105 & 0 & 0 & 0 \\
\hline Fair & 0.567 & 0.4 & 0.033 & 0 & 0 \\
\hline Bad & 0.7 & 0.3 & 0 & 0 & 0 \\
\hline Very Bad & 1 & 0 & 0 & 0 & 0 \\
\hline
\end{tabular}


For minor maintenance, there were no records of pavement performance condition in Florida Pavement Condition Data Survey. As a result, transition probability matrix for minor maintenance such as seal coating couldn't be obtained using the method described above. In the absence of such data, other literatures that studied the jump in pavement performance after the application of minor maintenance are referred. One such similar study was undertaken by Labi and Sinha (2004). They have suggested the following mathematical model by using annual condition data for pavement sections of Indiana State that received seal coating just before and after the application of this treatment, in terms of performance jump.

Performance Jump $(\mathrm{PJ})=1.158-0.275 *$ IPC

where, IPC is the initial pavement condition represented by the following pavement service index (PSI) scale as shown in Table 3.25.

Table 3.25: Pavement Service Index (PSI) Range for Indiana DOT Pavement Condition Rating

\begin{tabular}{|l|l|}
\hline Pavement Condition & $\begin{array}{l}\text { PSI } \\
\text { (1-5) }\end{array}$ \\
\hline Very Good & $>4.0$ \\
\hline Good & $3.5-4.0$ \\
\hline Fair & $3.0-3.5$ \\
\hline Bad & $2.5-3.0$ \\
\hline Very Bad & $<2.5$ \\
\hline
\end{tabular}

When any minor maintenance, such as seal coating, is applied the following performance jump as shown in Table 3.26 in pavement condition is expected which is obtained by using the equation for the performance jump mentioned earlier. 
Table 3.26: Deriving Transition Probability Matrix for Minor Maintenance

\begin{tabular}{|l|l|}
\hline $\begin{array}{l}\text { Condition Prior } \\
\text { to Minor } \\
\text { Maintenance }\end{array}$ & $\begin{array}{l}\text { Condition } \\
\text { Immediately After } \\
\text { Minor Maintenance }\end{array}$ \\
\hline Very Good & Very Good \\
\hline Good & Good \\
\hline Fair & Good \\
\hline Bad & Fair \\
\hline Very Bad & Bad \\
\hline
\end{tabular}

Table 3.26 shows that all the pavement sections (100\%) in Very Bad condition state move to Bad condition state, whereas the pavement in Good condition state remains unaffected when minor maintenance is applied. Following transition probability matrix is derived as shown in Table 3.27 when there is a performance jump from the lower condition state to the upper condition state as predicted from the results shown in the above table.

Table 3.27: Transition Probability Matrix for Minor Maintenance

\begin{tabular}{|l|l|l|l|l|l|}
\hline $\begin{array}{l}\text { Pavement } \\
\text { Condition } \\
\text { Before }\end{array}$ & \multicolumn{5}{|c|}{ Pavement Condition After } \\
\cline { 2 - 6 } & Very Good & Good & Fair & Bad & Very Bad \\
\hline Very Good & 1 & 0 & 0 & 0 & 0 \\
\hline Good & 0 & 1 & 0 & 0 & 0 \\
\hline Fair & 0 & 1 & 0 & 0 & 0 \\
\hline Bad & 0 & 0 & 1 & 0 & 0 \\
\hline Very Bad & 0 & 0 & 0 & 1 & 0 \\
\hline
\end{tabular}

Transition probability matrix for the pavement maintenance strategies for crack considered in this research are summarized in Table 3.28. 
Table 3.28: Transition Probability Matrix for Pavement Maintenance Strategies for Crack

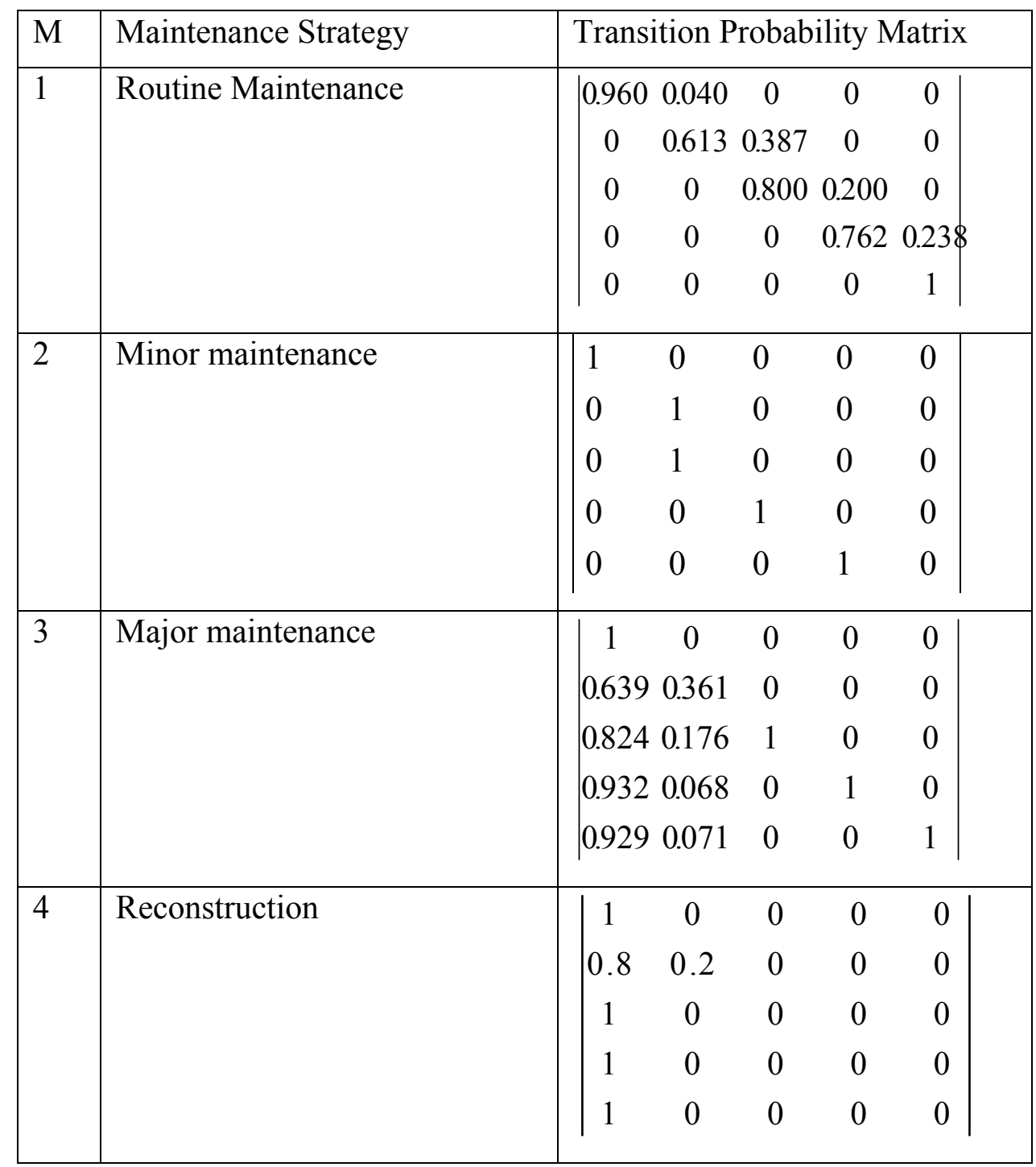

Similarly for ride, the transition probability matrices for the maintenance strategies are as shown in Table 3.29 . 
Table 3.29: Transition Probability Matrix for Pavement Maintenance Strategies for Ride

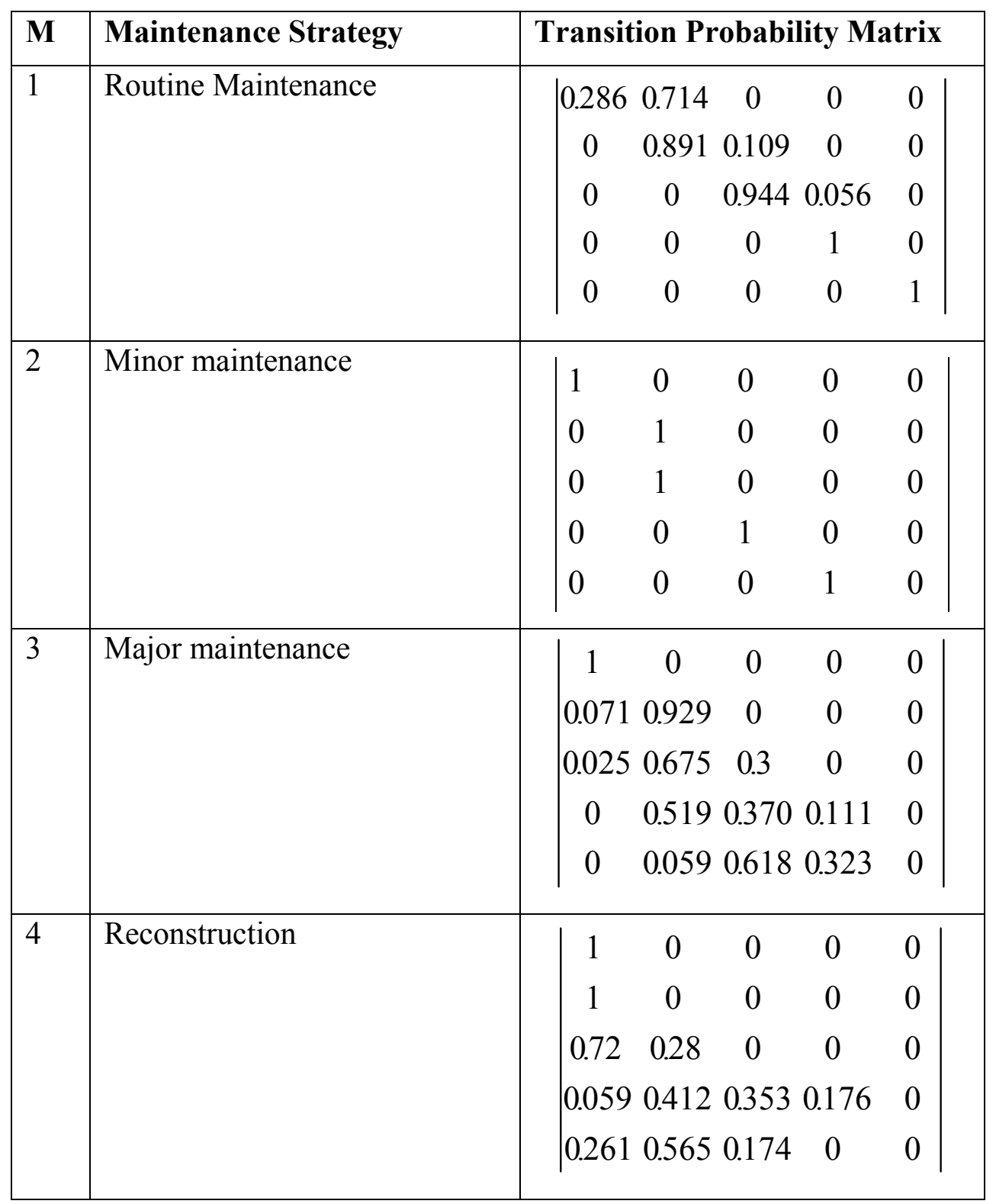

And finally for rut, the transition probability matrix for maintenance strategies is summarized in Table 3.30 . 
Table 3.30: Transition Probability Matrix for Maintenance Strategies for Rut

\begin{tabular}{|c|c|c|c|c|c|c|}
\hline $\mathbf{M}$ & Maintenance Strategy & Transit & ion $\mathrm{Pr}$ & cobabi & lity M & atrix \\
\hline 1 & Routine Maintenance & $\mid \begin{array}{c}0.276 \\
0 \\
0 \\
0 \\
0\end{array}$ & $\begin{array}{c}0.724 \\
0.832 \\
0 \\
0 \\
0\end{array}$ & $\begin{array}{c}0 \\
0.168 \\
0.884 \\
0 \\
0\end{array}$ & $\begin{array}{c}0 \\
0 \\
0.116 \\
0.807 \\
0\end{array}$ & $\begin{array}{c}0 \\
0 \\
0 \\
0.193 \\
1\end{array}$ \\
\hline 2 & Minor maintenance & $\begin{array}{l}1 \\
0 \\
0 \\
0 \\
0\end{array}$ & $\begin{array}{l}0 \\
1 \\
1 \\
0 \\
0\end{array}$ & $\begin{array}{l}0 \\
0 \\
0 \\
1 \\
0\end{array}$ & $\begin{array}{l}0 \\
0 \\
0 \\
0 \\
1\end{array}$ & $\begin{array}{l}0 \\
0 \\
0 \\
0 \\
0\end{array}$ \\
\hline 3 & Major maintenance & $\mid \begin{array}{c}1 \\
0.814 \\
0.767 \\
1 \\
0.666\end{array}$ & $\begin{array}{c}0 \\
0.186 \\
0.067 \\
0 \\
0.167\end{array}$ & $\begin{array}{c}0 \\
0 \\
0.166 \\
0 \\
0\end{array}$ & $\begin{array}{c}0 \\
0 \\
0 \\
0 \\
0.167\end{array}$ & $\begin{array}{l}0 \\
0 \\
0 \\
0 \\
0\end{array}$ \\
\hline 4 & Reconstruction & $\mid \begin{array}{c}1 \\
0.895 \\
0.567 \\
0.7 \\
1\end{array}$ & $\begin{array}{c}0 \\
0.105 \\
0.4 \\
0.3 \\
0\end{array}$ & $\begin{array}{c}0 \\
0 \\
0.033 \\
0 \\
0\end{array}$ & $\begin{array}{l}0 \\
0 \\
0 \\
0 \\
0\end{array}$ & $\begin{array}{l}0 \\
0 \\
0 \\
0 \\
0\end{array}$ \\
\hline
\end{tabular}

An important observation is made here for pavement improvement after resurfacing and reconstruction. It was expected that pavement condition would be restored to perfect or near-perfect condition after the application of major maintenance and reconstruction. Although the improvement of the pavement with respect to crack distress after the maintenance is quite representative of the actual condition, this is not the case for the improvement for ride and rut distresses as seen from the transition probability matrices. 
This anomaly between the improvement of pavement as determined from the actual observed data and the improvement expected from previous experience of pavement maintenance could be explained due to several factors. One of the important factor could be that if the pavement is structurally deficient, for example, its sub grade is damaged, resurfacing and reconstruction may not have the same effect as that for structurally sound pavement. Another reason could be because of the error in data collection. This error in prediction of transition probability for pavement improvement can easily be offset with inclusion of large number of pavement sections for analysis.

\subsection{Conclusion}

This chapter started with an introduction of transition probability matrix explaining its relevance with respect to optimization of asset management. A slight modification from the commonly adopted asset management model, the methodology described in this research makes use of large historical pavement condition rating data to estimate the elements of transition probability matrix using count proportion. When the current condition state of the pavement is known and the transition probability matrix for deterioration for each of the distress indicator is derived, future condition state of the pavement is easily predicted. Predicting future condition state of the pavement for this research has been explained in this chapter using pavement condition rating data obtained from Florida Pavement Condition Rating Survey. Performance-based pavement maintenance analysis comprises not only of pavement deterioration but also a mix of pavement maintenance strategies in order to meet the performance requirements. Transition probabilities are also needed for maintenance actions and are, therefore, derived in this chapter using the actual pavement condition rating data. When the link 
between the changes in pavement condition rating data and the maintenance action could not be established using the pavement survey condition data, as was the case with minor maintenance in this research, transition probability matrix was estimated using the performance jump concept from other research that used pavement of similar characteristics as the one used in this research. 


\section{CHAPTER 4}

\section{FRAMEWORK FOR THE COST ESTIMATION MODEL}

\subsection{Introduction}

This chapter provides an overall methodology to estimate the cost of performancebased pavement maintenance contract. There are various components that make up the overall model, which is analogous to "input-process-output" for characterizing a system. The chapter begins by explaining about the inputs of the model and the sources from which these inputs could be obtained. Performance specifications (warranty specifications) can be obtained from the actual contract agreed between the parties. This generally includes warranty term, performance indicators, threshold values, requirement for corrective actions, measurement method, and payment (Anderson and Russell, 2001). Pavement condition can be obtained from state department of transportation's pavement condition rating data. Maintenance actions and their unit costs may be obtained from contractor's own cost database of its past projects. Pavement deterioration and maintenance models are the key components of the processes that use the inputs to estimate the cost of performance-based pavement maintenance contracts. In order to ensure that minimal maintenance effort, and therefore the cost, is chosen to meet the performance requirement, iteration of maintenance action selection starting with the least effort maintenance is required for each year until the end of the analysis period. The output from this model is the total estimated cost of performance-based pavement maintenance contract. A methodological framework consisting of the components described herein is presented in Figure 4.1. 


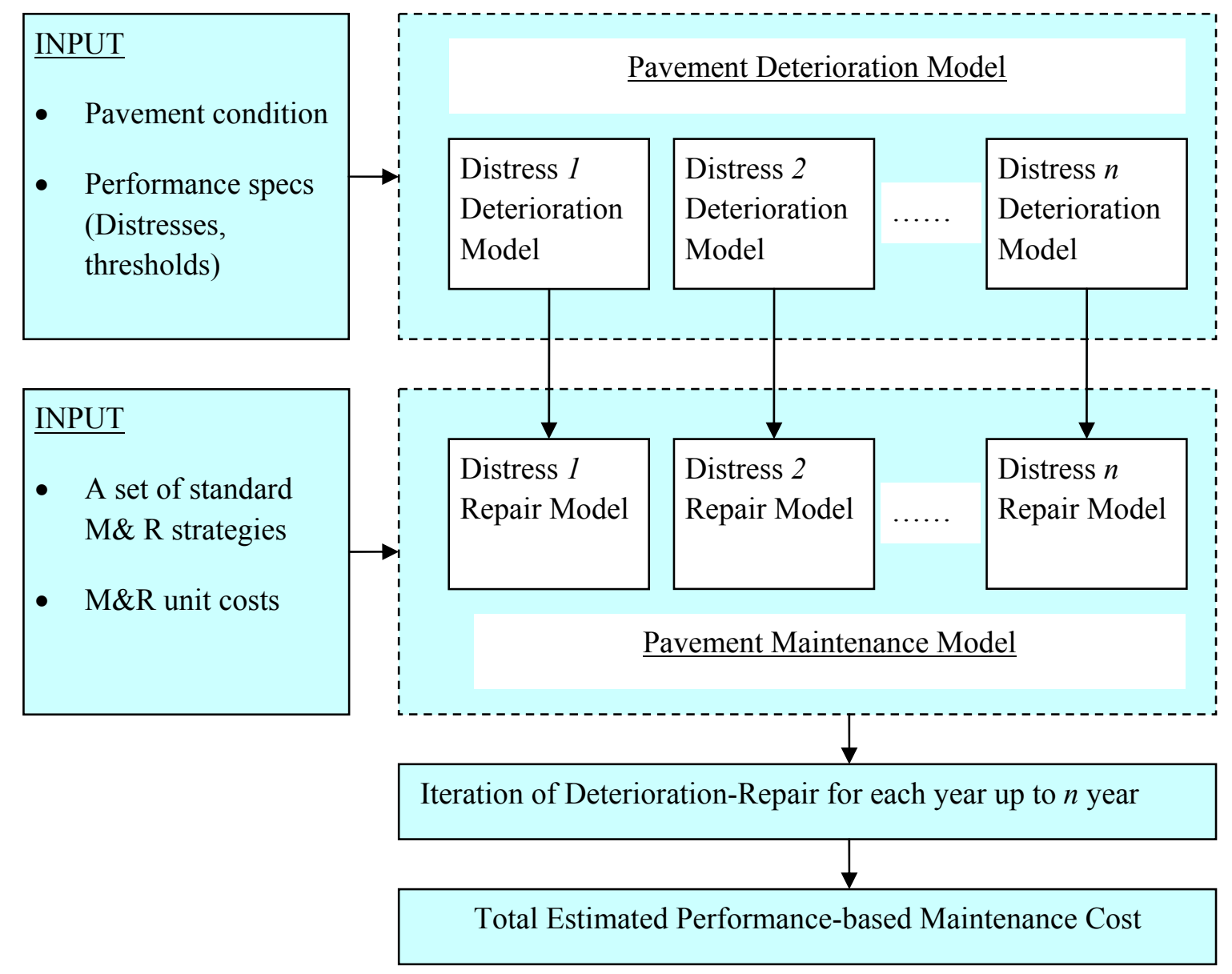

Figure 4.1: A Methodological Framework to Estimate Cost of Performance-based Pavement Maintenance Contracts

\subsection{Model Inputs}

\subsubsection{Performance Specifications}

Performance/warranty specifications form the basis for implementing and monitoring long term performance-based pavement maintenance contracts. Performance-based specifications are used in lieu of method-based contracts where the volume of work to be performed is easily quantifiable. In the absence of such specified volume of work in the performance-based contract, it is imperative to model the deterioration process of 
pavement in order to determine the failure rates of these pavements. These failure rates, in turn, also depend on performance threshold limits besides variety of other factors. These performance criteria and their threshold limits are prescribed on the performancebased contracts.

Performance-based maintenance contracts are a new form of contracting being developed between the highway agencies and the contractors to manage asset for a certain period of time. Highway agencies are responding to this change by developing new performance specification suitable for these contracts. Warranty contracts, in their original form or modified form, have been used in many instances to monitor and implement the performance-based contracts. A sample of such warranty contracts for pavement maintenance is attached in Appendix A. Warranty clauses from the performance/warranty contracts that are relevant in estimating costs of such contracts are explained in the following paragraph.

Performance Indicators: These are measures of quality; quite often the distress indicators which are monitored annually, or more frequently. It is assumed that these indicators which are visible distresses, and measured easily, give an accurate picture of the condition of the pavement. For asphalt pavement, the following distresses are commonly used in the warranty or performance clauses.

Rut: Rut is the longitudinal surface depressions which develop along the wheel paths due to repeated loading. Rut severity is measured in terms of depth of depressions in inch or millimeter. 
Rideability: Rideability is a measure of riding comfort and is measured using the IRI (International Roughness Index) format of millimeters of accumulated vertical displacements per linear meter.

Raveling, potholes, slippage areas, and other disintegrated areas: Raveling, potholes, slippage areas, and other disintegrated areas are measures of surface condition to see how much of the original surface has been lost with usage. They are usually measured in terms of pick outs per square meter.

Crack: These are visible cracks, both longitudinal and transverse, on the road surface. They are often measured in terms of depth, width, and percentage of crack area.

Besides projecting the functional condition of the road, these distress indicators are a good measure of structural condition of the road.

Performance Threshold: As important as it may be to specify these distress indicators, it is equally important to specify thresholds for each of the distresses specified in the contract. A pavement section is considered to have failed if any of the distresses mentioned in the contract reach a value below threshold limit. Pavement maintenance and repair should be carried out such that the condition state of the pavement never exceeds the threshold limit. These threshold limits are often specified in the contract. Moreover, to maintain the pavement network at required and stable performance levels over time, the proportions of pavements at low level of crack, ride, and rut should be maintained within a certain range. On the other hand, the proportions of pavements at levels of high crack, ride, and rut need to be kept as small as possible. Proportions of the pavement in high and low level of crack, ride, and rut should be specified in the contract. 
Length of Contract Duration: Performance-based pavement contracts are long term, often exceeding ten years. Longer duration contracts may demand an elaborate maintenance action than the shorter duration contracts. Annualized expenditure for long term contracts are usually more than those for the shorter duration contracts.

\subsubsection{Pavement Condition}

Source of data: Pavement condition data are usually obtained from pavement management system of state DOTs. These are historical records of either aggregate measure of performance, such as, PCI (performance condition index), or disaggregate measure of performance, such as, different surface distresses discussed in the previous section. Other countries also maintain a historical database of road performance over a long period of time. LTPP (Long Term Pavement Performance) is also a good source to obtain performance data of the US and Canada highways. Florida Department of Transportation (FDOT), like most other state DOTs, maintains a record of the pavement condition. Pavement condition of Florida highways since 1986 is available, and is used in the analysis to determine the pavement deterioration trend and also the jump in pavement performance when maintenance and repair activities are applied.

Deterioration trend: With the usage of pavement over time, pavement condition deteriorates. The condition state of pavement before any maintenance and repair works, which is manifested through various surface distresses, is observed and the deterioration rate is expressed probabilistically.

Pavement condition at the time of contract award: In order to determine the condition state of the pavement in the future using Markov chain, it is imperative to calculate the existing condition of the pavement. For example, if the contract is awarded in year 2008, 
distribution percentage of the pavement in various condition states, represented by a condition state vector, is determined for that year when there exist data for a large number of pavement sections.

\subsubsection{Maintenance and Repair Strategies, and Their Unit Costs}

Standard Maintenance/Repair Strategies: As an input to the cost estimation model, standard maintenance and repair strategies that are frequently used are listed and selected for the pavement repair model. If sufficient data exists on the pavement condition state for the year just before and after the application of maintenance activity, then such data can be utilized to determine the performance jump for the respective maintenance/repair strategies. More the number of standard maintenance activities and their performance data available, more accurate the cost estimation model becomes. However, establishing a performance jump for many of the maintenance activities in the list of standard maintenance strategies may be difficult as there may not be sufficient data to model performance jump when these maintenance activities are applied.

Unit Cost of Maintenance/Repair Strategies: State DOTs also maintain a record of contracts let and their dollar value. Contractors may also keep a database of unit cost from their previous similar projects, which may be used for estimating performancebased maintenance cost. Unit cost, which is often expressed in dollar per lane-mile, is required to calculate the cost of maintenance activities each year.

\subsection{Pavement Deterioration Model}

Markov chain model- Markov chain models have been used extensively in pavement management system to determine the pavement deterioration rate stochastically. These are represented in the form of transition probabilities, which express the percentage of 
distribution of pavement in each condition state. Deterioration of pavement in terms of all the distresses needs to be considered. Determination of transition probabilities to represent deterioration rate has been discussed in detail in Chapter 3 .

\subsection{Pavement Repair Model}

Pavement life cycle consists of series of pavement deterioration and repair activities as represented in Figure 4.2. Although such repetitions of "deterioration-repair" cycles may be only few in case of a performance-based contract, which in fact may be thought of as a sub-set of longer pavement life cycle, this figure, none the less, characterizes the change in performance level for the entire performance contract period. Since routine maintenance actions are continuously performed, deterioration of the pavement is, in fact, deterioration under routine maintenance. Other maintenance actions considered in this model are minor maintenance, major maintenance, and reconstruction. There is a sudden jump in performance level soon after these maintenance activities are applied. This performance jump is modeled for these maintenance activities, which is described in the following paragraph.

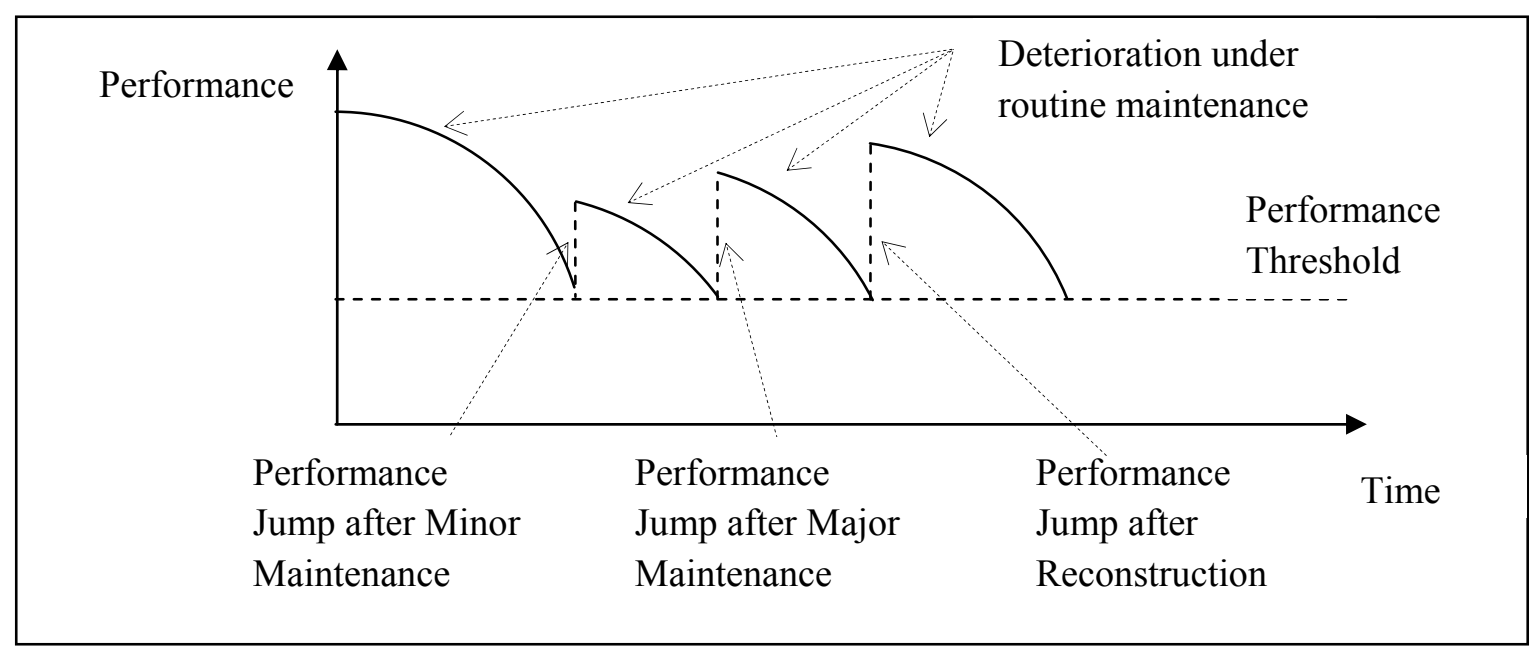

Figure 4.2: Pavement Failures and Repairs 
In order to model the effect of repair on the condition of the pavement, improvement of the condition state of the pavement just after the application of repair activity is observed. For example, if a minor maintenance activity took place for a pavement section in year 1998, condition state of that section in year 1997 and year 1999 are noted. For all the other sections that have undergone such a similar maintenance work, their condition states for these two years are noted. Percentage distributions of the pavement condition moving to the better state or remaining in the same state are then calculated. These are also the transition probability matrix for repair activities. Transition probability matrices for minor maintenance, major maintenance, and reconstruction activities for all the distress types are derived similarly.

\subsection{Iteration of Deterioration-Repair Process up to Analysis Period}

The aim of the model is to find an optimal set of maintenance program works that will keep the performance level of the pavement at least equal to or above the minimum threshold level specified in the contract. In order to achieve that, several trials of maintenance activities may be required before selecting the maintenance activity for a particular year up to the entire analysis period until the pavement meets the minimum performance requirement. This is done through iteration of deterioration-repair process as shown in Figure 4.3. The flowchart summarizes the process to check the adequacy of the different repair strategies to maintain the pavement at least at the minimum required level of service for each year up to the end of the analysis period. This iteration is started first by finding the existing state of the pavement when the maintenance contract is to commence. Time is increased by one year until the iteration process is complete for the entire analysis period. 


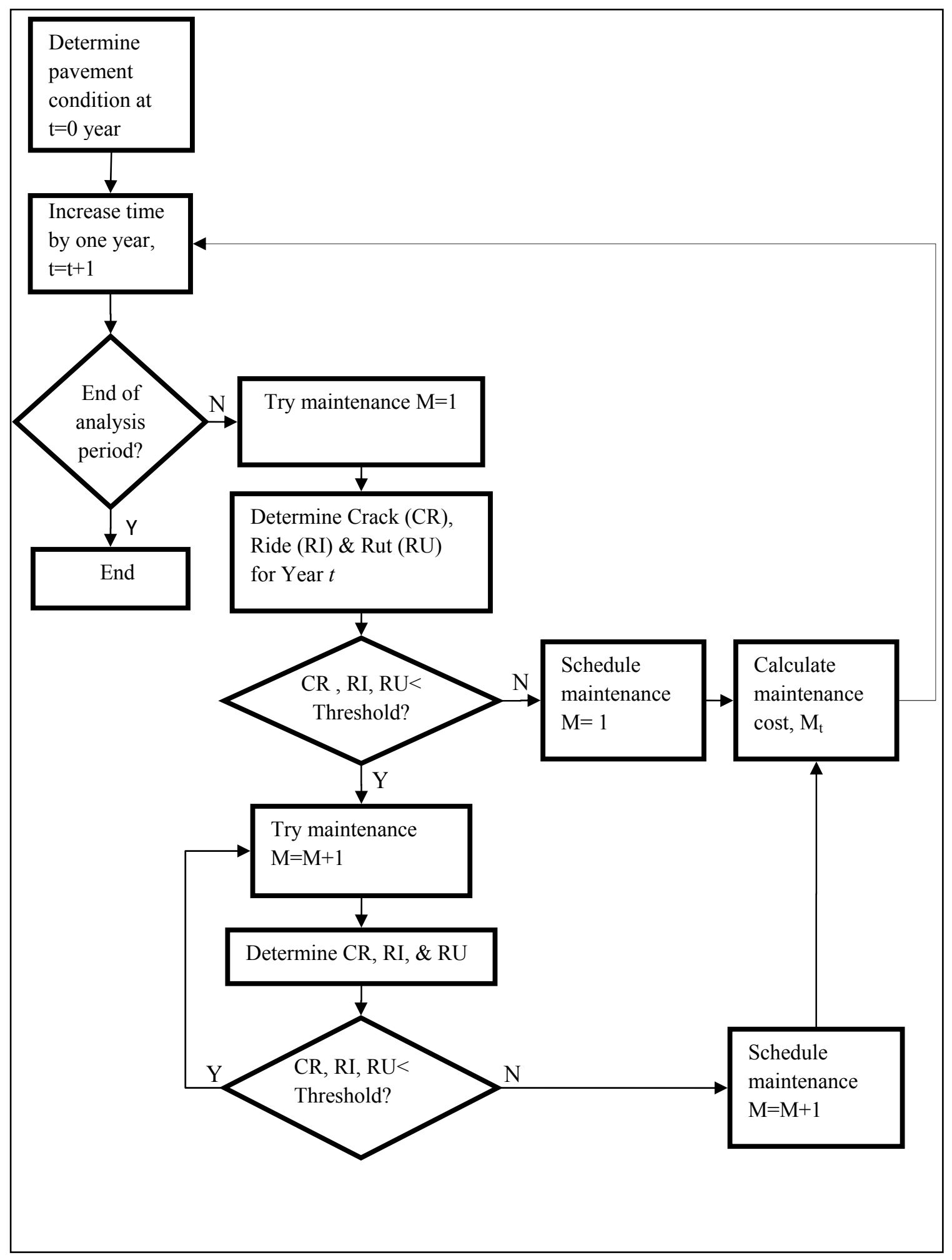

Figure 4.3: Flowchart for Selecting Pavement Maintenance Strategies 
Standard maintenance strategies are listed as shown in Table 4.1.Variable M, used in Figure 4.3, denotes different maintenance activities represented by numbers from 1 to 4 .

Table 4.1: Standard Maintenance Strategies

\begin{tabular}{|l|l|}
\hline $\mathbf{M}$ & Maintenance Strategies \\
\hline 1 & Routine maintenance \\
\hline 2 & Minor maintenance \\
\hline 3 & Major maintenance \\
\hline 4 & Reconstruction \\
\hline
\end{tabular}

From the list of standard maintenance treatments, maintenance treatment $M=1$, is chosen first. This maintenance strategy is a routine maintenance treatment that requires the least effort and the least cost among the list of maintenance treatments. The condition state in Year 1 is obtained by multiplying the condition state probabilities (condition state vector) for Year 0 with the transition probability matrix for routine maintenance. The resulting condition state is checked to see if it satisfies the minimum distress thresholds for all the distresses considered in the model. If the resultant condition state vectors for each of the distresses considered have a value within the threshold values for each of the distresses, then maintenance strategy $M=1$ (routine maintenance strategy) fulfills the minimum criterion and no other maintenance is required. Maintenance cost is determined for this maintenance treatment for that year. A year is increased and the same procedure is followed for the next year. However, if the minimum threshold performance is not satisfied with the maintenance strategy $M=1$, next maintenance strategy, $M=2$ (minor maintenance) is scheduled. Condition state vectors for all the distress indicators are determined in a similar manner as determined for the maintenance strategy $M=1$. If this 
maintenance treatment satisfies the minimum condition of the pavement, then this maintenance strategy is scheduled and the cost associated with the maintenance activity is determined. If not, next maintenance strategy from the list is chosen until the minimum condition of the pavement is satisfied. When the minimum condition for the pavement is fulfilled, cost is estimated and recorded for that year, and a year is added to the current year for further analysis. Thus, maintenance strategies for the entire contract duration are selected and their corresponding cost calculated.

\subsection{Total Estimated Performance Cost}

When maintenance strategies are selected for each year for the entire analysis period, total cost of maintenance is obtained by multiplying the unit cost of maintenance expressed in lane-mile with the total length of the pavement under the pavement maintenance contract. Cost per lane-mile, which are the inputs of the model, may be obtained from the contractor's cost database. The summation of the cost of maintenance for each year gives the total estimated cost for pavement maintenance contract.

\subsection{Conclusion}

Discussions in this chapter described different model components making up the overall methodological framework. Analogous to the customary input-process-output framework for charactering any system, the described model takes the input from various sources such as those mentioned in Section 4.2.1, and processes these inputs such that a mix of maintenance strategies for the analysis period are selected. With the least-effort maintenance activities selected in the form of output of the model to meet the performance requirement criteria, the ultimate objective of estimating the total cost of performance-based maintenance contract is achieved. 


\section{CHAPTER 5}

\section{APPLYING THE METHODOLOGICAL FRAMEWORK TO A CASE STUDY: MIAMI DADE EXPRESSWAY}

\subsection{Introduction}

In order to demonstrate and evaluate the applicability of the proposed model, a case study of Miami Dade Expressway using data from Florida Department of Transportation's (FDOT) Flexible Pavement Condition Survey is undertaken. The basic data, which is the pavement condition rating data for crack, ride, and rut for Dolphin Expressway chosen for this case study is presented in Appendix B. Although warranty specifications are confined to three performance indicators for this case study, the methodology can easily be extended to include other performance indicators as well. Crack, rut, and ride (roughness) are three widely used performance indicators in warranty contracting practices and these are the only performance indicators for which the condition rating data is available in FDOT's Pavement Condition Survey database. The thresholds and remedial action information is based on warranty clauses used by the Florida Department of Transportation for Contractor Guaranteed Asphalt Pavement with slight modifications.

Figure 5.1 shows the basis for scope definition of data collection and analysis for the case study used in this dissertation. First of all, condition rating data for all the pavements that are part of Miami Dade Expressway are selected. Only asphalt pavements were then used for developing pavement deterioration/improvement model. 


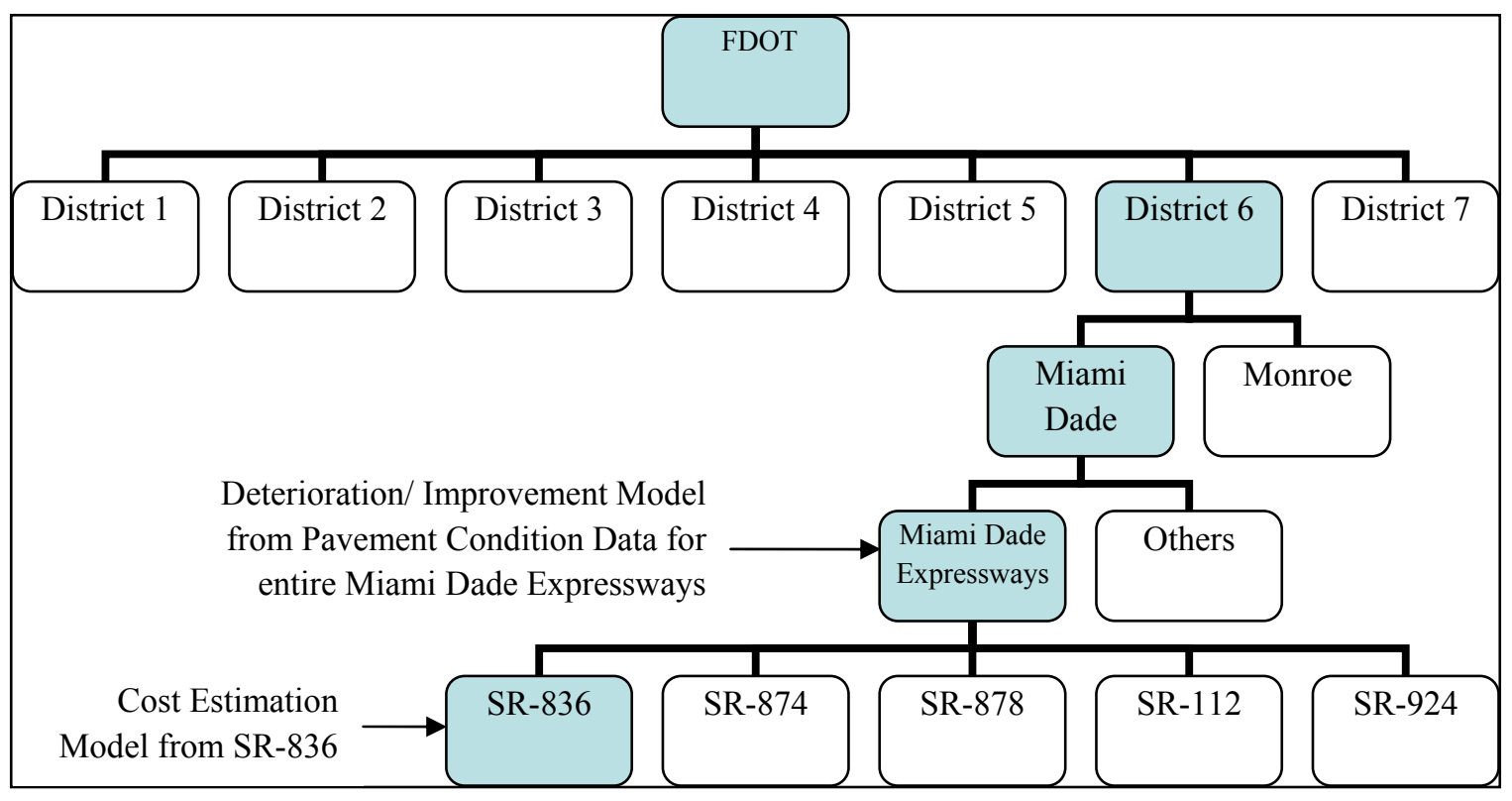

Figure 5.1: Focus Area of Case Study

\subsection{Miami Dade Expressway Asset Management Contract}

Miami Dade Expressway is a network of pavements in the metro-Miami region consisting of approximately 32 centerline miles of expressway and associated toll plaza facilities located on State Routes 112 (Airport Expressway), 836 (Dolphin Expressway), 874 (Don Shula Expressway), 878 (Snapper Creek Expressway), and 924 (Gratigny Parkway). Transfield Services North America (formerly VMS, Inc.) entered a 5 year asset management contract with the Miami Dade Expressway Authority (MDX). Although this contract was awarded in October 2001, its period of performance was from July 2002 to June 2007. After the completion of this contract, Transfield Services were again awarded an additional 5 and a half year contract worth approximately $\$ 31$ Million for routine maintenance. Figure 5.2 shows the locations of the five expressways included in the MDX asset management contract. They are all 4- to 6-lane facilities and they range in length between 2.7 and 13.0 miles. 


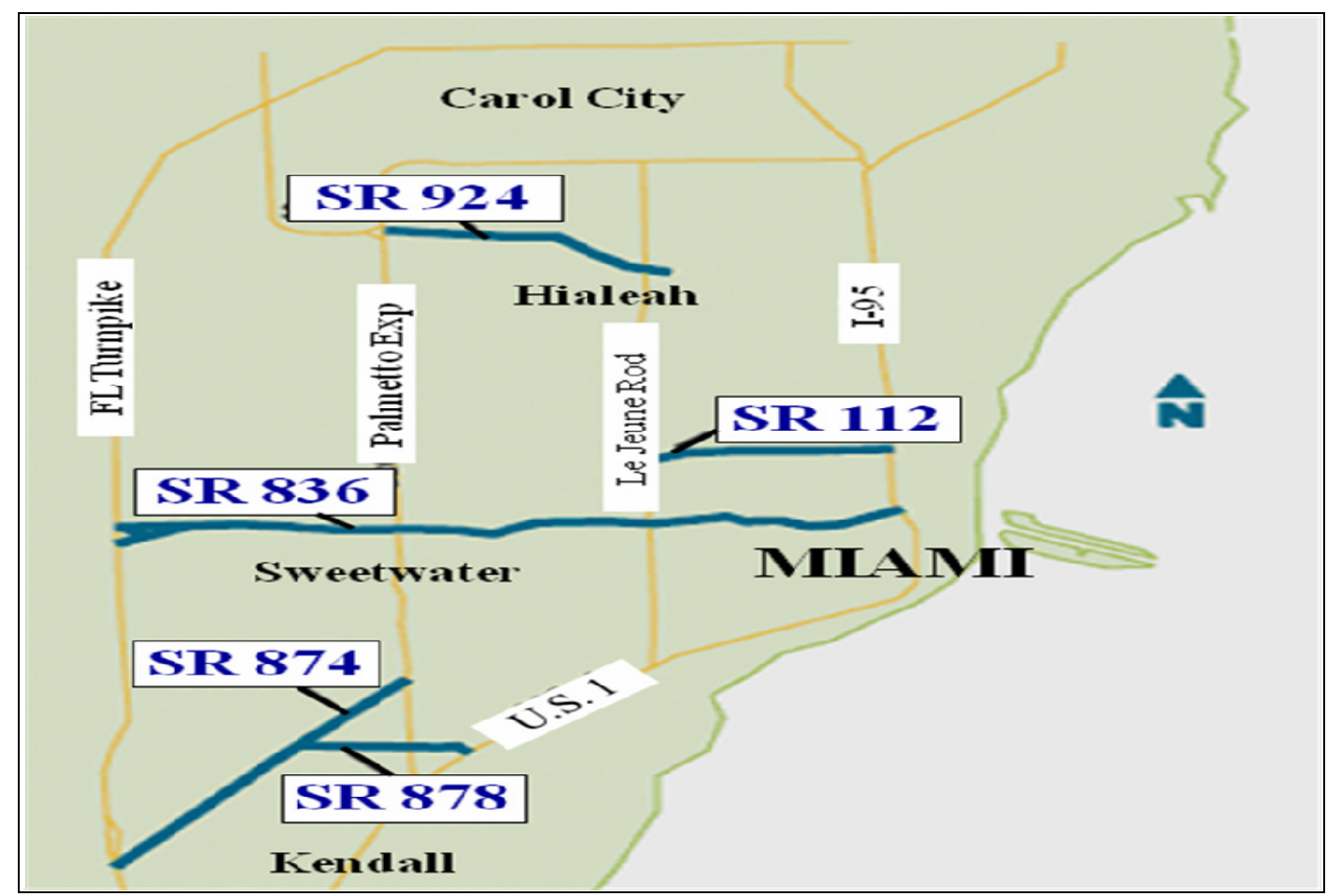

Figure 5.2: Miami Dade Expressways Pavement Network

For this contract, the MDX has required Transfield Services to evaluate the quality of its maintenance using an expanded version of the Florida DOT's maintenance rating program (MRP). The expanded MRP requires a 1 to 5 scale field rating approach instead of the pass-fail strategy that is used in the Florida MRP. But, like the Florida MRP, it involves taking the field ratings and generating 0 to 100 scale maintenance quality ratings for individual features, groups of similar features or elements, and all elements combined. The generated maintenance quality ratings must then satisfy MDX's requirements of 70 for individual features, 75 for individual elements, and 80 for all elements combined. There are a total of 36 maintenance features under five maintenance elements evaluated as part of Florida's MRP. Each element consists of 5 to 10 individual features that are similar in function as shown in Table 5.1. 
Table 5.1: Maintenance Elements Covered Under the Asset Management Contract

\begin{tabular}{|l|l|c|}
\hline S. No. & Maintenance Elements & Features \\
\hline 1 & Roadway & $\begin{array}{l}\text { Potholes, edge raveling, shoving, } \\
\text { depressions/bumps, joints/cracks, } \\
\text { paved shoulders/turnouts }\end{array}$ \\
\hline 2 & Roadside & $\begin{array}{l}\text { Unpaved shoulders, front slopes, } \\
\text { sloped pavement, sidewalk, fencing }\end{array}$ \\
\hline 3 & Traffic Services & $\begin{array}{l}\text { Pavement markers, striping, symbols, } \\
\text { guardrail, attenuators, signs, object } \\
\text { markers/delineators, lighting }\end{array}$ \\
\hline 4 & Drainage & $\begin{array}{l}\text { Side/cross drains, roadside/median } \\
\text { ditches, outfall ditches, inlets, } \\
\text { miscellaneous drainage structures } \\
\text { roadway sweeping }\end{array}$ \\
\hline 5 & Vegetation/aesthetics & $\begin{array}{l}\text { Roadside mowing, slope mowing, } \\
\text { landscaping, tree trimming, } \\
\text { curb/sidewalk, edge, litter removal, turf } \\
\text { condition }\end{array}$ \\
\hline
\end{tabular}

Among the five maintenance elements that MDX has contracted with Transfield Services for the maintenance management, only roadway maintenance has been chosen for this study. In fact, the asset management contract does not include the type of maintenance treatments proposed in the methodology. As part of the routine roadway maintenance works, only cosmetic treatments are assigned to Transfield Services where as for any other maintenance works, other contractors are contracted by Miami Dade Expressway Authority on a separate contract basis. In essence, the scope of work assigned to Transfield Services is quite different from the scope of work that is covered under the proposed methodological framework. Although the estimate of cost obtained as a result of this model cannot be compared with the actual asset management contract value, the proposed methodology is still applicable for the scope of work assumed for this 
case study. A major type of roadway that comprises the Miami Dade Expressways is asphalt pavement. Therefore, the focus of this research is centered on asphalt pavement maintenance.

\subsection{Model Inputs}

\subsubsection{Performance Specifications}

Pavement management models use distress indicators to describe how a pavement deteriorates over time. Generally, rather than several distress indicators, a single composite indicator that best describes the condition of the pavement, is taken as a performance indicator. However, with the evolvement of warranty and performance specifications in pavement management contracts, a number of distress indicators or indices have been used instead of a single composite distress (performance) indicator. In order to address these warranty and performance based pavement management contracts, multiple distress indicators are used in the model. Although as many distress indicators as specified may be used in the model, only few distinct distresses are considered here owing to the similarity of some of these distresses with each other. Three such distinct distresses that FDOT has been keeping a historical record of, for pavement management system are rut, crack, and roughness. These three distresses have been taken into account in estimating the cost of performance-based maintenance contracts. If the condition rating of the pavement exceeds the threshold value specified in the contract, the pavement is said to have failed for the purpose of this analysis. When pavement fails due to any of these distresses, maintenance and repair activities are required. In fact, maintenance and repair of pavements is carried out such that the pavement does not reach the failed condition state. 
FDOT's Specifications and Estimates Office has developed performance based warranty and guarantee specifications for different types of pavements and bridge components. A detailed description of Contractor Guaranteed Asphalt Pavement (CGAP) is attached as Appendix A. In its new amendment, CGAP is also known as value added asphalt pavement. A summarized version of the warranty that is relevant to the application of the methodology to the case study is discussed in the following paragraph.

There are eight sub-sections in the Contractor Guaranteed Asphalt Pavement Section (Section 338). Not all clauses in this section are deemed relevant for the purpose of this dissertation. Some of the clauses that are relevant and serve as the basis for performance specification in this dissertation are described as follows:

- Section 338-4 Pavement Evaluation and Remedial Work

For evaluating the pavement, FDOT's flexible pavement condition survey program will be used as a basis for determining the extent and the magnitude of the pavement distresses occurring on the project during the performance contract period.

○ Section 338-4.1 Distress Indicators

The FDOT will use the following pavement distress and their associated threshold values for remedial work for all category 1 pavement as specified in Table 5.2. Category 1 pavement, for purpose of this specification, is defined as mainline roadways, access roads and frontage roads with a design speed $50 \mathrm{mph}$ and greater; approach transition and merge areas at toll booths; ramps; acceleration and deceleration lanes (including tapers); and turn lanes.

Typical distresses, their threshold values, and the related remedial work as specified in FDOT Contractor Guaranteed Asphalt Pavement is presented in Table 5.2. 
Table 5.2: Distress Threshold Values and Remedial Work Specified in the FDOT

Contractor Guaranteed Asphalt Pavement (CGAP)

\begin{tabular}{|c|c|c|c|}
\hline $\begin{array}{l}\text { Type of } \\
\text { Distress }\end{array}$ & $\begin{array}{l}\text { Type } \\
\text { of } \\
\text { Survey }\end{array}$ & $\begin{array}{l}\text { Threshold } \\
\text { Values for } \\
\text { Each LOT }(0.1 \\
\text { Mile) per Lane. }\end{array}$ & Remedial Work \\
\hline \multirow[t]{2}{*}{ Rut } & \multirow[t]{2}{*}{$\begin{array}{l}\text { Any } \\
\text { Survey }\end{array}$} & $\begin{array}{l}\text { Depth } \leq 0.25 \\
\text { inch }\end{array}$ & None required \\
\hline & & $\begin{array}{l}\text { Depth }>0.25 \\
\text { inch }\end{array}$ & $\begin{array}{l}\text { Remove and replace the distressed LOT(s) to the } \\
\text { full depth of all layers, and to the full lane width }\end{array}$ \\
\hline Ride & $\begin{array}{l}\text { Any } \\
\text { Survey }\end{array}$ & $\mathrm{RN}<3.70$ & $\begin{array}{l}\text { Remove and replace the friction course for the full } \\
\text { length and the full lane width of the distressed } \\
\text { LOT(s) }\end{array}$ \\
\hline Crack & $\begin{array}{l}\text { Any } \\
\text { Survey }\end{array}$ & $\begin{array}{l}\text { Cumulative } \\
\text { length of crack } \\
>30 \text { feet for } \\
\text { Cracks }>1 / 8 \\
\text { inch }\end{array}$ & $\begin{array}{l}\text { Remove and replace the distressed LOT(s) to the } \\
\text { full depth of all layers, and to the full lane width }\end{array}$ \\
\hline \multirow{2}{*}{$\begin{array}{l}\text { Raveling } \\
\text { and/or } \\
\text { Delamina- } \\
\text { tion } \\
\text { affecting } \\
\text { the } \\
\text { Friction } \\
\text { Course }\end{array}$} & \multirow[t]{2}{*}{$\begin{array}{l}\text { Any } \\
\text { Survey }\end{array}$} & $\begin{array}{l}\text { Individual } \\
\text { length }<10 \text { feet. }\end{array}$ & $\begin{array}{l}\text { Patch the distressed area(s) to the full distressed } \\
\text { depth and to a minimum surface area of } 150 \% \text { of } \\
\text { each distressed area, subject to performance at final } \\
\text { survey }\end{array}$ \\
\hline & & $\begin{array}{l}\text { Individual } \\
\text { length } \geq 10 \text { feet. }\end{array}$ & $\begin{array}{l}\text { Remove and replace the distressed area(s) to the full } \\
\text { distressed depth and the full lane width, for the full } \\
\text { distressed length plus 50' on each end }\end{array}$ \\
\hline $\begin{array}{l}\text { Pot holes } \\
\text { and } \\
\text { Slippage } \\
\text { Area(s) }\end{array}$ & $\begin{array}{l}\text { Any } \\
\text { Survey }\end{array}$ & $\begin{array}{l}\text { Observation by } \\
\text { Engineer }\end{array}$ & $\begin{array}{l}\text { Remove and replace the distressed area(s) to the full } \\
\text { distressed depth, and to a minimum surface area of } \\
150 \% \text { of each distressed area OR temporarily patch } \\
\text { the distressed area(s) AND, prior to the final survey, } \\
\text { remove and replace the distressed area(s) to the full } \\
\text { distressed depth, and to a minimum surface area of } \\
150 \% \text { of each distressed area. }\end{array}$ \\
\hline Bleeding & $\begin{array}{l}\text { Any } \\
\text { Survey }\end{array}$ & $\begin{array}{l}\text { Loss of surface } \\
\text { texture due to } \\
\text { excess asphalt, } \\
\text { individual } \\
\text { length } \geq 10 \text { feet } \\
\text { and } \geq 1 \text { foot. in } \\
\text { width. }\end{array}$ & $\begin{array}{l}\text { Remove and replace the distressed area(s) to the full } \\
\text { distressed depth, and to a minimum surface area of } \\
150 \% \text { of each distressed area }\end{array}$ \\
\hline
\end{tabular}

Rut

Rut is defined as longitudinal surface depressions. These develop in the wheel paths due to the repeated load of the moving vehicles. Rut severity is measured in terms of 
depth. Rut depths are monitored while transitioning the sections for ride. The Profiler will measure rut depths at highway speeds and record the average rut depth. The computer program then converts the average rut depth to a one point per $1 / 8$ inch $(3.18 \mathrm{~mm})$ of rut as indicated in Table 5.4. FDOT uses a scale of 0 to 10 to denote the different condition states of pavement rut. Flexible pavement having rut rating of 6.4 or less is considered to be deficient by FDOT. For the purpose of this case study, a rut rating value of 7 is taken as the threshold value.

\section{Crack}

FDOT considers crack to be of three different types in flexible pavements. Only significant crack is considered. These classes of cracks as defined by FDOT are described as follows:

Class IB- Hairline cracks that are less than or equal to $1 / 8$ inch $(3.18 \mathrm{~mm})$ wide in either the longitudinal or transverse direction are treated as Class IB cracks. They may have slight spalling and slight to moderate branching.

Class II- Cracks greater than $1 / 8$ inch $(3.18 \mathrm{~mm})$ to $1 / 4$ inch $(6.35 \mathrm{~mm})$ wide in either the longitudinal or transverse direction are considered Class II cracks. They may have moderate spalling or severe branching. They also include all cracks less than $1 / 4$ inch $(6.35 \mathrm{~mm})$ wide that have formed cells less than 2 feet $(0.61 \mathrm{~m})$ on the longest side, also known as alligator crack.

Class III- Cracks greater than $1 / 4$ inch $(6.35 \mathrm{~mm})$ wide that extend in a longitudinal or transverse direction and cracks that are opened to the base or underlying material fall in this class. They also include progressive Class II crack resulting in severe spalling with chunks of pavement breaking out. 
Raveling (loss of surface aggregate) would also be classified as Class III crack.

Class IB cracks are estimated individually for the total linear length of the cracks. The width of the affected area is taken as one foot. The accumulated square footage of the linear cracks for the entire rated section is added to the totals for Class II and Class III crack and recorded as the predominate type present .

Class II and Class III area cracks are considered rectangular, and the total square feet of pavement affected is accumulated with Class IB crack and recorded as the predominate type present.

FDOT's Contractor Guaranteed Asphalt Pavement requires that the cracking should be limited to 50 feet for Class $1 \mathrm{~B}$ crack. There is a difficulty of relating this threshold value with the pavement condition rating values that are used for this case study. In this case, distress ratings used by FDOT to maintain its road network is used. FDOT specifies that for speed limit greater than $45 \mathrm{mph}$, a crack rating of 6.4 or less is considered a deficient pavement, for which maintenance should be carried out. For the purpose of this study, a crack rating value of 7 is taken as the threshold value.

\section{Roughness (Ride)}

Roughness is usually taken as a measure of riding comfort. Its severity is measured using the Ride Number (RN) denoted by millimeters of accumulated displacement per meter $(\mathrm{mm} / \mathrm{m})$. Ride Number is collected using a recording interval of 6 inches and processed using 300-foot wavelength filtering. Ride Number is reported as the average of the left and right wheel paths. Ride rating is calculated on a scale of 100 and then reported on a scale of 10 . A Ride Rating of 10 indicates a pavement that is perfectly 
smooth. As specified in Table 5.2, FDOT's Contractor Guaranteed Asphalt Pavement considers ride (roughness) value of 3.7 in a scale of 5 as the threshold value so that the pavements with ride number less than 3.7 are considered to have failed. Since, the ride value were measured in a scale of 1 to 10 by the FDOT's road condition survey, this threshold value for ride rating in a scale of 10 is 7.4. For the purpose of the dissertation, a ride rating threshold value of 7 is considered for analysis.

The set of distresses applied in the model have been selected from FDOT's Flexible Pavement Condition Survey and can be found in Table 5.3 with the corresponding condition state limits. It can be seen from the table that other types of distresses such as raveling, pot holes, and bleeding have not been taken into account in this dissertation because of the fact that according to the Flexible Pavement Condition Survey Handbook of FDOT, raveling (loss of surface aggregate) would also be classified as Class III crack and it is expected that the remedial actions for crack, rut, and ride also improve the raveling and potholes of the pavement.

Table 5.3: Five-step Classification of Condition States

\begin{tabular}{|l|l|l|l|l|l|l|}
\hline Distress & $\begin{array}{l}\text { Distress } \\
\text { Abbreviation }\end{array}$ & $\mathbf{1 0 - 9 . 1}$ & $\mathbf{9 . 0 - 8 . 1}$ & $\mathbf{8 . 0 - 7 . 1}$ & $\mathbf{7 - 6 . 1}$ & 6 \& Less \\
\hline Rut & RU & Very Good & Good & Fair & Bad & Very Bad \\
\hline Crack & CR & Very Good & Good & Fair & Bad & Very Bad \\
\hline Ride & RI & Very Good & Good & Fair & Bad & Very Bad \\
\hline
\end{tabular}

\subsubsection{Pavement Condition}

When a maintenance contract is awarded for a certain period of time, it is essential to determine the existing condition of the pavement because all the future projections of the 
pavement conditions are dependent on the initial condition of the pavement. For example, for a performance-based maintenance contract of 10 years duration, the future conditions of the pavement from year 1 to year 10 are determined by multiplying the deterioration matrix (transition probability matrix) with the existing condition of the pavement at year 0 (i.e., the year of contract award).

The pavement condition is represented by a single row matrix, also referred to as a row vector. The elements of the vector are the percentage of the pavement in each of the five different states of pavement condition. This vector is easily determined from the pavement condition survey data summarized in Table 5.4.

Table 5.4: Distress Condition Rating of SR-836 (Dolphin Expressway) for Year 2008

\begin{tabular}{|l|l|l|l|l|l|}
\hline $\begin{array}{l}\text { Beginning } \\
\text { Mile Post }\end{array}$ & $\begin{array}{l}\text { End Mile } \\
\text { Post }\end{array}$ & Miles & $\begin{array}{l}\text { Crack } \\
\text { Rating }\end{array}$ & $\begin{array}{l}\text { Ride } \\
\text { Rating }\end{array}$ & Rut Rating \\
\hline 0.000 & 0.445 & 0.445 & $7.1-8.0$ & $7.1-8.0$ & $8.1-9.0$ \\
\hline 0.445 & 2.980 & 2.535 & $9.1-10$ & $7.1-8.0$ & $8.1-9.0$ \\
\hline 5.199 & 6.195 & 0.996 & $9.1-10$ & $8.1-9.0$ & $8.1-9.0$ \\
\hline 8.002 & 8.527 & 0.525 & $6.1-7.0$ & $7.1-8.0$ & $6.1-7.0$ \\
\hline 8.527 & 9.144 & 0.617 & $6.1-7.0$ & $7.1-8.0$ & $8.1-9.0$ \\
\hline 9.144 & 9.514 & 0.370 & $6.1-7.0$ & $<6.0$ & $7.1-8.0$ \\
\hline 9.514 & 10.596 & 1.082 & $9.1-10$ & $7.1-8.0$ & $8.1-9.0$ \\
\hline 8.797 & 9.514 & 0.717 & $6.1-7.0$ & $7.1-8.0$ & $8.1-9.0$ \\
\hline 8.527 & 8.797 & 0.270 & $9.1-10$ & $7.1-8.0$ & $7.1-8.0$ \\
\hline 6.530 & 7.960 & 1.430 & $9.1-10$ & $8.1-9.0$ & $8.1-9.0$ \\
\hline 2.890 & 4.413 & 1.523 & $6.1-7.0$ & $8.1-9.0$ & $8.1-9.0$ \\
\hline 2.146 & 2.890 & 0.744 & $9.1-10$ & $7.1-8.0$ & $8.1-9.0$ \\
\hline 0.966 & 2.146 & 1.180 & $9.1-10$ & $7.1-8.0$ & $8.1-9.0$ \\
\hline 0.383 & 0.966 & 0.583 & $9.1-10$ & $7.1-8.0$ & $8.1-9.0$ \\
\hline 0.000 & 0.383 & 0.383 & $9.1-10$ & $7.1-8.0$ & $8.1-9.0$ \\
\hline
\end{tabular}


The steps of estimating the elements of the condition state vector are illustrated through Tables 5.5 to Table 5.7 using actual current condition data from State Road 836 (Dolphin Expressway), which is a component of the pavement network of Miami Dade Expressway (MDX).

Table 5.5: Condition State Distribution for Crack

\begin{tabular}{|l|l|l|}
\hline Condition State & Miles & Distribution Proportion \\
\hline $9.1-10$ & 9.203 & 0.687 \\
\hline $8.1-9$ & 0 & 0 \\
\hline $7.1-8$ & 0.445 & 0.033 \\
\hline $6.1-7$ & 3.752 & 0.280 \\
\hline$\leq 6$ & 0 & 0 \\
\hline
\end{tabular}

Table 5.6: Condition State Distribution for Ride

\begin{tabular}{|l|l|l|}
\hline Condition State & Miles & Distribution Proportion \\
\hline $9.1-10$ & 0 & 0 \\
\hline $8.1-9$ & 3.949 & 0.295 \\
\hline $7.1-8$ & 9.081 & 0.678 \\
\hline $6.1-7$ & 0 & 0 \\
\hline$\leq 6$ & 0.370 & 0.027 \\
\hline
\end{tabular}

Table 5.7: Condition State Distribution for Rut

\begin{tabular}{|l|l|l|}
\hline Condition State & Miles & Distribution Proportion \\
\hline $9.1-10$ & 0 & 0 \\
\hline $8.1-9$ & 12.235 & 0.913 \\
\hline $7.1-8$ & 0.64 & 0.048 \\
\hline $6.1-7$ & 0.525 & 0.039 \\
\hline$\leq 6$ & 0 & 0 \\
\hline
\end{tabular}


These condition distributions for each distress indicators are finally represented in vector notation as shown below.

$$
\begin{aligned}
& \mathrm{CR}=\left|\begin{array}{lllll}
0.687 & 0.000 & 0.033 & 0.280 & 0.000
\end{array}\right| \\
& \mathrm{RI}=\left|\begin{array}{lllll}
0.000 & 0.295 & 0.678 & 0.000 & 0.027
\end{array}\right| \\
& \mathrm{RU}=\left|\begin{array}{lllll}
0.000 & 0.913 & 0.048 & 0.039 & 0.000
\end{array}\right|
\end{aligned}
$$

It can be seen from this vector notation and Figure 5.3 that in Year 2008, SR-836 had $68.7 \%$ of its total pavement length in Very Good condition with respect to crack distress (i.e. condition rating above 9). There is no portion of the pavement in Good condition and $3.3 \%$ of the total length is in Fair condition. $28 \%$ of the pavement is in bad condition and none exists in very bad condition. It is evident that the pavement needs maintenance work since it does not meet the threshold criteria specified in the contract. The threshold value of crack assumed in this case study is 7 ( $\mathrm{Bad}$ condition state).

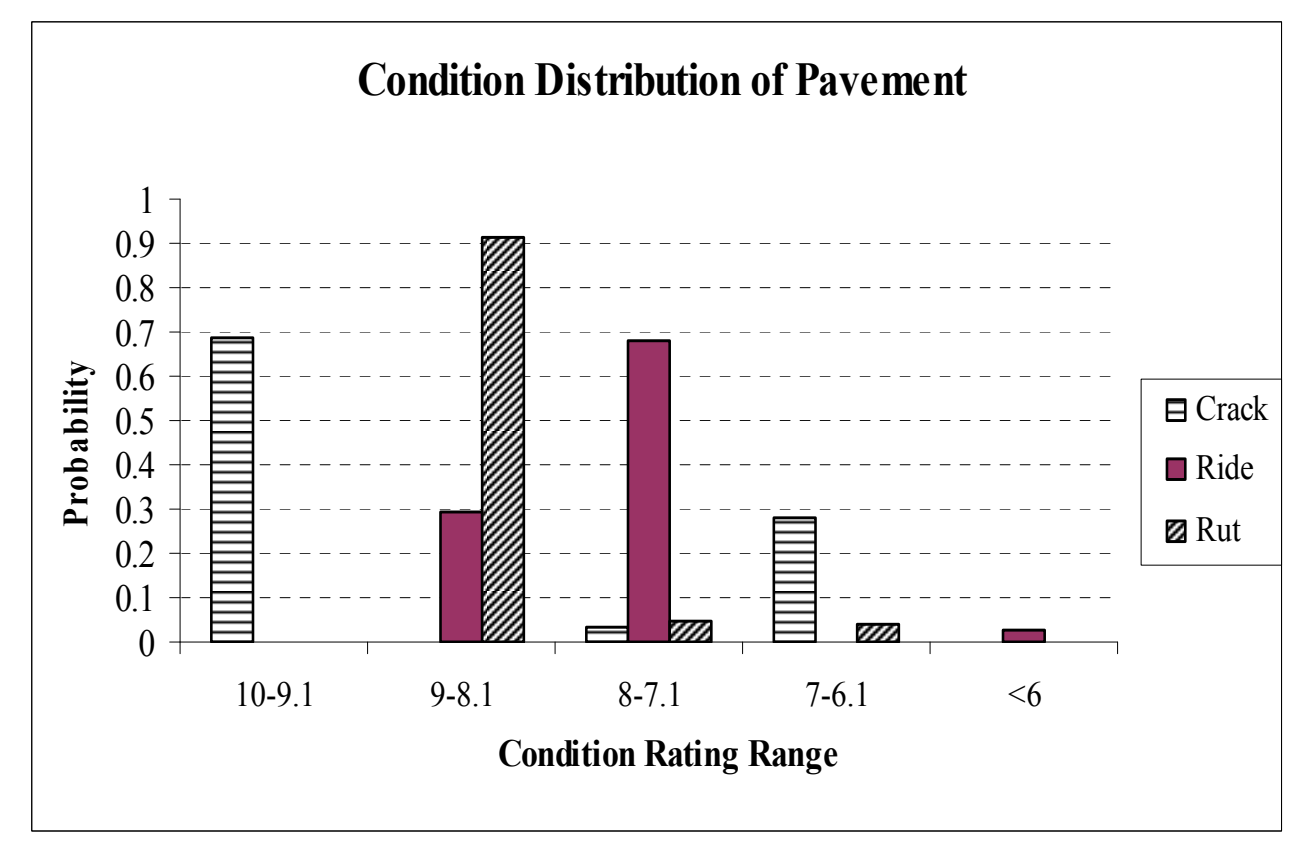

Figure 5.3: Condition Distribution of Pavement in Various Condition Ratings in Year 2008 


\subsubsection{Maintenance and Repair Strategies, and Their Unit Cost}

Maintenance and repair actions either slow or reverse the pavement deterioration process. For flexible pavements, there are many such maintenance actions ranging from simple and inexpensive operations such as crack sealing to more elaborate and expensive operations such as structural overlay. Since the aim of this dissertation is to approximate the cost of taking such maintenance and repair actions over the period of maintenance contract rather than laying out a detailed program of maintenance works, all of these maintenance actions are categorized into one of these-routine maintenance, minor maintenance, major maintenance, and reconstruction work.

Practically, maintenance strategies should include an option of 'no-maintenance.' Pavement survey condition data, which has been used in the performance modeling, contains a record of resurfacing and reconstruction activities. Although routine maintenance is performed, there are no records made in the pavement condition survey. As a result, it is difficult to distinguish between pavements that have been treated with routine maintenance and that do not receive any maintenance. For this research, all the pavements taken for deterioration modeling are considered to have received routine maintenance. It could be argued reasonably well that the same pavements could have been considered as those that have not received any routine maintenance works. In that case, 'no-maintenance' option should be one of the strategies. Transition probabilities for other forms of maintenance action must also be determined. Standardized maintenance and repair strategies that are considered for this case study are: i) routine maintenance ii) minor maintenance iii) major maintenance, and iv) reconstruction. 
As an input of the overall model, unit costs of each of these maintenance actions are required. Unit costs are expressed in dollar per lane-mile. In the absence of such data specific to this case study, unit costs derived from other sources are used. One such source of information is the Long Term Pavement Performance (LTPP) data.

LTPP keeps a record of the actual unit costs of different maintenance treatments from all over the US and Canada for the pavements which are designated under the LTPP study. Unit cost of crack sealing (routine maintenance), and seal coating (minor maintenance) are obtained from the LTPP data for asphalt pavements. There are not sufficient records for resurfacing (major maintenance) and reconstruction work in the LTPP data. For this reason, unit costs of major maintenance and reconstruction work are obtained from literature search for similar projects. These unit costs are average and expected costs which have a wide range. When many such unit cost data are available for the same maintenance treatment but with a different probability of occurrence, they can be described using a probability distribution. For unit cost, a normal probability distribution can be suitably assumed. A normal probability distribution can be described using its mean and a standard deviation. Mean and standard deviation for unit cost (cost per lane-mile) of routine and minor maintenance obtained from LTPP unit cost data, and major maintenance and reconstruction unit cost data obtained from other literatures are summarized in Table 5.8. 
Table 5.8: Unit Cost of Different Maintenance Treatments

\begin{tabular}{|l|l|l|}
\hline $\begin{array}{l}\text { Maintenance } \\
\text { Treatment }\end{array}$ & $\begin{array}{l}\text { Mean Value of Unit } \\
\text { Cost (\$/lane-mile) }\end{array}$ & $\begin{array}{l}\text { Standard Deviation of Unit Cost (\$/ } \\
\text { lane-mile) }\end{array}$ \\
\hline $\begin{array}{l}\text { Routine } \\
\text { Maintenance }\end{array}$ & 731 & 479 \\
\hline $\begin{array}{l}\text { Minor } \\
\text { Maintenance }\end{array}$ & 8,632 & 7,213 \\
\hline $\begin{array}{l}\text { Major } \\
\text { Maintenance }\end{array}$ & 21,288 & 6,759 \\
\hline Reconstruction & $1,466,000$ & Not Available \\
\hline
\end{tabular}

\subsection{Pavement Deterioration Model}

Pavement condition rating data collected by FDOT's Flexible Pavement Condition Survey are used for developing pavement deterioration models as described earlier in Chapter 3.This pavement condition data is collected every year since 1983. Based on a rating scale of 1 to 10 , each road section is assigned a value that best describes its condition on various distress indicators such as crack, ride (roughness), and rut.

For the purpose of this dissertation, a subset (i.e. Miami Dade Expressway) of this entire data set (FDOT's pavement network) was carefully analyzed for any discrepancies in data. For example, pavement sections that showed a sudden change in improved condition which was not accounted by any maintenance treatments were disregarded for the analysis. Pavement segments that received maintenance treatments were not included in the deterioration model but were used for developing the pavement repair model. Therefore, pavement sections containing consecutive condition ratings from one year to the next year without showing increase in pavement condition ratings were considered for analysis. Condition ratings are assumed to remain constant or decrease with time when there are no maintenance activities. Methodology for developing transition probability 
matrix for pavement deterioration when there is minimal routine maintenance was discussed in detail in Chapter 3. Transition probability matrices were derived for asphalt pavements of Miami Dade Expressways for high AADT volume and low AADT volume separately. By categorizing pavements under high AADT and low AADT volume and deriving the transition probabilities separately, a better approximation of the deterioration rate is expected. Transition probability matrices as summarized in Table 5.9 for High AADT volume are used for the pavement sections of SR-836, which also fall under High AADT volume category.

Table 5.9: Transition Probability Matrix for Distresses Under Pavement Deterioration (High AADT Volume)

\begin{tabular}{|c|c|c|c|c|c|}
\hline Distress & $\begin{array}{l}\text { Tran } \\
\text { Matr }\end{array}$ & $\begin{array}{l}\text { ition } \\
\mathbf{x}\end{array}$ & roba & bility & \\
\hline Crack & $\mid \begin{array}{c}0.960 \\
0 \\
0 \\
0 \\
0\end{array}$ & $\begin{array}{c}0.040 \\
0.613 \\
0 \\
0 \\
0\end{array}$ & $\begin{array}{c}0 \\
0.387 \\
0.800 \\
0 \\
0\end{array}$ & $\begin{array}{c}0 \\
0 \\
0.200 \\
0.762 \\
0\end{array}$ & $\begin{array}{c}0 \\
0 \\
0 \\
0.238 \\
1\end{array}$ \\
\hline Ride & $\mid \begin{array}{c}0.286 \\
0 \\
0 \\
0 \\
0\end{array}$ & $\begin{array}{c}0.714 \\
0.891 \\
0 \\
0 \\
0\end{array}$ & $\begin{array}{c}0 \\
0.109 \\
0.944 \\
0 \\
0\end{array}$ & $\begin{array}{c}0 \\
0 \\
0.056 \\
1 \\
0\end{array}$ & $\begin{array}{l}0 \\
0 \\
0 \\
0 \\
1\end{array}$ \\
\hline Rut & $\mid \begin{array}{c}0.276 \\
0 \\
0 \\
0 \\
0\end{array}$ & $\begin{array}{c}0.724 \\
0.832 \\
0 \\
0 \\
0\end{array}$ & $\begin{array}{c}0 \\
0.168 \\
0.884 \\
0 \\
0\end{array}$ & $\begin{array}{c}0 \\
0 \\
0.116 \\
0.807 \\
0\end{array}$ & $\begin{array}{c}0 \\
0 \\
0 \\
0.193 \\
1\end{array}$ \\
\hline
\end{tabular}

\subsection{Pavement Repair Model}

Pavement repair model, determined earlier in section 3.3.5, is applied without any modification for the case study. The same distress-repair model developed in Chapter 3 
will be used for this case study. For a five step condition category, transition probability matrices for different repair treatments are again summarized in Table 5.10.

Table 5.10: Transition Probability Matrix for Pavement Repair

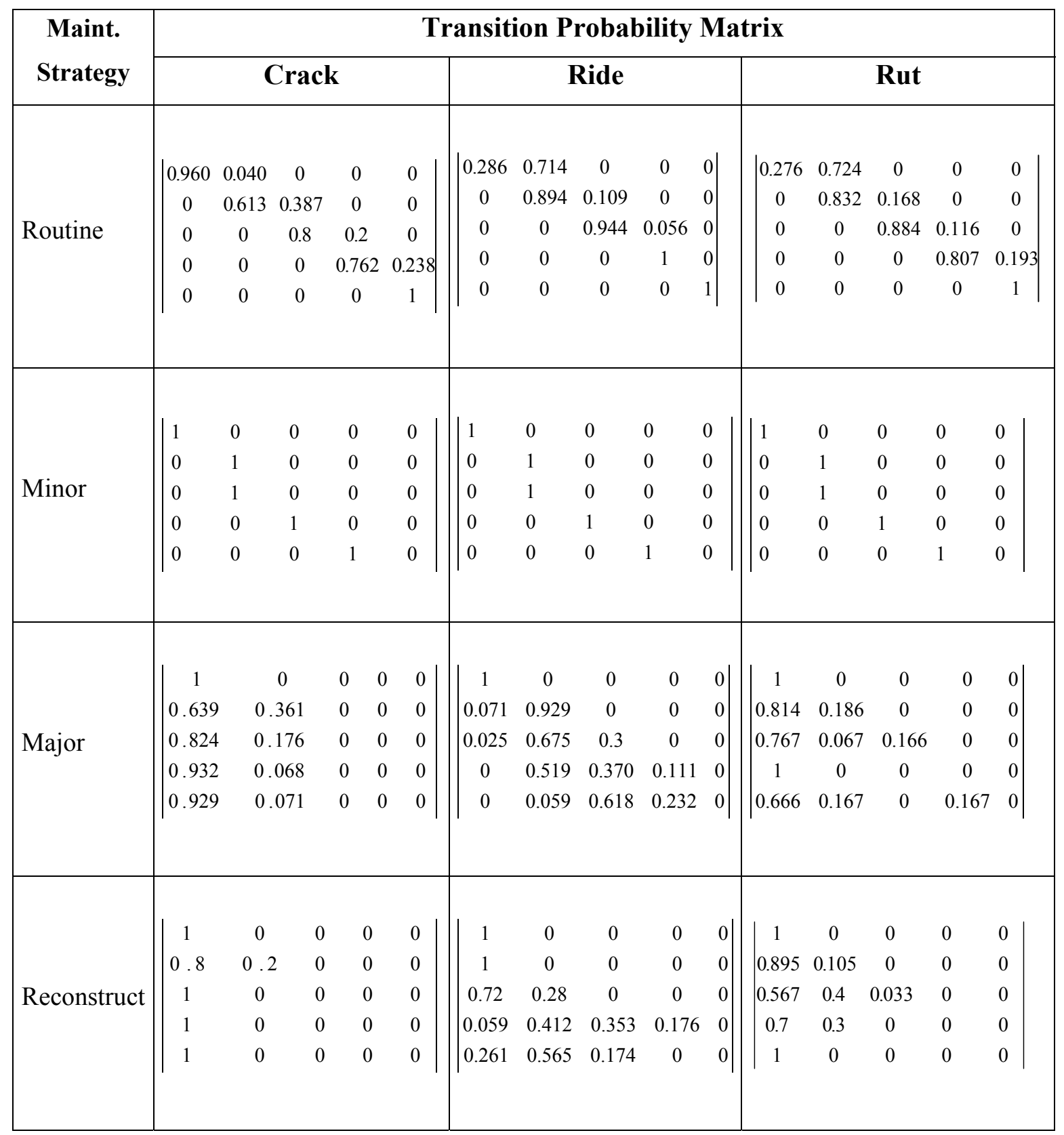




\subsection{Iteration of Deterioration-Repair Process}

Until now, deterioration and repair models for the methodological frameworks have been developed separately. However, in reality the final pavement performance outcome after a few years is the result of interaction of deterioration-repair process repetitively. When input, deterioration model, and repair model are available, iteration is performed as shown in Figure 5.4.

Figure 5.4 is divided into three sections: (1) input, (2) iteration, and (3) output. Now that the inputs for the model have been defined, the next step is to perform the iteration. The objective of the iteration process is to model the effect of maintenance strategies on the condition state of the pavement. For each year up to the end of the analysis period (10 years), maintenance actions from a set of standard maintenance strategies are selected such that the maintenance activity that requires the minimum effort, and hence the cost while satisfying the pavement condition requirement of the performance-based maintenance contract. Application of the methodology to a case study of SR-836 (Dolphin Expressway) as shown in Figure 5.4 summarizes the overall methodology followed by the descriptions of the calculation steps for first two years. Flow chart developed and presented in Figure 4.3 in Chapter 4 provides guidance on the iteration process. The detailed iteration process is explained as follows. 


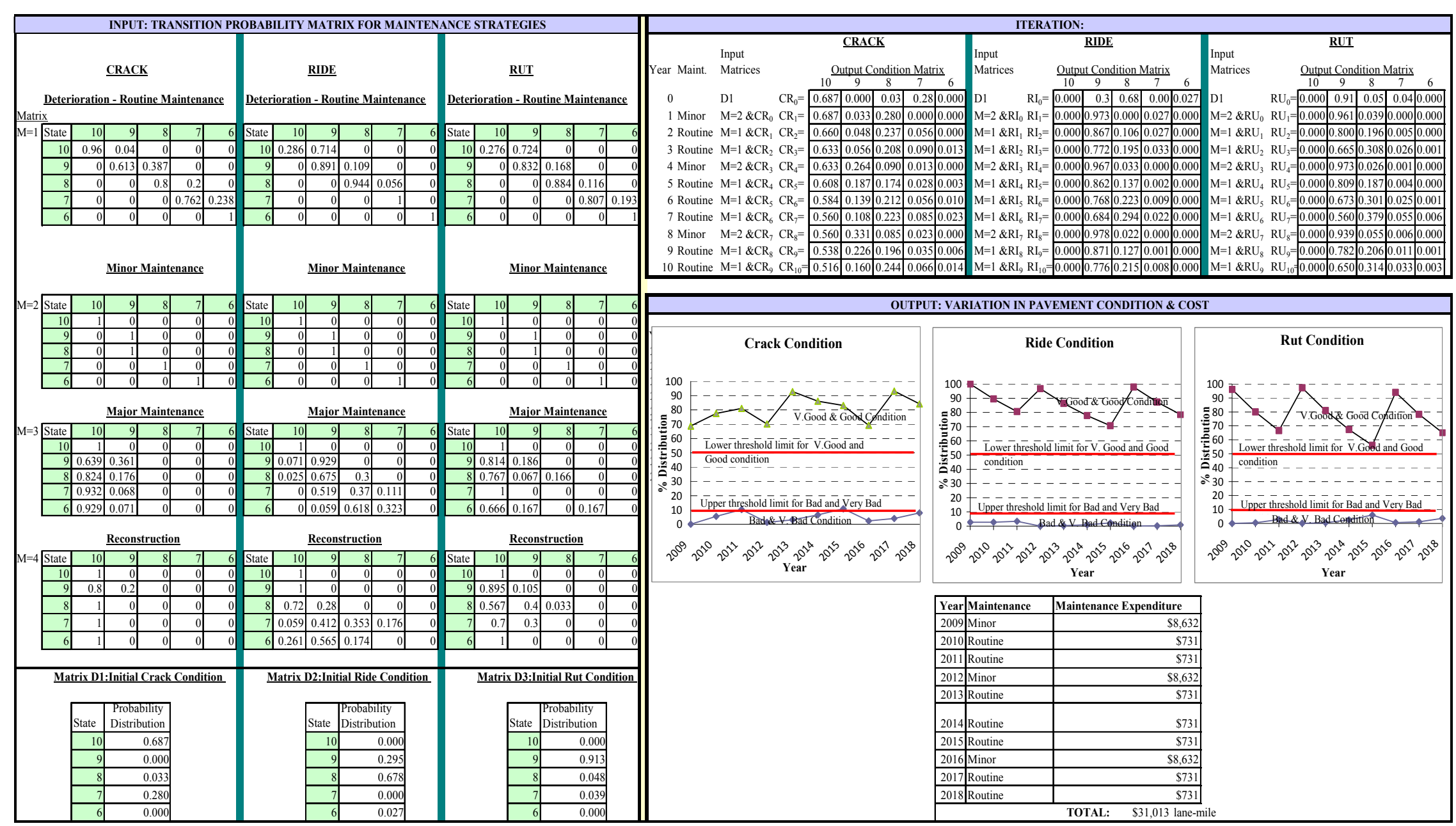

Figure 5.4: An Example of Application of the Methodology to a Case Study Using Excel Spreadsheet 


\section{Iteration steps:}

Year 0: Determine the existing pavement condition at year $t=0$ in terms of three distresses — crack (CR), ride (RI), and rut (RU).

The initial conditions of the pavement in terms of these distresses have been determined in section 5.2 as required for the input of the model. For year $\mathrm{t}=0$, these conditions are represented by condition state vector as follows:

For crack:

$\mathrm{CR}_{0}=\left|\begin{array}{lllll}0.687 & 0.000 & 0.033 & 0.280 & 0.000\end{array}\right|$

For ride:

$\mathrm{RI}_{0}=\left|\begin{array}{lllll}0.000 & 0.295 & 0.678 & 0.000 & 0.027\end{array}\right|$

For rut:

$\mathrm{RU}_{0}=\left|\begin{array}{lllll}0.000 & 0.913 & 0.048 & 0.039 & 0.0000\end{array}\right|$

As per the developed flowchart as shown in Figure 4.3, increase the time by one year, i.e., $t=1$ year. Check if this is the end of the analysis period. The analysis period (performance-based contract period) in this case is 10 years and therefore, the analysis should be continued until the $10^{\text {th }}$ year.

Year 1: Try maintenance $M=1$ (routine maintenance) for this year. The impact of carrying out the maintenance activity is that it changes the condition state distribution of the pavement. This condition state distribution is nothing but the percentage of the pavement in very good, good, fair, bad, and very bad condition states. Change in condition state distribution of the pavement at Year 1 after scheduling routine maintenance activity is obtained by multiplying the condition at Year 0 by the transition 
probability matrix for maintenance strategy $\mathrm{M}=1$. The multiplication process for these matrices is as shown in Figure 5.5, Figure 5.6 and Figure 5.7.

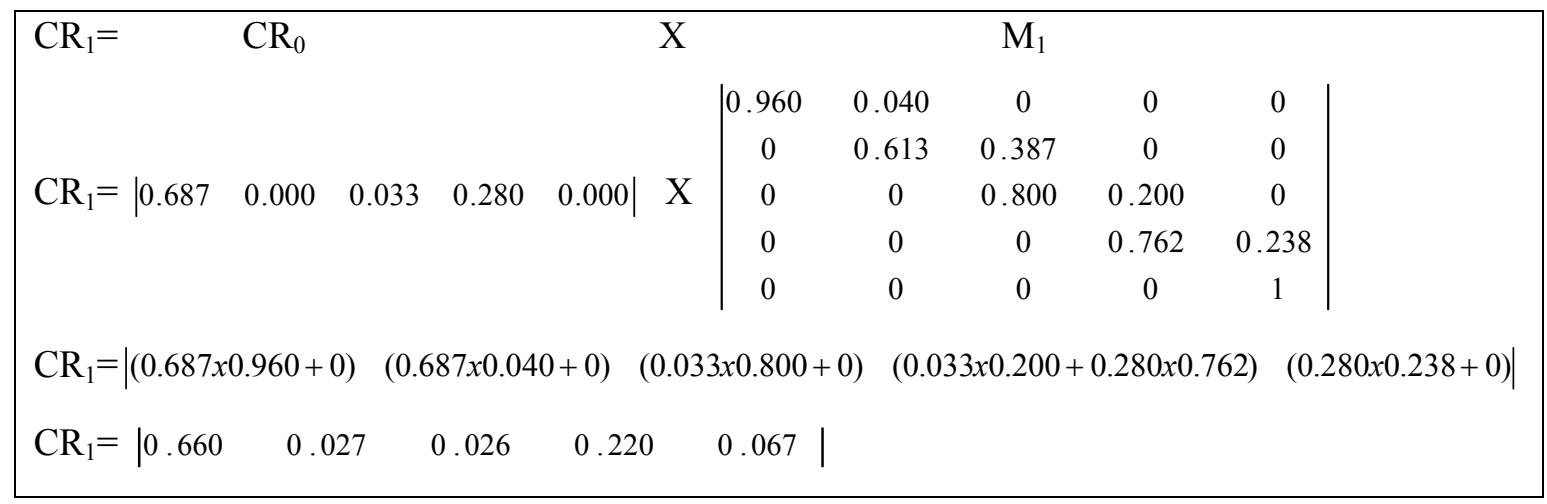

Figure 5.5: Multiplication Process to Obtain Condition State Vector for Crack in Year One with Routine Maintenance

Similarly for ride, the multiplication process of these matrices is as shown in Figure 5.6.

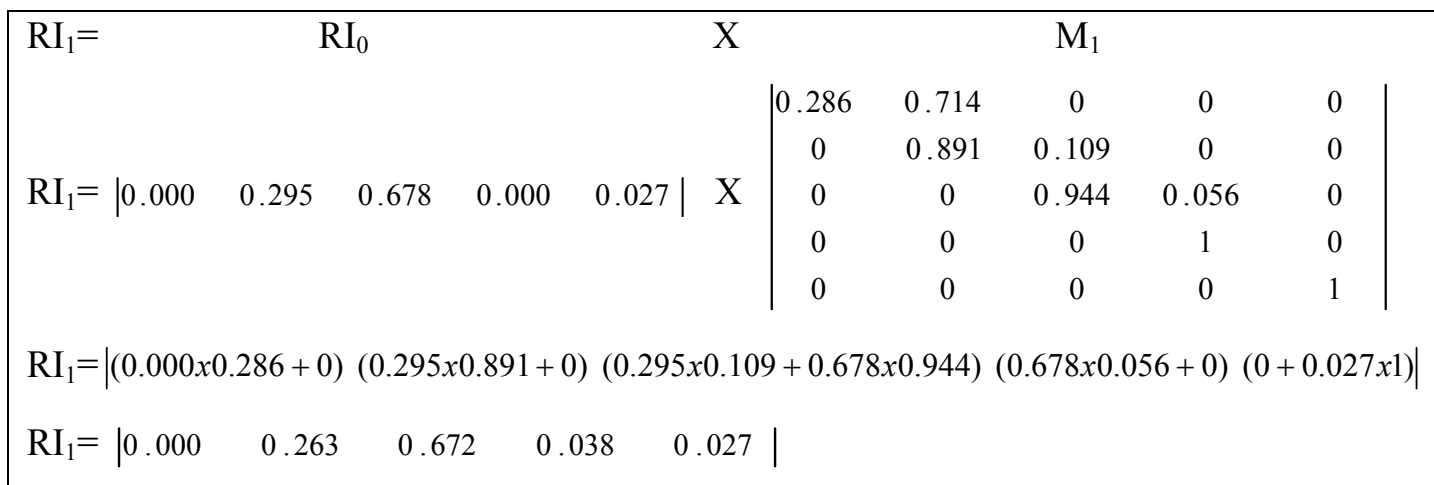

Figure 5.6: Multiplication Process to Obtain Condition State Vector for Ride in Year One with Routine Maintenance

And finally for rut, the multiplication process for these matrices is as shown in Figure 5.7 .

\begin{tabular}{llll}
\hline $\mathrm{RU}_{1}=$ & $\mathrm{RU}_{0}$ & $\mathrm{X}$ & $\mathrm{M}_{1}$
\end{tabular}




\begin{tabular}{|c|c|c|c|c|c|c|c|c|c|}
\hline \multirow{5}{*}{$\mathrm{RU}_{1}=\mid 0.000$} & \multirow{5}{*}{0.913} & \multirow{5}{*}{0.048} & \multirow{5}{*}{0.039} & \multirow{5}{*}{$0.000 \mid \mathrm{X}$} & \multirow{3}{*}{$\mid \begin{array}{c}0.276 \\
0 \\
0\end{array}$} & \multirow{3}{*}{$\begin{array}{c}0.724 \\
0.832\end{array}$} & \multirow{2}{*}{$\begin{array}{c}0 \\
0.168\end{array}$} & \multirow{3}{*}{$\begin{array}{c}0 \\
0 \\
0.116\end{array}$} & \multirow{3}{*}{$\begin{array}{l}0 \\
0 \\
0\end{array}$} \\
\hline & & & & & & & & & \\
\hline & & & & & & & 0.844 & & \\
\hline & & & & & 0 & 0 & 0 & 0.807 & 0.193 \\
\hline & & & & & 0 & 0 & 0 & 0 & 1 \\
\hline \multicolumn{10}{|c|}{$\begin{array}{l}\mathrm{RU}_{1}= \\
|(0.0 \times 0.276+0)(0.913 \times 0.832+0)(0.913 \times 0.168+0.048 \times 0.844)(0.048 \times 0.116+0.039 x 0.807)(0+0.039 \times 0.193)|\end{array}$} \\
\hline $\mathrm{RU}_{1}=\mid 0.000$ & 0.760 & 0.194 & 0.038 & 0.008 & & & & & \\
\hline
\end{tabular}

Figure 5.7: Multiplication Process to Obtain Condition State Vector for Rut in Year One with Routine Maintenance

Summarizing the result, the condition distribution of the pavement at Year 1 after the maintenance strategy $\mathrm{M}=1$ is shown in Table 5.11.

Table 5.11: Percentage Distribution of Condition State for Year One with Routine Maintenance

\begin{tabular}{|c|c|c|c|c|c|c|c|c|}
\hline \multirow[t]{2}{*}{$\begin{array}{l}\text { Distress } \\
\text { Indicator }\end{array}$} & \multicolumn{5}{|c|}{$\begin{array}{l}\text { \% Distribution of Pavement Condition } \\
\text { State (Condition State Vector) }\end{array}$} & \multirow{2}{*}{$\begin{array}{l}\text { \% of } \\
\text { V. Good } \\
\text { \& Good } \\
\text { Pavement }\end{array}$} & \multirow{2}{*}{$\begin{array}{l}\text { \% of } \\
\text { V. Bad \& } \\
\text { Bad } \\
\text { Pavement }\end{array}$} & \multirow{2}{*}{$\begin{array}{l}\text { Within } \\
\text { Acceptable } \\
\text { Condition? }\end{array}$} \\
\hline & $\begin{array}{l}\text { V. } \\
\text { Good }\end{array}$ & Good & Fair & $\mathrm{Bad}$ & $\begin{array}{l}\mathrm{V} . \\
\mathrm{Bad}\end{array}$ & & & \\
\hline Crack & 66 & 2.7 & 2.6 & 2.2 & 6.7 & 68.7 & 28.7 & No \\
\hline Ride & 0 & 26.3 & 67.2 & 3.8 & 2.7 & 26.3 & 6.5 & No \\
\hline Rut & 0 & 76 & 19.4 & 3.8 & 0.8 & 76 & 4.6 & Yes \\
\hline
\end{tabular}

Given that from the performance specifications that the percentage of the pavement in Very Good and Good condition need to be more than 50\%, and also that the percentage in $\mathrm{Bad}$ and Very Bad condition need to be less than $10 \%$, it can be seen from the results summarized in Table 5.11 that Crack and Ride Condition of the pavement under consideration does not satisfy the performance specifications for Year 1. As such, next maintenance activity, $M=2$ (minor maintenance) from the set of standard maintenance strategies is tried. 
The change in condition distribution of the pavement in Year 1 after trying pavement maintenance activity, $\mathrm{M}=2$ (minor maintenance) is determined by multiplying the condition state in Year 0 by the transition probability matrix for maintenance strategy $M=2$. The multiplication process for these matrices is as shown in Figure 5.8:

$\mathrm{CR}_{1}=$

Figure 5.8: Multiplication Process to Obtain Condition State Vector for Crack in Year One with Minor Maintenance

Similarly for ride, the multiplication process of these matrices is as shown in Figure 5.9.

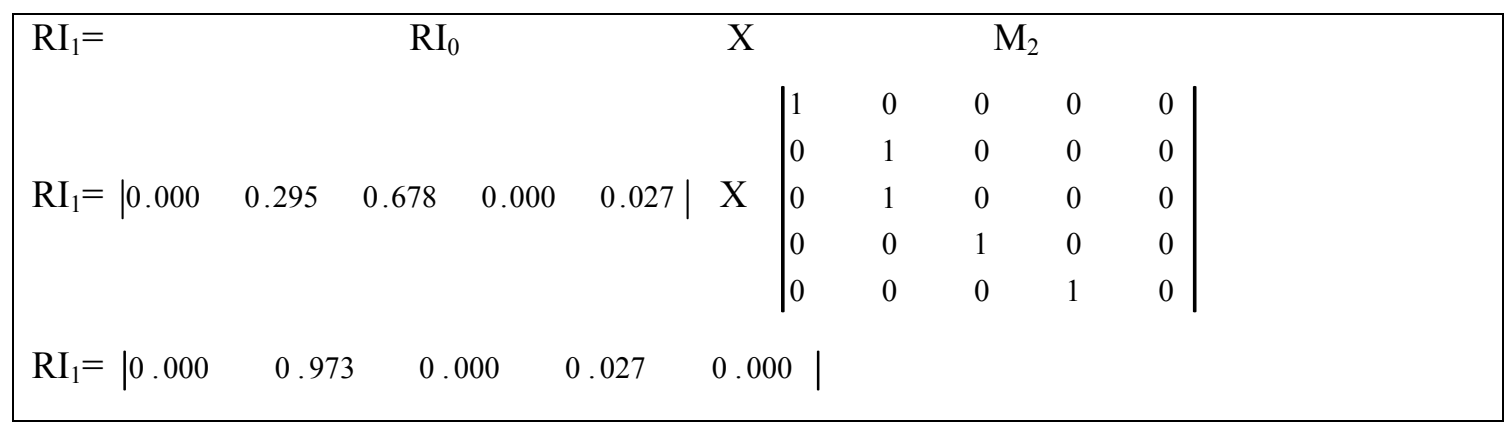

Figure 5.9: Multiplication Process to Obtain Condition State Vector for Ride in Year One with Minor Maintenance

And finally for rut, the multiplication process for these matrices is as shown in Figure 5.10 . 


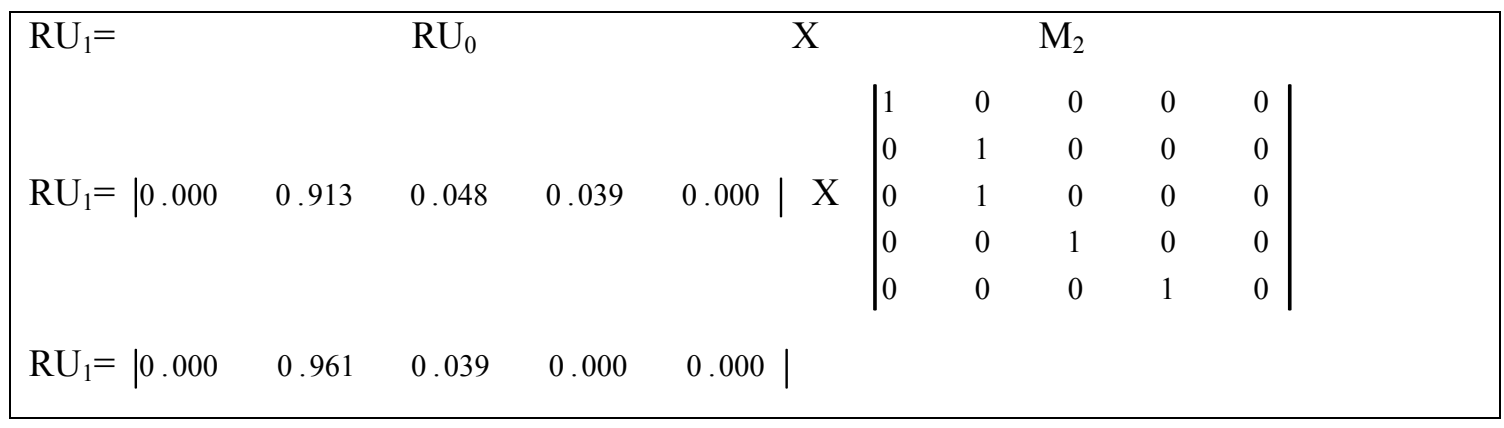

Figure 5.10: Multiplication Process to Obtain Condition State Vector for Rut in Year One with Minor Maintenance

Summarizing the result, the condition distribution of the pavement after the maintenance strategy $\mathrm{M}=2$ is shown in Table 5.12.

Table 5.12: Percentage Distribution of Condition State for Year One with Minor Maintenance

\begin{tabular}{|l|l|l|l|l|l|l|l|l|}
\hline \multirow{2}{*}{$\begin{array}{l}\text { Distress } \\
\text { Indicator }\end{array}$} & \multicolumn{9}{|l|}{$\begin{array}{l}\text { \% Distribution of Pavement Condition } \\
\text { State }\end{array}$} & $\begin{array}{l}\text { \% of } \\
\text { V. Good } \\
\text { \& Good } \\
\text { Pavement } \\
\text { Good }\end{array}$ & Good & Fair & Bad & $\begin{array}{l}\text { V. of } \\
\text { V. Bad \& } \\
\text { Bad } \\
\text { Pavement }\end{array}$ & $\begin{array}{l}\text { Within } \\
\text { Acceptable } \\
\text { Condition? }\end{array}$ \\
\hline Crack & 68.7 & 3.3 & 28 & 0 & 0 & 72 & 0 & Yes \\
\hline Ride & 0 & 97.3 & 0 & 2.7 & 0 & 97.3 & 2.7 & Yes \\
\hline Rut & 0 & 96.1 & 3.9 & 0 & 0 & 96.1 & 0 & Yes \\
\hline
\end{tabular}

Table 5.12 shows that all the distresses are within the threshold limit allowed for this performance-based contract as per the performance specification. Therefore, maintenance strategy $\mathrm{M}=2$ (minor maintenance) is scheduled for Year 1 . When maintenance is scheduled, there is cost associated with such maintenance action. That cost is calculated for Year 1. After storing the cost of maintenance for Year 1, time is increased by $\mathrm{t}=\mathrm{t}+1$, i.e., $\mathrm{t}=2$ year. End of analysis is checked. Since, analysis is needed up to the $10^{\text {th }}$ year, the above process is repeated for $2^{\text {nd }}$ Year as follows: 
Year 2: To start with, try maintenance $M=1$ (routine maintenance) for this year. The change in condition distribution of the pavement in Year 2 after trying pavement maintenance activity is determined by multiplying the condition state vector in Year 1 by the transition probability matrix for maintenance strategy $M=1$. The multiplication process for these matrices is as shown in Figure 5.11:

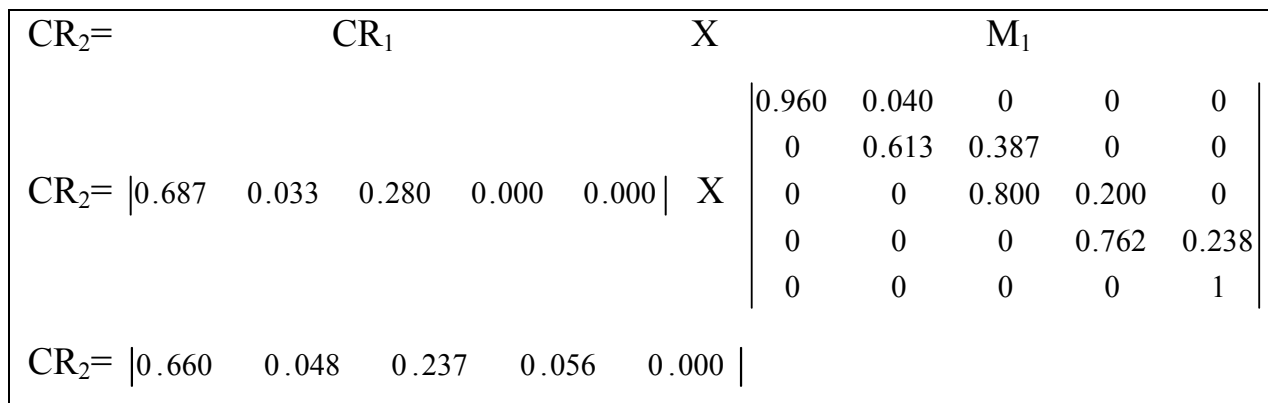

Figure 5.11: Multiplication Process to Obtain Condition State Vector for Crack in Year Two with Routine Maintenance

Similarly for ride, the multiplication process of these matrices is as shown in Figure 5.12 .

\begin{tabular}{|c|c|c|c|c|c|c|c|c|c|c|}
\hline $\mathrm{RI}_{2}=$ & & $\mathrm{RI}_{1}$ & & & $\mathrm{X}$ & & & $\mathrm{M}_{1}$ & & \\
\hline & & & & & & 0.286 & 0.714 & 0 & 0 & 0 \\
\hline & & & & & & 0 & 0.891 & 0.109 & 0 & 0 \\
\hline $\mathrm{RI}_{2}=\mid 0.000$ & 0.973 & 0.000 & 0.027 & 0.000 & $\mathrm{X}$ & 0 & 0 & 0.944 & 0.056 & 0 \\
\hline & & & & & & 0 & 0 & 0 & 1 & 0 \\
\hline & & & & & & 0 & 0 & 0 & 0 & 1 \\
\hline $\mathrm{RI}_{2}=\mid 0.000$ & 0.867 & 0.106 & 0.027 & 0.000 & & & & & & \\
\hline
\end{tabular}

Figure 5.12: Multiplication Process to Obtain Condition State Vector for Ride in Year Two with Routine Maintenance

And finally for rut, the multiplication process for these matrices is as shown in Figure 5.13 . 


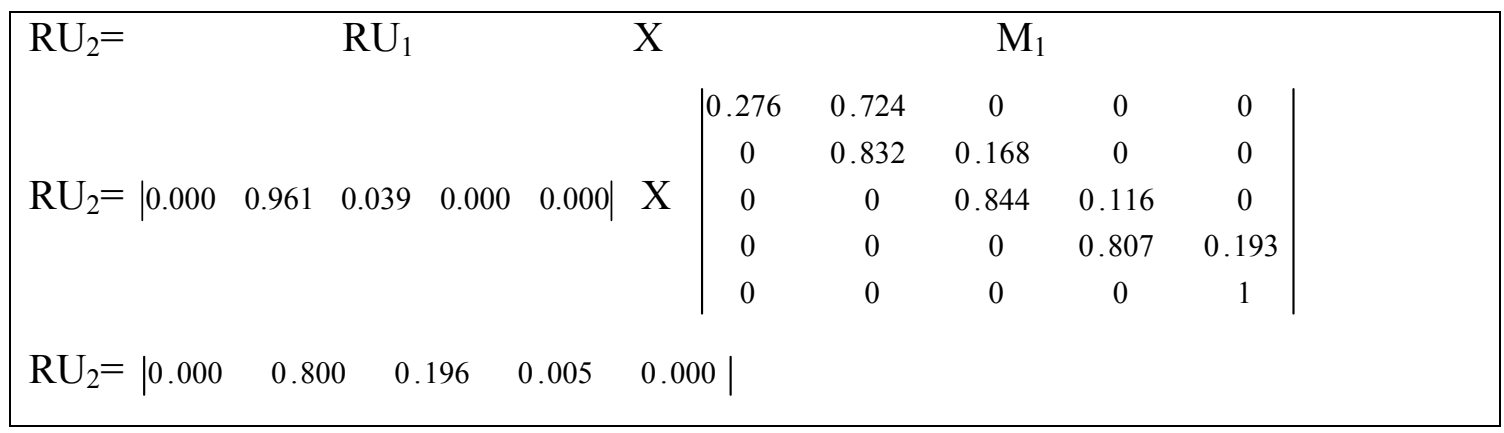

Figure 5.13: Multiplication Process to Obtain Condition State Vector for Rut in Year Two with Routine Maintenance

Summarizing the result, the condition state distribution of the pavement in Year 2 after the maintenance strategy $M=1$ is shown in Table 5.13.

Table 5.13: Percentage Distribution of Condition State for Year Two with Routine Maintenance

\begin{tabular}{|c|c|c|c|c|c|c|c|c|}
\hline \multirow{2}{*}{$\begin{array}{l}\text { Distress } \\
\text { Indicator }\end{array}$} & \multicolumn{5}{|c|}{$\begin{array}{l}\text { \% Distribution of Pavement } \\
\text { Condition State }\end{array}$} & \multirow{2}{*}{$\begin{array}{l}\text { \% of } \\
\text { V. Good } \\
\text { \& Good } \\
\text { Pavement }\end{array}$} & \multirow{2}{*}{$\begin{array}{l}\text { \% of Bad } \\
\text { \& Very } \\
\text { Bad } \\
\text { Pavement }\end{array}$} & \multirow{2}{*}{$\begin{array}{l}\text { Within } \\
\text { Acceptable } \\
\text { Condition? }\end{array}$} \\
\hline & $\begin{array}{l}\text { V. } \\
\text { Good }\end{array}$ & Good & Fair & $\mathrm{Bad}$ & $\begin{array}{l}\text { V. } \\
\text { Bad }\end{array}$ & & & \\
\hline Crack & 66 & 4.8 & 23.7 & 5.6 & 0 & 70.8 & 5.6 & Yes \\
\hline Ride & 0 & 86.7 & 10.6 & 2.7 & 0 & 86.7 & 2.7 & Yes \\
\hline Rut & 0 & 80 & 19.6 & 0.5 & 0 & 80 & 0.5 & Yes \\
\hline
\end{tabular}

It can be seen from the results summarized in Table 5.13 that all of the distresses under consideration satisfy the performance specifications for Year 2. Therefore, with maintenance activity $\mathrm{M}=1$ (routine maintenance), performance criteria are satisfied. Routine maintenance strategy is selected for Year 2. After storing the cost of maintenance for Year 2, time is increased by $\mathrm{t}=\mathrm{t}+1$, i.e., $\mathrm{t}=3$ year. End of analysis period is checked. Since, analysis is needed up to the $10^{\text {th }}$ year, the above process is repeated for $3^{\text {rd }}$ Year and for the remaining years until the end of the analysis period is reached. Table 5.14 
summarizes the maintenance actions selected for the entire analysis period of 10 years and Figure 5.14 through Figure 5.16 illustrate the predicted condition distributions of the pavement with respect to crack, ride, and rut respectively.

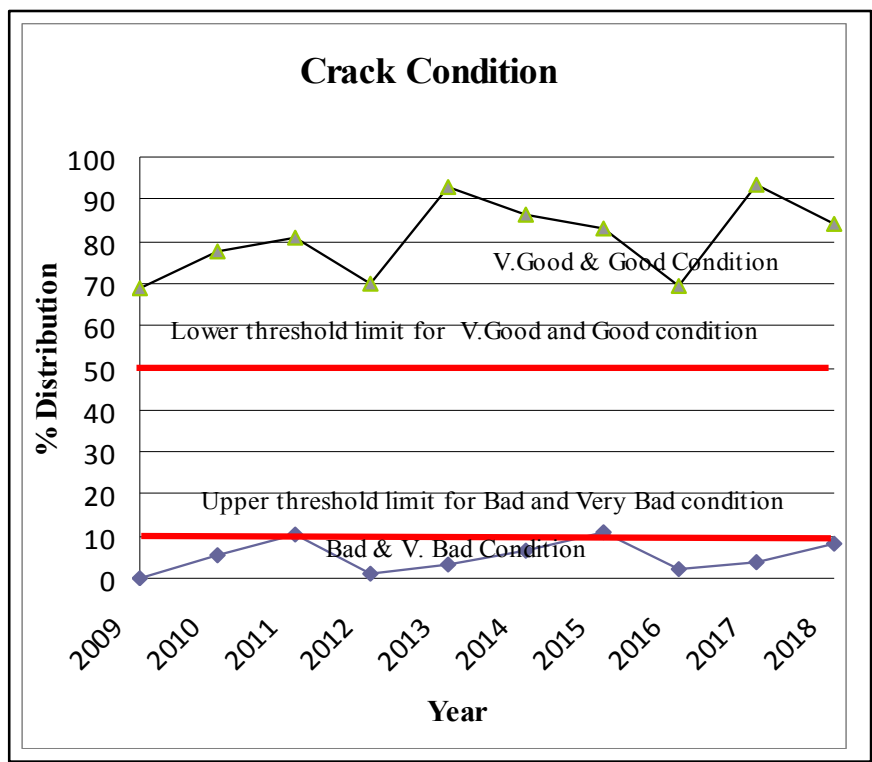

Figure 5.14: Condition Distribution of Crack

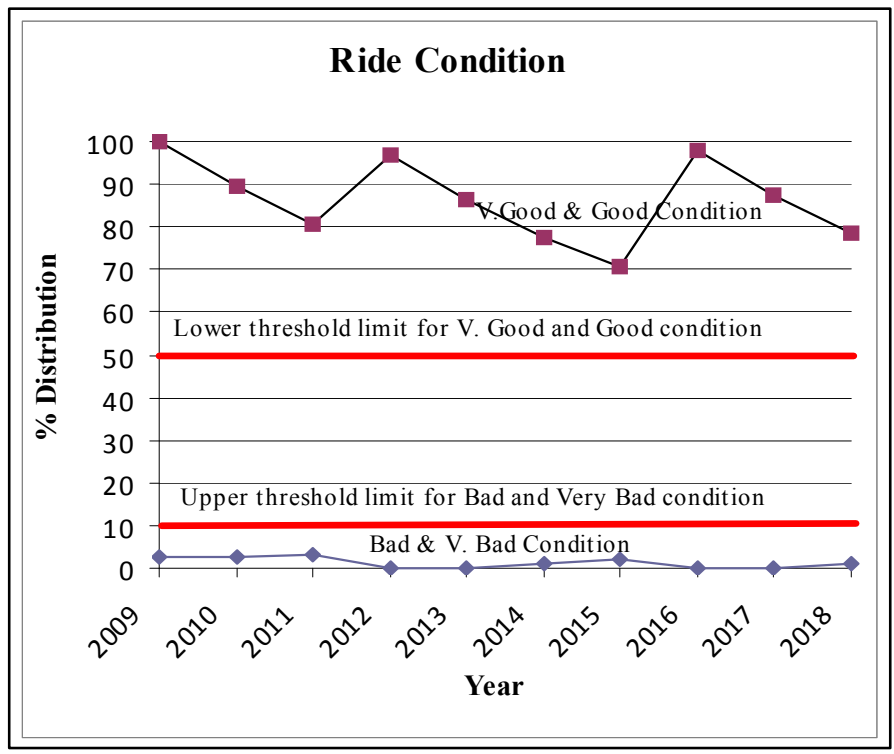

Figure 5.15: Condition Distribution of Ride 


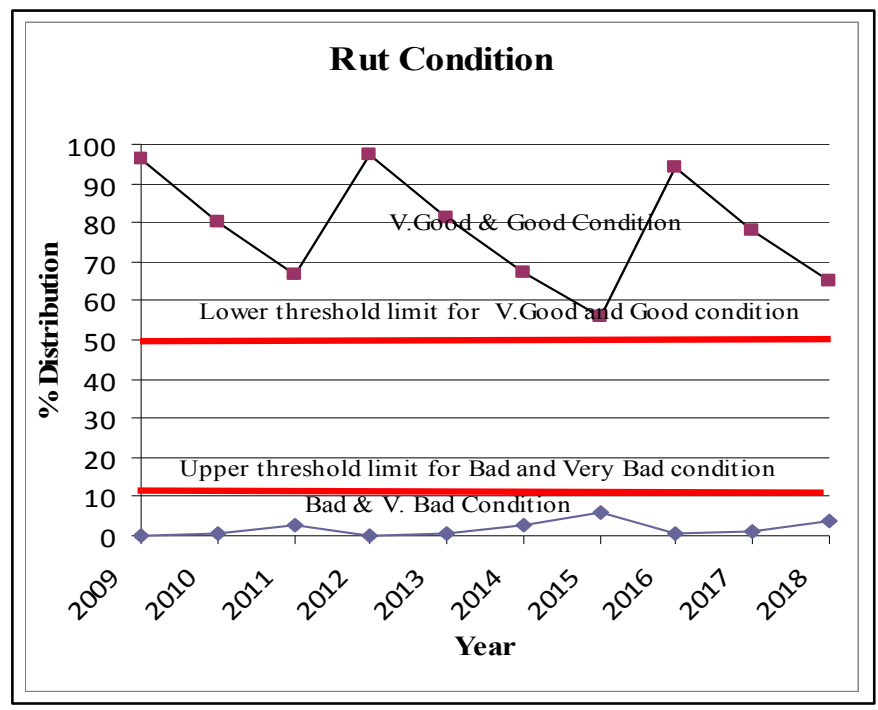

Figure 5.16: Condition Distribution of Rut

Some of the important observations that are made from this case study are:

- Threshold limit for Bad and Very Bad condition of crack is the sole trigger criteria influencing maintenance decisions. A performance threshold of condition rating 7 (pavement with condition rating of Bad and Very Bad) is reached first by crack distress before other distresses reach their corresponding threshold limit.

- Cracking distress shows the most variability in condition distribution, with a large portion of the pavement in Very Good condition and a substantial portion also in the Bad condition category. Other distresses are not as widely distributed in different condition categories as the crack distress. This is one of the reasons for crack being the distress indicator triggering maintenance actions.

- For this case study, it was taken that the percentage distribution in Bad and Very Bad condition (trigger value condition rating of 7) for none of 
the distresses exceeded $10 \%$. Similarly, another condition imposed was that at least $50 \%$ of the pavement section needed to be in Good condition or better (trigger value condition rating of 9). Between these two conditional criteria, it is seen from this case study that pavement condition in Bad and Very Bad condition state played a decisive role in triggering maintenance actions throughout the analysis period.

\subsection{Total Expected Costs}

As shown in Figure 5.3, the output section provides variation in pavement condition for each year up to the analysis period. Maintenance activities are scheduled for each year until the end of the contract period as shown in Table 5.14. The cost associated with carrying out these maintenance activities each year, the sum of which gives the total expected cost of maintaining pavement under performance-based maintenance contracts, is determined.

Table 5.14: Program of Maintenance Works and Their Cost

\begin{tabular}{|l|l|l|}
\hline Year & Maintenance Strategy & Cost (\$/lane-mile) \\
\hline 1 & Minor maintenance & 8,632 \\
\hline 2 & Routine maintenance & 731 \\
\hline 3 & Routine maintenance & 731 \\
\hline 4 & Minor maintenance & 8,632 \\
\hline 5 & Routine maintenance & 731 \\
\hline 6 & Routine maintenance & 731 \\
\hline 7 & Routine maintenance & 731 \\
\hline 8 & Minor maintenance & 8,632 \\
\hline 9 & Routine maintenance & 731 \\
\hline 10 & Routine maintenance & 731 \\
\hline Total estimated cost & 31,013 \\
\hline
\end{tabular}


The total estimated cost obtained in Table 5.14 is based on the assumption made on the iteration process whereby the least maintenance effort is selected first. It may be worthwhile to check if a larger investment on the maintenance of the pavement early on in its performance contract period reduces the total cost required to maintain the pavement without failing the performance requirements. For this, major maintenance action is tried on the first year of the contract. For other succeeding years, the same flow chart used for iteration for the previous case is used. Schedule of repair actions obtained with this maintenance policy is summarized in Table 5.15. It can be seen that the total estimated cost for this maintenance policy is actually higher than that obtained using the policy that required the repair treatment with the least effort first. This suggests to the fact that the proposed methodology of using the least maintenance effort first in the iteration process provides a valid approximation of the total cost of maintenance when optimization techniques are not used.

Table 5.15: Program of Maintenance Works and Their Cost When Major Maintenance is Scheduled in the First Year

\begin{tabular}{|c|c|c|}
\hline Year & Maintenance Strategy & Cost (\$/lane-mile) \\
\hline 1 & Major maintenance & 21,288 \\
\hline 2 & Routine maintenance & 731 \\
\hline 3 & Routine maintenance & 731 \\
\hline 4 & Routine maintenance & 731 \\
\hline 5 & Routine maintenance & 731 \\
\hline 6 & Routine maintenance & 731 \\
\hline 7 & Minor maintenance & 8,632 \\
\hline 8 & Routine maintenance & 731 \\
\hline 9 & Routine maintenance & 731 \\
\hline 10 & Minor maintenance & 8,632 \\
\hline \multicolumn{2}{|r|}{ Total estimated cost } & 43,669 \\
\hline
\end{tabular}




\subsection{Unit Cost Variability in Estimating Total Cost}

Total cost of performance-based maintenance work estimated in the previous section is based on the average unit cost of these maintenance activities which are by no means precise. There is a considerable variation in the unit prices taken from LTPP data and other literatures that were used for cost estimation in this dissertation. In order to account for this large variation of unit cost in the cost estimation methodology, a measure of variance is introduced. Standard deviation, which is the square root of variance, measures this variability of the unit cost. The uncertainty in unit cost is best described using a normal distribution, specified by its mean and the standard deviation. For routine maintenance, mean of unit cost is $\$ 731$ per lane-mile, and standard deviation is $\$ 479$ per lane-mile. For minor maintenance, unit cost is $\$ 8,632$ per lane-mile, and standard deviation is $\$ 7,212.9$ per lane-mile. For major maintenance, unit cost is $\$ 21,288$ per lane-mile, and standard deviation is $\$ 6,759$ per lane-mile. For reconstruction work, unit cost is $\$ 146,600$ per lane-mile and standard deviation could not be established as there were not sufficient data to analyze the variation.

The next step is to model the effect of unit cost uncertainty in the total cost. Since, the total cost is the summation of cost of maintenance from Year 1 to Year 10 as shown in Table 5.14, normal distributions for each maintenance cost are added to give yet another

normal distribution. The mean of this normal distribution gives the total expected cost of maintenance. This addition of normal distribution is achieved through Monte Carlo Simulation. There are many off-the-shelf application softwares available that can perform this simulation. One such simulation software that enables Monte Carlo Simulation as an EXCEL add-in is @RISK from Palisade, which has been used here for the simulation. 
Essentially what it does is, it picks a value from each distribution randomly and total cost is calculated many times, each time using a different combination of values for the unit cost. After 10,000 trial runs, there will be 10,000 estimations of total cost and summary statistics of the output can be obtained from the simulation as shown in Table 5.16.

Table 5.16: Summary Statistics of Monte Carlo Simulation on Total Cost

\begin{tabular}{|l|l|l|l|}
\hline \multirow{2}{*}{\multicolumn{2}{|c|}{ Statistics }} & \multicolumn{2}{c|}{ Percentile } \\
\cline { 3 - 4 } \multicolumn{2}{|c|}{} & $10 \%$ & 14,459 \\
\hline Maximum & 76,102 & $20 \%$ & 20,238 \\
\hline Mean & 31,010 & $30 \%$ & 24,268 \\
\hline Std Dev & 12,870 & $40 \%$ & 27,825 \\
\hline Variance & $165,640,403$ & $50 \%$ & 31,114 \\
\hline Skewness & -0.0113135 & $60 \%$ & 34,373 \\
\hline Kurtosis & 2.9603362 & $70 \%$ & 37,699 \\
\hline Median & 31,114 & $80 \%$ & 41,725 \\
\hline Mode & 32,217 & $90 \%$ & 47,661 \\
\hline
\end{tabular}

Different charts in the analysis of the results can be added for illustration. The frequency chart as shown in Figure 5.17, for example, shows the degree of uncertainty in the total estimated cost, namely the range of the obtained 10,000 values for total cost and how often they occur.

The cumulative frequency chart as shown in Figure 5.18 and the percentile table as shown in Table 5.16 provide another way to explain the results and are often preferred. These give the probability that a value will fall within, above or below a given range. The fiftieth percentile, for instance, is $\$ 31,010$, which means that $50 \%$ of the values are $\$ 31,010$ or less. 


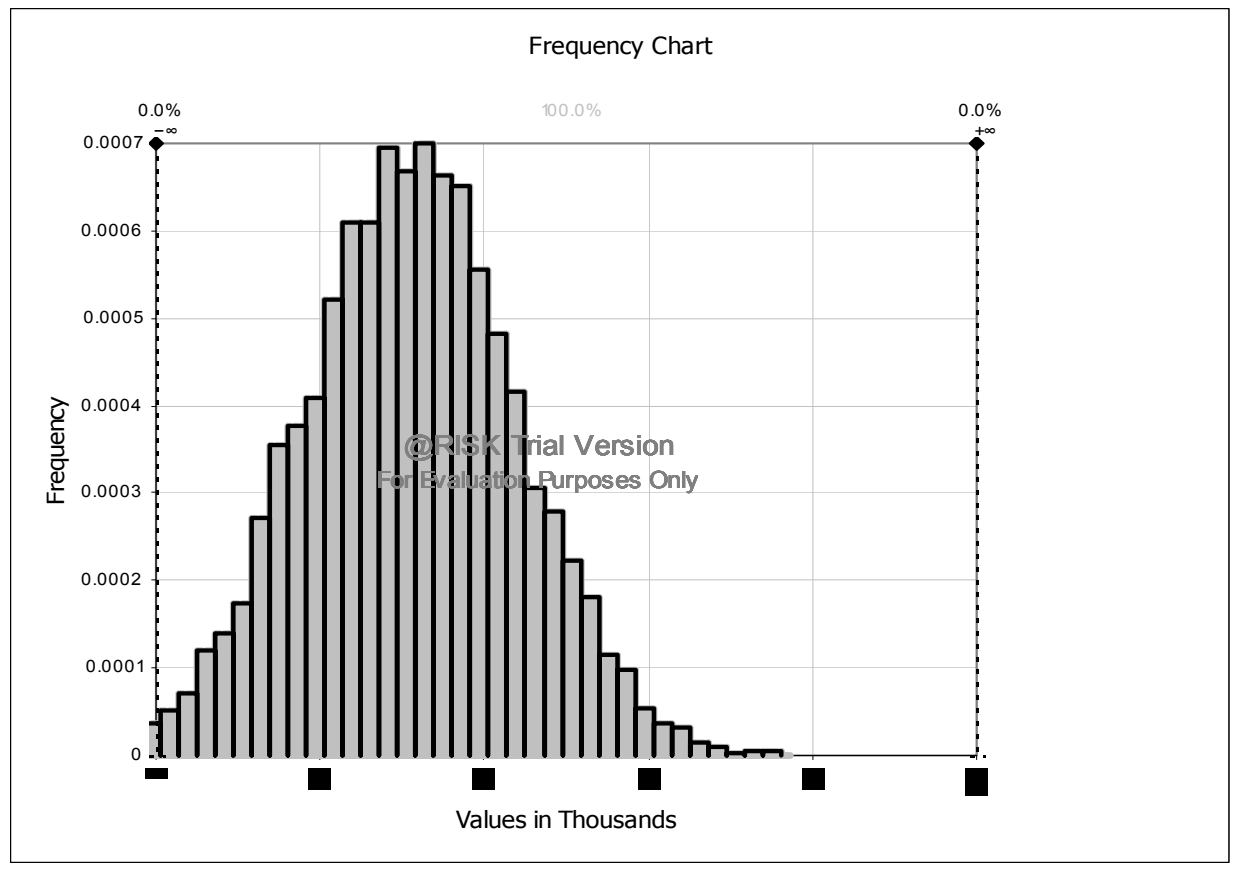

Figure 5.17: Frequency Chart from Monte Carlo Simulation

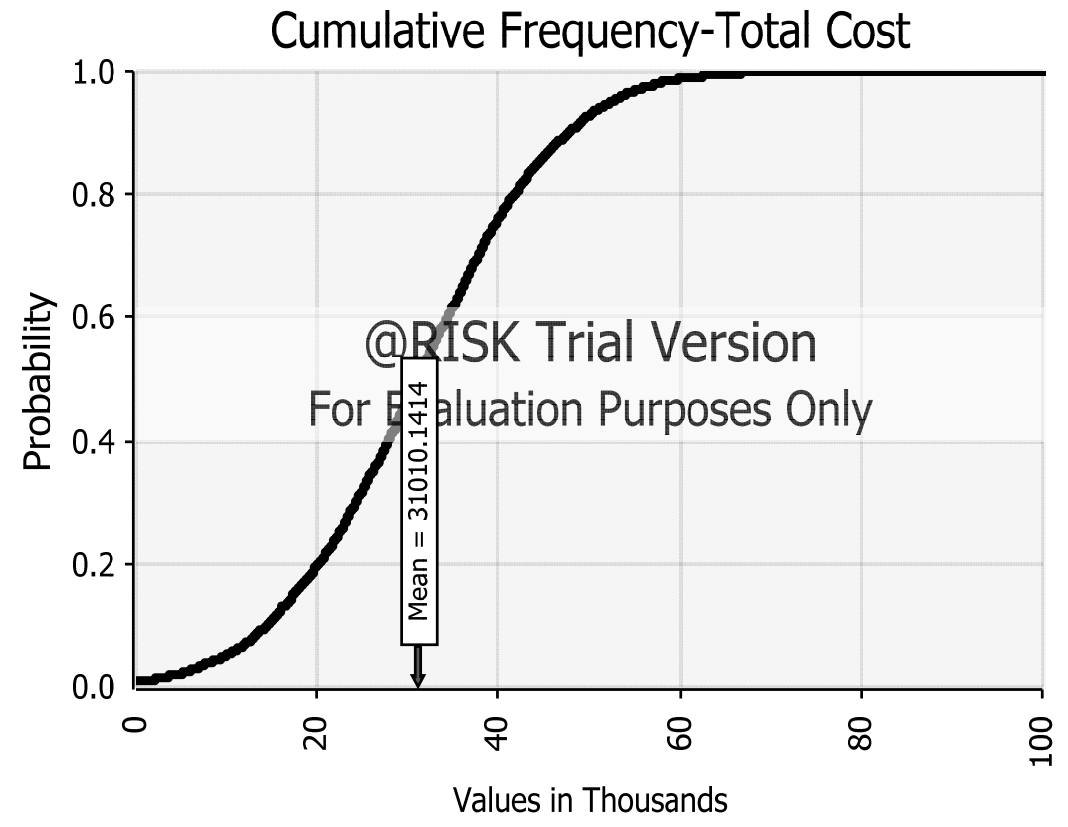

Figure 5.18: Cumulative Frequency Chart 


\subsection{Conclusion}

This chapter provided a detailed description of the methodological framework that was proposed in Chapter 4 by applying it to a case study. Pavement condition data from FDOT that was limited to asphalt pavements from Miami Dade Expressways were taken for developing pavement deterioration models and some of the pavement repair models. Data for other pavement repair models, for which there was insufficient data in the FDOT's pavement condition rating, were taken from similar pavement studies from other states. Since pavement condition is a result of interaction between deterioration and repair processes over a long period of time, condition of pavement at the end of different

years were obtained by the combination of deterioration-repair process. Iteration of different maintenance actions from the set of standard maintenance strategies was done starting from the least-effort-least-cost maintenance action to the maintenance action that required the most effort and therefore the greatest cost until the minimum performance criteria were met. Iteration for a particular year was stopped when these conditions were satisfied with the selected maintenance. This iteration process resulted in a variety of maintenance strategies selected for the entire contract period. With the units cost given for each maintenance action as an input, total estimated cost of performance-based pavement maintenance contract was finally obtained. 


\section{CHAPTER 6}

\section{SENSITIVITY ANALYSIS AND MODEL VALIDATION}

\subsection{Introduction}

The most useful aspect of pavement modeling is quantitative risk assessment (or sensitivity). As was evident in Chapter 5, the inputs to pavement performance modeling are based on data and assumptions. These are by no means precise, and there are many uncertainties associated with them. Outputs obtained from the model in Chapter 5 are absolute values, rather than the range of possible outcomes as a result of various levels of uncertainty. As we know that risks that the contractors are being asked to accept in performance-based contracts are many and varied and usually more comprehensive, this

demands a detailed investigation of the contract risks. Performing a series of what-if scenarios is one of the ways of investigating the contract risks.

From the proposed model, it can be seen that there are primarily three input variables which can be tested for sensitivity. These include pavement condition, warranty specifications, a set of standard maintenance strategies. While pavement condition, warranty specifications, and M\&R unit costs are variables of interest, there is no variability associated with the choice of standard M\&R strategies. Variability in M\&R unit costs is accounted through probability distribution functions obtained from actual cost of performing these maintenance and rehabilitation actions. Therefore, only two variables of interest, pavement condition and warranty specifications (distress thresholds), remain for which sensitivity testing needs to be done as shown in Table 6.1. 
Table 6.1: Variables and Their Range for Sensitivity Analysis

\begin{tabular}{|l|l|l|}
\hline Model Input & Variables to test & Range \\
\hline Pavement Condition & $\begin{array}{l}\text { Pavement } \\
\text { deterioration rate }\end{array}$ & $-25 \%$ to $+25 \%$ \\
\cline { 2 - 3 } & $\begin{array}{l}\text { Allowable extent of } \\
\text { pavement below } \\
\text { threshold }\end{array}$ & $-5 \%$ to $+5 \%$ \\
\hline $\begin{array}{l}\text { Warranty } \\
\text { Specifications }\end{array}$ & $\begin{array}{l}\text { Change in pavement } \\
\text { condition rating } \\
\text { threshold from the } \\
\text { base case }\end{array}$ & -1 to +1 \\
\hline
\end{tabular}

Since there were no existing established cost estimation models that included similar input variables found during the literature search, the results for each of the model components are validated individually. For an overall model validation, a qualitative approach is undertaken.

\subsection{Models}

\subsubsection{Base Case}

The model discussed in Chapter 5 is used as the base case. This base model uses the same three performance indicators — crack, ride, and rut. Deterioration rate of pavement for the base case, represented by the transition probability matrices, is derived from the pavement performance rating recorded over a long period of time. Although not specifically mentioned in the typical standard performance-based maintenance or warranty contracts, it has been assumed here that the condition rating of the entire length $(100 \%)$ of the pavement need not be above the minimum threshold limit. A very small percentage of the total pavement length may be allowed to be below threshold limit (i.e., Bad and Very Bad condition rating). It is assumed in the base case that this extent of 
pavement damage is $10 \%$. Additionally, at least $50 \%$ of the entire pavement length should be in Good and Very Good condition rating. Threshold value for condition rating of pavement for all the distress indicators should be 7 (on a scale of 1-10). This ensures that at least $90 \%$ of the pavement length is in a fair condition or better. Table 6.2 provides a list of variables for sensitivity analysis along with the base case for those variables.

Table 6.2: Variables for Sensitivity and the Base Case

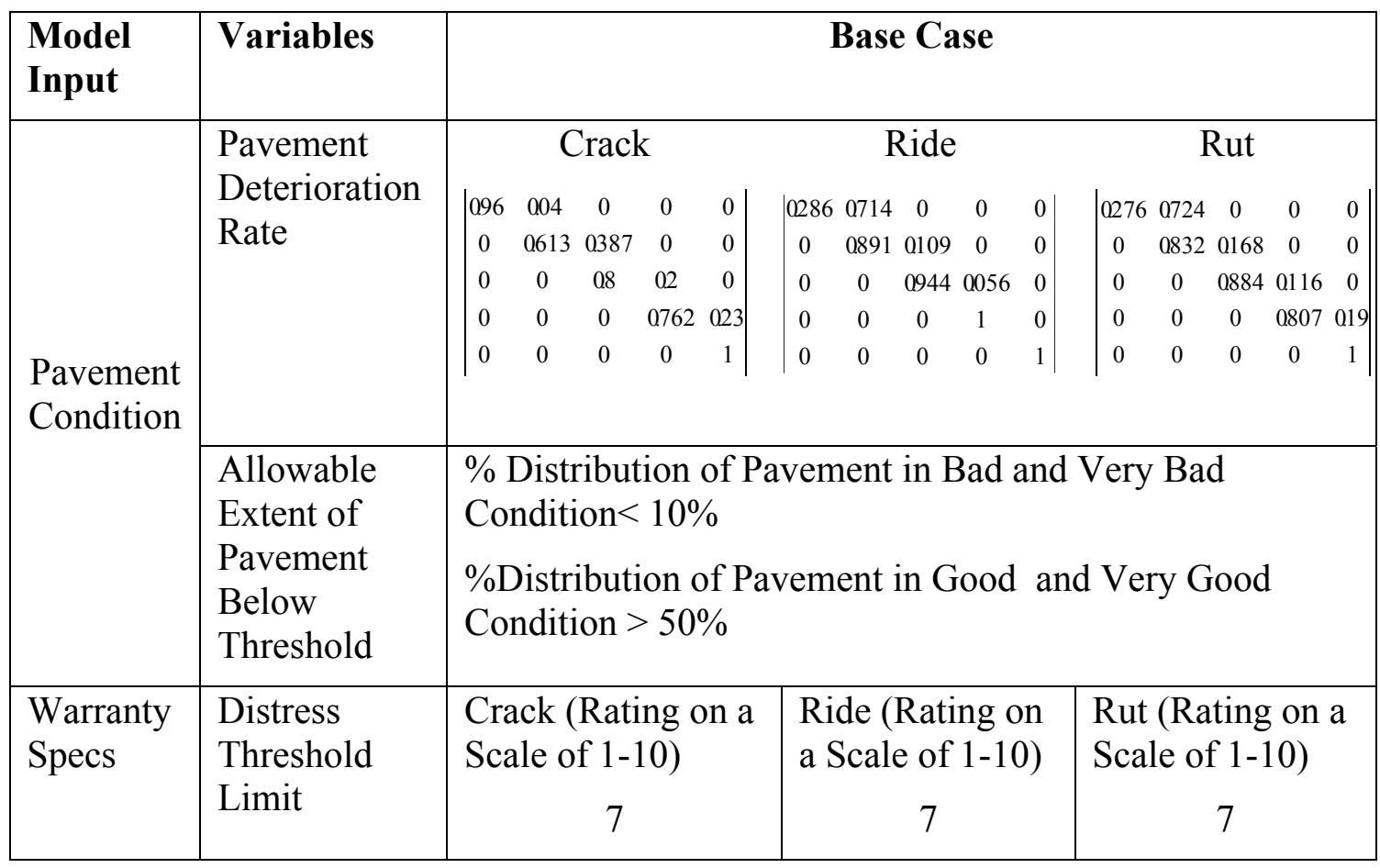

\subsubsection{Sensitivity for Improved Pavement Performance}

Improved pavement performance implies that the pavement is deteriorating slowly. When compared to the base case, the proportion of pavement transitioning to poorer condition is less. Table 6.3 compares the base case with the improved performance case, where the deterioration is slowed by $5 \%$ of the base case. For example, there is a $96 \%$ probability of pavement condition rating staying in the same Very Good condition state 
the next year and a $4 \%$ probability of degrading to Good condition rating. However, when the deterioration rate is slowed by $5 \%$, there is a $100 \%(96 \% * 1.05)$ probability of pavement staying in the same Very Good condition rating the next year. Probabilities for other transitions are calculated in a similar manner for slower deterioration rate. Pavement condition cannot go below very bad condition rating, and therefore this state is known as the absorbing state with a $100 \%$ probability of remaining in this same state. Improved performance increment at the rate of $5 \%$ up to $25 \%$ is considered for the sensitivity analysis. Transition probability matrices for improved performance of $10 \%$, $15 \%, 20 \%$, and $25 \%$ are derived similarly and are included in Appendix C.

Table 6.3: Transition Probabilities Generated for Improved Performance (5\% Less Deterioration)

\begin{tabular}{|c|c|c|c|c|c|c|c|c|c|c|}
\hline \multirow{2}{*}{$\begin{array}{l}\text { Distress } \\
\text { Crack }\end{array}$} & \multicolumn{5}{|c|}{ Base Case } & \multicolumn{5}{|c|}{ Improved Performance } \\
\hline & 0.960 & 0.040 & 0 & 0 & 0 & 1 & 0 & 0 & 0 & 0 \\
\hline & 0 & 0.613 & 0.387 & 0 & 0 & 0 & 0.644 & 0.356 & 0 & 0 \\
\hline & 0 & 0 & 0.800 & 0.200 & 0 & 0 & 0 & 0.840 & 0.160 & 0 \\
\hline & 0 & 0 & 0 & 0.762 & 0.238 & 0 & 0 & 0 & 0.800 & 0.200 \\
\hline & 0 & 0 & 0 & 0 & 1 & 0 & 0 & 0 & 0 & 1 \\
\hline \multirow[t]{5}{*}{ Ride } & 0.286 & 0.714 & 0 & 0 & 0 & 0.300 & 0.700 & 0 & 0 & 0 \\
\hline & 0 & 0.891 & 0.109 & 0 & 0 & 0 & 0.936 & 0.064 & 0 & 0 \\
\hline & 0 & 0 & 0.944 & 0.056 & 0 & 0 & 0 & 0.991 & 0.009 & 0 \\
\hline & 0 & 0 & 0 & 1 & 0 & 0 & 0 & 0 & 0.847 & 0.153 \\
\hline & 0 & 0 & 0 & 0 & 1 & 0 & 0 & 0 & 0 & 1 \\
\hline \multirow[t]{5}{*}{ Rut } & 0.276 & 0.724 & 0 & 0 & 0 & $\mid 0.290$ & 0.710 & 0 & 0 & 0 \\
\hline & 0 & 0.832 & 0.168 & 0 & 0 & 0 & 0.874 & 0.126 & 0 & 0 \\
\hline & 0 & 0 & 0.884 & 0.116 & 0 & 0 & 0 & 0.928 & 0.072 & 0 \\
\hline & 0 & 0 & 0 & 0.807 & 0.193 & 0 & 0 & 0 & 0.847 & 0.153 \\
\hline & 0 & 0 & 0 & 0 & 1 & 0 & 0 & 0 & 0 & 1 \\
\hline
\end{tabular}

Output of the sensitivity analysis for improved pavement performance illustrated by Figure 6.1 shows that there is a drop in maintenance cost with the improvement of 
pavement performance. So, when there is less deterioration of pavement than that derived in the base case, maintenance effort to meet the performance criteria reduces, thereby lowering the cost.

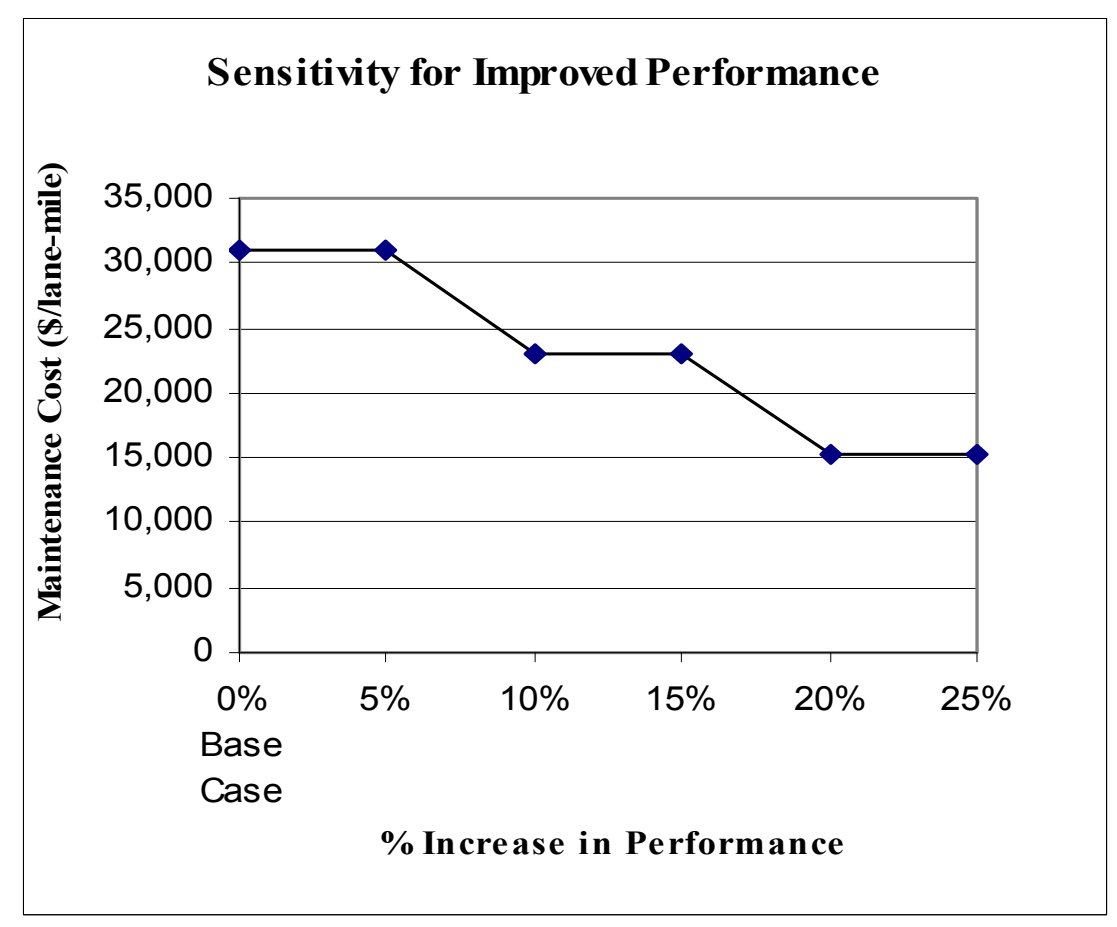

Figure 6.1: Sensitivity for Improved Performance

\subsubsection{Reduced Pavement Performance}

Rate of pavement deterioration is affected by so many factors. If these factors have a harsh effect on the condition of pavement, then the pavement deteriorates at a faster rate than that is obtained here. Although the effect of severe climatic condition are already taken into account while developing the transition probabilities, impact of increase in traffic load in the future have not been considered in developing the transition probability matrix. In order to consider the negative impact of such deteriorating forces for the future time period, sensitivity of the model with respect to deterioration is considered. As shown 
in Table 6.4, transition probability for the reduced performance of $5 \%$ is derived by multiplying the diagonal elements of the matrices by $95 \%$. For example, of the $96 \%$ of the pavement in Very Good condition that remained in the same condition state the next year in the base case, $91.2 \%$ (which is a product of $96 \%$ and $95 \%$ ) of the pavement in Very Good condition remains in Very Good condition. The remaining 8.8\% (100\%91.2\%) of the pavement deteriorates to Good condition in the next year. Since pavement condition cannot deteriorate further to a lower level than the Very Bad condition, the probability of pavement staying at this lowest condition level is $100 \%$. Transition probability matrices for reduced performance of $10 \%, 15 \%, 20 \%$, and $25 \%$ are derived similarly and are included in Appendix C.

Table 6.4: Transition Probabilities Generated for Reduced Performance (5\% More Deterioration)

\begin{tabular}{|c|c|c|c|c|c|c|c|c|c|c|}
\hline \multirow{2}{*}{$\begin{array}{l}\text { Distress } \\
\text { Crack }\end{array}$} & \multicolumn{5}{|c|}{ Base Case } & \multicolumn{5}{|c|}{ Reduced Performance } \\
\hline & 0.960 & 0.040 & 0 & 0 & 0 & 0.912 & 0.088 & 0 & 0 & 0 \\
\hline & 0 & 0.613 & 0.387 & 0 & 0 & 0 & 0.582 & 0.418 & 0 & 0 \\
\hline & 0 & 0 & 0.800 & 0.200 & 0 & 0 & 0 & 0.760 & 0.240 & 0 \\
\hline & 0 & 0 & 0 & 0.762 & 0.238 & 0 & 0 & 0 & 0.724 & 0.276 \\
\hline & 0 & 0 & 0 & 0 & 1 & 0 & 0 & 0 & 0 & 1 \\
\hline \multirow[t]{5}{*}{ Ride } & 0.286 & 0.714 & 0 & 0 & 0 & 0.272 & 0.728 & 0 & 0 & 0 \\
\hline & 0 & 0.891 & 0.109 & 0 & 0 & 0 & 0.846 & 0.154 & 0 & 0 \\
\hline & 0 & 0 & 0.944 & 0.056 & 0 & 0 & 0 & 0.897 & 0.103 & 0 \\
\hline & 0 & 0 & 0 & 1 & 0 & 0 & 0 & 0 & 0.950 & 0.050 \\
\hline & 0 & 0 & 0 & 0 & 1 & 0 & 0 & 0 & 0 & 1 \\
\hline \multirow[t]{5}{*}{ Rut } & 0.276 & 0.724 & 0 & 0 & 0 & 0.262 & 0.738 & 0 & 0 & 0 \\
\hline & 0 & 0.832 & 0.168 & 0 & 0 & 0 & 0.790 & 0.210 & 0 & 0 \\
\hline & 0 & 0 & 0.884 & 0.116 & 0 & 0 & 0 & 0.840 & 0.160 & 0 \\
\hline & 0 & 0 & 0 & 0.807 & 0.193 & 0 & 0 & 0 & 0.767 & 0.233 \\
\hline & 0 & 0 & 0 & 0 & 1 & 0 & 0 & 0 & 0 & 1 \\
\hline
\end{tabular}


As expected, with the reduced pavement performance, cost to maintain to achieve the pavement performance requirement increases as shown in Figure 6.2.

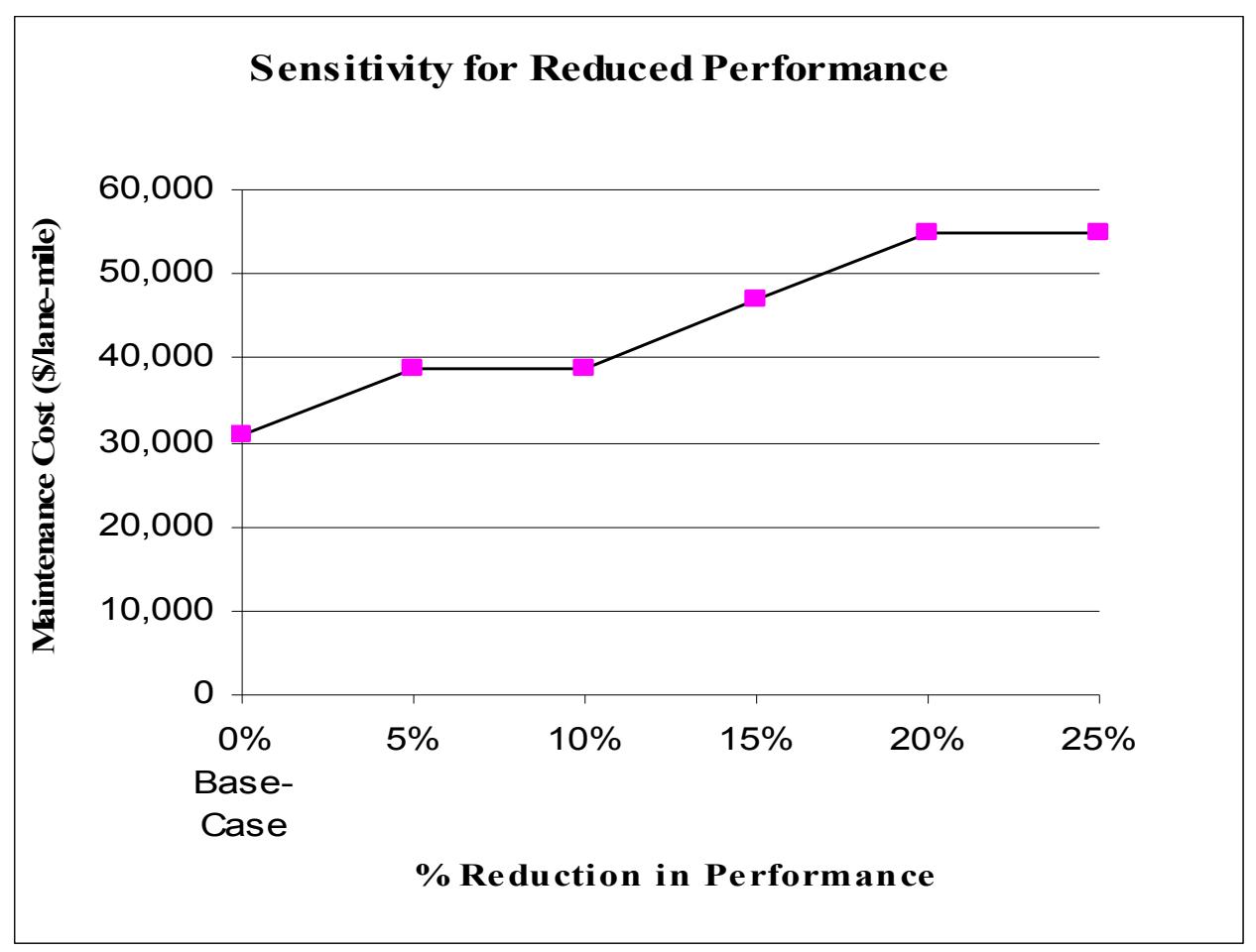

Figure 6.2: Sensitivity for Reduced Performance

\subsubsection{Relaxing a Performance Constraint}

Performance constraints are dictated by highway agencies when the contract is being agreed with contractor. These constraints are sometimes rather restrictive, meaning that the performance requirements are stringent. The consequence of such stringent performance requirement may be that contractor raises the bid amount for such maintenance projects. To better understand the effect of relaxing the performance constraint on the contract cost, sensitivity of maintenance cost with respect to performance constraint is analyzed. For the base case, pavement in Bad condition rating 
(a numerical condition rating of 7 and less) was taken as the trigger value for maintenance work. By relaxing this trigger value to a condition rating of Very Bad (a numerical condition rating of 6 and less), the impact on frequency and the extent of maintenance work is analyzed. Lowering the trigger value to a condition rating of 6 from the base case trigger value of 7 did not have any effect on the total cost of the performance-based contract for this case study. Total estimated cost remained unchanged at $\$ 31,013$.

\subsubsection{Restricting a Performance Constraint}

Restricting a performance constraint to a more stringent performance requirement has just the opposite effect of relaxing the performance constraint. In order to analyze the impact of a more stringent performance constraint, base case trigger condition rating of Bad is raised to Fair condition rating. It is assumed that this necessitates more frequent maintenance actions and this is verified by performing sensitivity analysis.

Increasing the trigger value to a condition rating of 8 as compared to the base case trigger value of 7 increased the maintenance effort greatly and therefore the total estimated cost also increased sharply. This requires a maintenance cost of $\$ 1,535,787$ as compared to the base case of 31,010 .

\subsubsection{Relaxing Proportion of Pavement under Threshold Limit}

Although it was not evident from the standard warranty contracts issued by FDOT, like the contractor guaranteed asphalt pavement contract or the value added asphalt pavement contract, and contracts issued by other state DOTs to what extent of the entire pavement should be above the threshold limit specified, most asset management models specify this allowable percentage. Since it is a very difficult requirement to maintain 
$100 \%$ of the pavement above the specified threshold limit, which is not economically feasible, there should be a leeway in allowing a very small proportion of the pavement below a threshold condition rating. For the base case, pavement in Bad and Very Bad condition state should be less than $10 \%$ of the total pavement length, whereas the pavement in Good and Very Good condition state should be at least $50 \%$ of the whole pavement length considered in the performance-based maintenance contracts.

For sensitivity analysis, the proportion of road allowed in Bad and Very Bad condition state is increased to $15 \%$. The effect of relaxing this performance criterion did not change the total cost when compared with the base case.

\subsubsection{Restricting Proportion of Pavement under Threshold Limit}

Few highway agencies may want to keep the full stretch of the road in near-perfect condition. They will specify so in the contract by allowing only a very small percentage of the pavement in Bad and Very Bad condition. For this sensitivity analysis, the base case proportion of pavement in Bad and Very Bad condition state is reduced to just 5\%. However, proportion of pavement in Good and Very Good condition state should be kept at least $50 \%$ of the total length of the pavement as in the base case.

The effect of reducing the proportion of pavement allowed in Bad and Very Bad condition state to $5 \%$ increases the maintenance effort required to meet the performance criteria, and thus the estimated cost is increased to $\$ 38,914$ from the base case of $\$ 31,013$.

\subsection{Model Validation}

Upon completion of the cost estimation model development, model validation must be performed to check if the results obtained from the model are as expected. Had there 
been other established models with which the results of this model could be compared to, the objective of validation would be achieved. However, in the absence of such acceptable models, model components are validated on an individual basis. However, a qualitative validation of the results from the overall methodology is achieved through expert opinion.

\subsubsection{Component Model Validation}

By breaking down the overall methodology, validation of the model components making up the overall model is performed individually.

\section{Pavement Deterioration Model Validation}

Pavement performance modeling is a very important component of any pavement management system that largely influences the outcomes. By accurately predicting the future pavement performances, pavement maintenance strategies can be planned in advance. In this research, pavement deterioration models were developed for individual distresses — crack, ride, and rut. Validation is done by comparing the future pavement condition rating in Year 2013 projected by the FDOT's Pavement Condition Survey Unit with the condition rating predicted by the deterioration models developed. The reason for comparing the condition rating in Year 2013 is that this is the only year for which the Pavement Condition Survey Unit of FDOT has forecasted the future condition rating. $\underline{\text { Pavement Deterioration for Crack under Routine Maintenance }}$

Figure 6.3 shows the deterioration trend of the pavement with regard to crack distress predicted using the deterioration model developed in this research. In Year 2013, the crack condition rating obtained by using the model is 8.29 , where as the mean value of the crack condition rating forecasted by FDOT for the same year is 8.11 . This result 
shows that the developed crack deterioration model is able to predict future crack condition rating with a reasonable degree of accuracy.

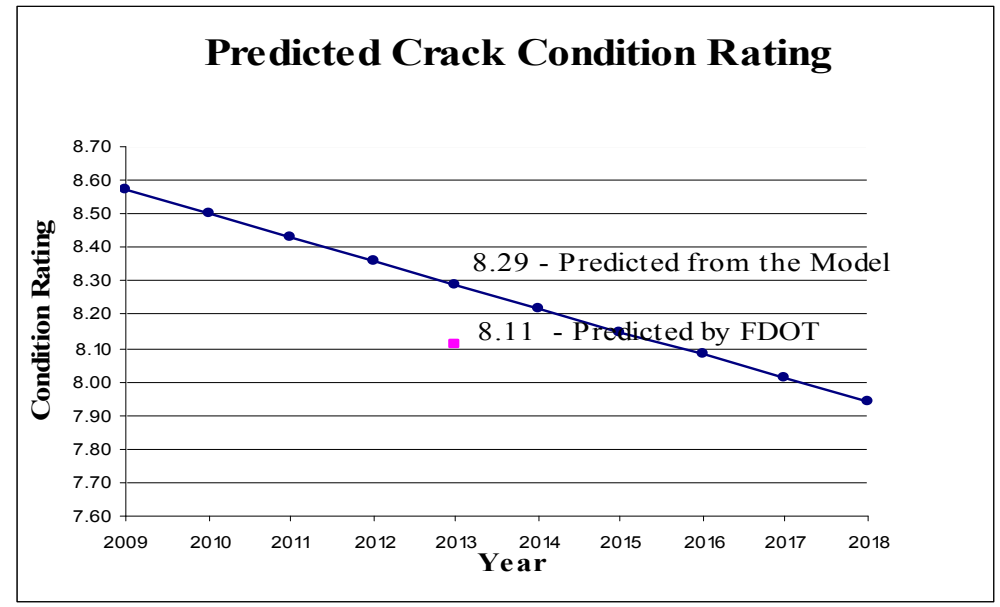

Figure 6.3: Comparison of Predicted Crack Condition Rating

$\underline{\text { Pavement Deterioration for Ride under Routine Maintenance }}$

Figure 6.4 shows a graph comparing the predicted ride condition rating obtained from the model and the one predicted by FDOT for the Year 2013. The results show that the developed model predicted the ride condition rating quite accurately.

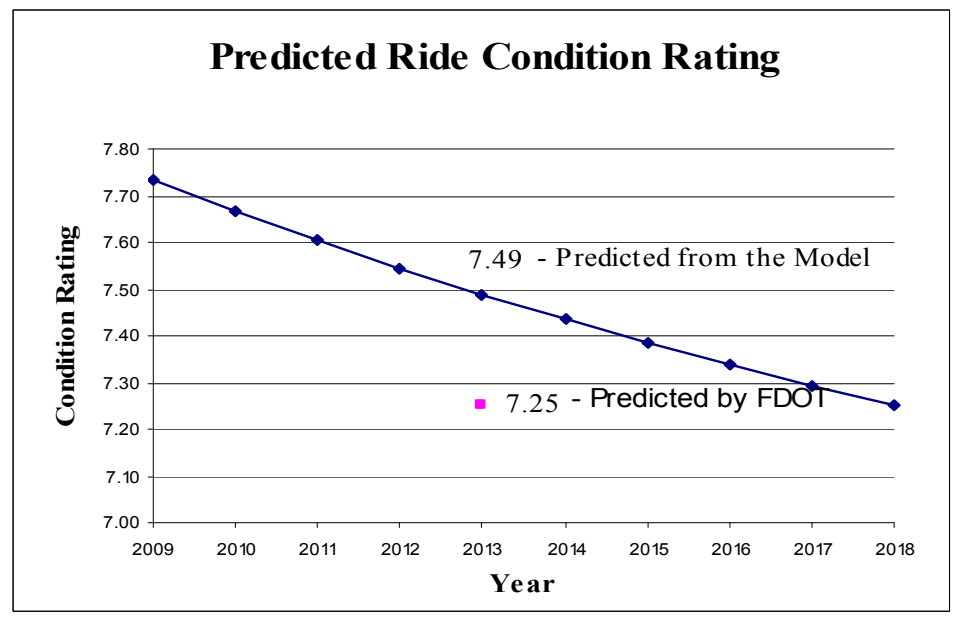

Figure 6.4: Comparison of Predicted Ride Condition Rating 


\section{$\underline{\text { Pavement Deterioration for Rut under Routine Maintenance }}$}

Figure 6.5 compares the rut condition rating value predicted by the model with the average value forecasted by FDOT for Year 2013. It can be seen that there is not much difference in these two values. Therefore, the developed deterioration models can be used with confidence for predicting future pavement condition ratings to determine the pavement maintenance strategies.

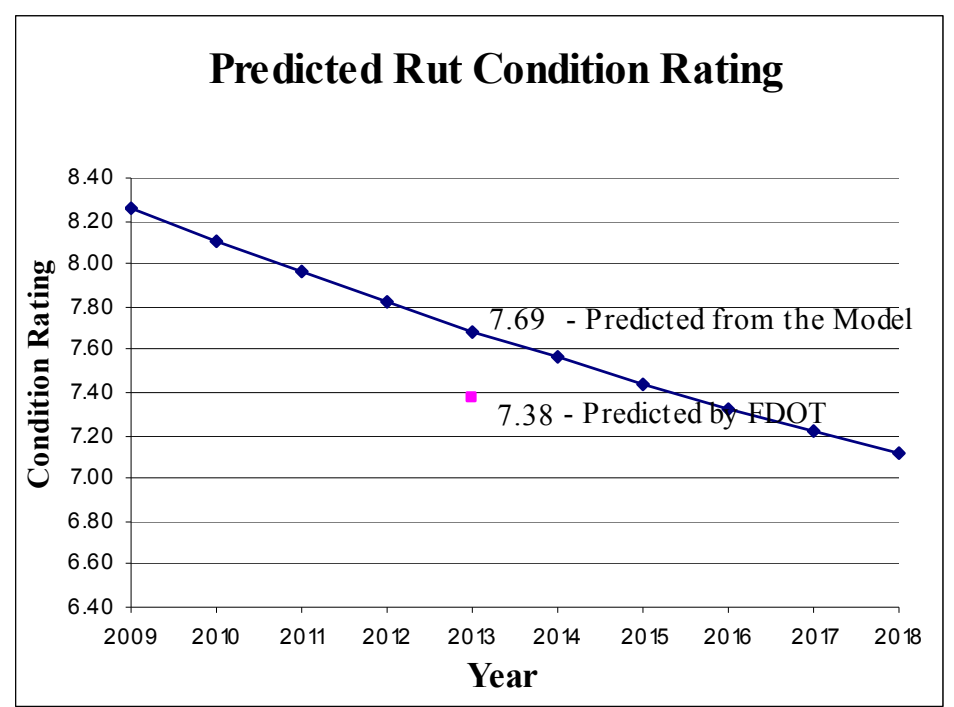

Figure 6.5: Comparison of Predicted Rut Condition Rating

For the pavement improvement models developed in this research, no comparison of the predicted performance jump in condition rating could be done as there were no such forecasts of the future pavement conditions.

\subsubsection{Overall Model Validation}

Validation of the overall model could not be achieved by comparing the results quantitatively. For this to be possible, there should be either well established models available, whose inputs are similar to the ones developed here, or the results obtained 
could be compared with the cost of actual performance-based pavement maintenance projects having similar conditions. In the absence of both of these, it was necessary to do a qualitative evaluation of the overall methodology. Expert opinions have been utilized heavily in the construction research in the past to validate the model with respect to the ability of the model to replicate the actual process as closely as possible, and the same technique has been adopted in this research. For this study, expert groups comprised people from Miami Dade Expressways Authority (representing Highway Agency), Transfield Services, Inc. (representing contractor) and Florida's Turnpike Enterprise. They were asked to comment on the utility and accuracy of the model, and the ease with which this model could be applied in performance-based pavement maintenance contracts with little or no modifications. Maintenance Engineers and Managers, which formed the expert group from Miami Dade Expressways Authority and the Transfield Services, Inc., that manage the pavement sections taken as case study opined that the need for such a methodology was quite high. The feedback obtained from them verified that the estimated cost obtained from the methodology was quite reasonable. Maintenance officials from Miami Dade Expressways Authority agreed that the low estimated maintenance cost of the Dolphin Expressways taken as the case study could be attributed to the very good existing condition of this pavement section. Only routine and minor maintenance works were required for the entire contract period.

\subsection{Conclusion}

The effect of changing the input values on the result of the model is studied through sensitivity analysis. It is quite obvious to see that the increase in deterioration rate of the pavement (reduction in pavement performance) increases the maintenance effort required 
and thus the total estimated cost to meet the performance requirement. Decrease in the deterioration rate (increase in pavement performance) on the other hand, reduces the maintenance effort and the total cost required. Allowing only $5 \%$ of the total pavement section to remain in Bad and Very Bad condition rating as compared to $10 \%$ for the base case increases the maintenance effort and thus, the total cost to achieve the performance requirement. Relaxing this performance criterion to $15 \%$, however, does not affect the total cost required to achieve this change in performance requirement. Pavement condition rating of 7 was assumed to be the threshold performance limit for all distress indicators. However, when this performance threshold value was relaxed to a condition rating of only 6 (as compared to a base case of 7), there was no change in the maintenance effort required. However, by imposing stricter performance rating of 8 , the maintenance effort was tremendously increased. This increased the total cost drastically. By performing a component validation of the pavement deterioration model, it was found that the developed deterioration model forecasted the future pavement condition rating with a reasonable accuracy. Expert opinion verified that the developed model satisfactorily fulfilled its purpose of estimating the total cost of performance-based pavement maintenance contracts. 


\section{CHAPTER 7}

\section{RESEARCH SUMMARY, RESEARCH LIMITATIONS AND RECOMMENDATIONS FOR FUTURE RESEARCH}

\subsection{Research Summary and Conclusions}

There is a gradual switch from method-based contracts to performance-based contracts for highway maintenance projects as the latter have proved to be a promising means of reducing the asset management cost. Unlike the cost estimation process in method-based contracts where the quantity of work is defined, cost estimation of performance-based contracts requires relating cost to performance. Linking performance to cost is often difficult, and it is this difficulty and uncertainty that makes the contractors more concerned about using the performance-based contracting in their future work. An extensive literature search conducted in this research found no similar works that linked performance with the cost of these performance-based pavement maintenance contracts. In order to assist the contractors as well as the highway agencies to provide a scientific approach to relate cost to the performance, a methodological framework was developed in this research. Pavement failure, which is decided by multiple factors including distress indicators and threshold values specified in the performance-based contracts, and the pavement deterioration which has strong stochastic characteristics, were all taken into account when developing this methodology. Markov Chain theory, characterized by transition probabilities, is applied to evaluate pavement failure probability caused by multiple distresses. Pavement deterioration process, described by transition probabilities, is easily derived from historical pavement performance data to predict future pavement failures with respect to different distress indicators. 
The described approach has several advantages over the previous methods. The foremost advantage is that all possible failures due to multiple distresses that are normally included in the performance/warranty contracts are considered, thereby making the method applicable to long term highway performance contracts. Moreover, the failure probability models were developed from real in-service pavement performance and practical performance/warranty contracts. Thus, its applicability for such contracts is very high. With slight modification on distress threshold values and other inputs such as the length of the contract, the method could be applied to other performance/warranty projects. The developed methodology provides greater flexibility, and is adaptable to various pavement performances and warranty specifications.

The development of the overall model involved various steps summarized here:

- A procedure to generate transition probability matrices to represent pavement deterioration in terms of three distinct distress indicators- crack, ride, and rut from pavement condition rating data was described.

- Transition probability matrices to represent pavement improvement in terms of crack, ride, and rut due to the effects of maintenance treatments were developed from in-service pavement condition rating data (when such data was available). When such data was not available, transition probability matrices for pavement improvement were derived from similar studies that had recorded the effects of maintenance activity on the performance rating.

- Relating cost to pavement performance was achieved by scheduling maintenance activities such that the minimum performance criteria were 
- Any impact on the total cost of achieving the required minimum performance criteria was investigated by changing the model inputs (sensitivity analysis).

The framework has been validated using a case study of Miami Dade Expressways. The case study presented a sample run of the performance-based cost estimation methodology, including all input values from the performance-based contracts. Miami Dade Expressways Authority, which is a state sanctioned, locally administered public agency mandated to manage Miami Dade Expressways, lets these assets to contractors for management for certain number of years on a performance basis. It was learned from the conversations with the maintenance manager from MDX that currently they have no such frameworks to assist them with the cost estimation of future maintenance predictions. In fact, any major works (other than routine maintenance) were let to the individual contractors on a fixed amount method-based contract. Other roadways and roadside management work that included only routine maintenance was awarded to Transfield Services on a Performance-based contract. The success of letting these long term maintenance work on a performance basis largely depends on the use of robust cost estimation methodology appropriate for such contracts, such as the one presented in the dissertation.

From the results, it is seen that performance requirements throughout the length of the contract period are met by employing only routine and minor maintenance strategies. This is because of the fact that pavements under the Miami Dade Expressways, including 
the SR-836 (Dolphin Expressway) have been kept in a very good condition until now and there was very little deterioration of the pavement in the Year 2008. Since future pavement condition predictions in the case study were based on the condition state in the Year 2008, there were only few pavement sections that were below the performance threshold and therefore, required only minor treatments. This fact corroborated with the opinion of the MDX maintenance manager who confirmed that there was little or no major maintenance activity required for majority of the Dolphin Expressway.

The results of the developed model showed that the model is very responsive to even slight changes in deterioration rate and the performance constraints. Therefore, if the contractors foresee a poorer pavement performance due to any of the pavement deteriorating factors unaccounted by the past pavement condition rating data, a higher cost risk premium should be factored in their bids. Unnecessary tighter performance constraints that do not add much value to the overall pavement performance should be avoided by the highway agencies in the performance-based contracts, as the results of the model point out that a slight change in the performance threshold values drastically influences the total estimated cost.

\subsection{Research Contributions}

The emergence of innovative contract mechanism, such as the performance-based maintenance contracts, especially in pavement management, has made it necessary to estimate cost based on performance criteria as opposed to the material-and method-based cost estimating in traditional contracts. At present, there are no frameworks or models available to highway agencies as well as the contractors, which provide methodologies to estimate the cost of these performance-based contracts with multiple performance 
criteria. The developed methodological framework will greatly assist the contractors as well as the highway agencies to model the pavement performance, and above all to estimate the cost associated with maintaining the pavement at the required minimum level of service for the entire duration of the contract period. This is achieved by developing probabilistic performance models from the historical pavement performance data that predict failure probabilities for multiple performance indicators. This problem is important for warranty/performance contracts that specify multiple failure criteria for different distress indicators, such as crack, roughness and rut, among others.

While developing an overall cost estimation methodology, it was required to model the effects of maintenance on the pavement performance. Although the author of this dissertation was aware of the existence of different empirical and mathematical expressions to characterize the performance jump, the author did not find literatures that described the probabilistic model for these performance jumps. Transition probabilities were derived using the historical pavement condition data to represent performance jump as a result of different M\&R activities in this dissertation. This is a novel contribution of this research in the area of pavement management system.

\subsection{Research Limitations and Future Research}

Due to the limitation of availability of performance data, the effect of only few maintenance actions on the pavement performance could be studied. Pavement condition rating survey obtained from FDOT, which were the basis of generating pavement performance model in this research, did not keep a record of maintenance actions other than resurfacing and reconstruction. As a result, maintenance strategies that were considered in pavement performance modeling were only few. Involving a more 
comprehensive maintenance and rehabilitations options with an established performance improvement record would make the output of the model more precise besides offering the contractors with a larger array of maintenance actions to choose from.

The effects of maintenance on deterioration processes were limited to only few maintenance strategies namely, minor maintenance, major maintenance, and reconstruction. Although the developed performance models are capable of differentiating between the effects of minor maintenance, major maintenance, and reconstruction, still they are not sensitive enough to differentiate the effects of different repair actions within each maintenance category. For example, subtle effect of seal coat and fog seals on the pavement performance would not be differentiated by the developed model. Future endeavors may be directed on developing the effects of different maintenance actions on the pavement performance so that more number of maintenance strategies may be used.

For the network of asphalt pavements in Miami Dade Expressways, percentage of trucks varied from $1.5 \%$ to $13.7 \%$. SR-878 had the lowest in the network with only $1.5 \%$ of trucks, whereas SR 112 had the highest in the network with 13.7\% of trucks. Weighted average percentage of trucks for the entire MDX network was 5.7\%. The analysis in this dissertation was for weighted average value taken from the entire network. In order to forecast the deterioration rate of asphalt pavements more accurately, analysis of state roads in the Miami Dade Expressways network should be done separately so that the unique effects of various pavement deterioration factors, including the percentage of trucks, are given due consideration. Deterioration models based on these factors will provide a better representation of the actual deterioration process that is so unique to each 
section of the pavement network. However, a more generalized approach based on the average percentage of trucks for the entire Miami Dade Expressway network was adopted in this research due to lack of sufficient pavement condition rating data in different categories of percentage of trucks to generate reliable transition probability matrix to represent the pavement deterioration process.

The unit cost of maintenance (dollar per lane-mile) used in estimating the total cost are the average or expected cost which are by no means precise. There is some probability distribution associated with these unit costs, which in this dissertation was assumed to be a normal distribution. The result of this assumption is that there is no specific deterministic total estimated cost but a range of costs with different probability of occurrence. Future research could be directed towards finding an optimal bidding price the contractor should submit given its risk tolerance and the probability distribution associated with the expected cost of a long term pavement maintenance contract.

Different states use different system of rating pavement conditions. While FDOT uses a condition rating scale of 1-10, other states may use a different scale such as $0-5,0-100$, etc. Adding to the complexity, performance-based contracts or warranty contracts may not necessarily be specified so as to conform to the scales adopted by state DOTs, as was the case with the condition rating scale adopted by the FDOT and the standard Contractor Guaranteed Asphalt Pavement specifications issued by FDOT. In such circumstances, it becomes difficult to convert the condition rating scale to match that of the scale required for performance-based contracts. It is therefore recommended that the performance-based contracts should be written such that it is easy to measure the performance outputs, and 
performance rating scales used should conform to the performance measures and scales adopted by state DOTs.

User costs, which include cost due to accidents, user delay, and excess vehicle operating cost, were not taken into consideration while calculating the unit cost of maintenance actions. This is because there is no single widely accepted method of evaluating the user cost. Determination of appropriate user cost in itself is a big task which requires an in depth research. However, if widely accepted user cost methods and their values are available, then user cost can also be incorporated in the unit cost that is used in this dissertation.

Although the developed methodology is capable of selecting optimal maintenance strategies based on input provided by the user, no such program was developed in this dissertation that could actually generate output based on logical flow chart presented. Instead, the cost calculations were performed in Excel spreadsheets without using the logical expressions, such as IF, THEN, etc. It is recommended that a program be developed using such logical expressions to represent the flowchart so that the total estimated cost (output) is obtained from minimal user inputs. A Visual Basic Program in combination with Microsoft Excel application can be employed in the future. 


\section{REFERENCES}

ASCE (2009). “2009 Progress Report for America’s Infrastructure.” Online at http://www.infrastructurereportcard.org/. Accessed on October 2, 2009.

Anderson, S. D., and Russell, J. S. (2001). "Guidelines for Warranty, Multi-parameter, and Best Value Contracting”, NCHRP Report 451, National Research Council, Washington, D.C.

Ayyub, B.M. (2003). Risk Analysis in Engineering and Economics. Chapman and $\mathrm{Hall} / \mathrm{CRC}$.

Bayraktar, M.E., Cui, Q., Hastak, M., and Minkarah, I. (2004). "State-of-Practice of Warranty Contracting in the United States." Journal of Infrastructure Systems, ASCE, 10(2), 60-68.

Bulusu, S. and Sinha, K.C. (1997). "Comparison of Methodologies to Predict Bridge Deterioration." Transportation Research Record 1597, Transportation Research BoardNational Research Council, 34-42.

Butt, A.A., Shahin, M.Y., Feighan, K.J. and Carpenter, S.H. (1987). "Pavement Performance Prediction Model Using the Markov Process." Transportation Research Record 1123, Transportation Research Board, 12-19.

Butt, A.A., Shahin, M.Y., Carpenter, S.H. and Carnahan, J.V. (1994), “Application of Markov Process to Pavement Management Systems at Network Level." Proceedings of the Third International Conference on Managing Pavements, Transportation Research Board- National Research Council, 89-100.

Collucci Rios, B., and Sinha, K. C. (1985). ' 'Optimal Pavement Management Approach Using Roughness Measurements.' Transportation Research Record 1048, Transportation Research Board, National Research Council, 13-18.

Cook, W. D., and Lytton, R. I. (1987) "Recent Developments and Potential Future Developments in Ranking and Optimization Procedures for Pavement Management." Proceedings of $2^{\text {nd }}$ North American Conference on Managing Pavements, Ministry of Transportation, Ontario, (2), 2.135-2.155.

Cui, Q., Johnson, P.W., and Sees, E. (2008). “Long Term Warranties on Highway Projects.” UTCA Report Number 06109, University Transportation Center for Alabama.

Damnjanovic, I. (2006). "A Risk-based Approach to Modeling Life-cycle Costs Associated with Warranty Specifications for Transportation Infrastructure," Ph.D. dissertation, University of Texas at Austin, Texas, USA. 
Emery, S.J. (2000) "Improved Construction Practices: Pavement Performance Evaluation as an Input to Stochastic Asset Management." Proceedings of $1^{\text {st }}$ Conference on World of Asphalt Pavements, Sydney.

FDOT (Florida Department of Transportation). (2009). Plans Preparation Manual, Volume 1.

FHWA (Federal Highway Administration). (1990). "An Advanced Course in Pavement Management.' Washington, D.C.

FHWA (Federal Highway Administration). (2002). Analysis of PMS Data for Engineering Applications-Reference Manual., FHWA, Washington, D.C.

FHWA (Federal Highway Administration). (2003). Asphalt Pavement Warranties Technology and Practice in Europe, Report FHWA-PL-04-002, FHWA, Washington, D.C.

Gallagher, P., and Mangan, D. (1998). "Risk Issues in Performance-Specified Flexible Paving Contracts." Proceedings of 19th Conference of the Australian Road Research Board Transport, 361-370.

Garcia, J.J., Costello S.B., and Snaith, M.S. (2006). "Derivation of Transition Probability Matrices for Pavement Deterioration Modeling." ASCE Journal of Transportation Engineering. 132(2)141-161.

Garza, J.M., Pinero, J.C., Ozbek, M.E. (2008). "Sampling Procedure for PerformanceBased Road Maintenance Evaluations.” Transportation Research Record 2044, Transportation Research Board, National Research Council, 11-18.

Golabi, K., Kulkarni, R., and Way, G. (1982). “A Statewide Pavement Management System.”Interfaces, 12, 5-21.

Haas, R., Hudson, W, R., and Zniewski, J. (1994). Modern Pavement Management, Krieger Publishing Company, Malabar, Florida.

Jiang, Y., Saito, M. and Sinha, K.C. (1988). "Bridge Performance Model Using the Markov Chain.” Transportation Research Record 1180, Transportation Research Board, National Research Council, 939-46.

Kazakov, A., and Cook,W. D. (1988). "Risk Considerations in Financial Planning for Pavement Rehabilitation." Transportation Research Record 1200, Transportation Research Board, National Research Council, 11-18.

Keir, M., and Blerk, G.V. (2006). "A Preview of the Performance Specified Maintenance Contract (PSMC) Model Using a Case Study of MSMC 001." Proceedings of the NZIHT Annual Conference, Auckland. Online at 
http://www.transit.govt.nz/content_files/conference/M-Keir.pdf. Accessed on July 12, 2008.

Kostuk, K.J. (2003). Quantifying the Uncertainty Associated with Long Term Maintenance Contracts. Ph.D. Dissertation, University of Saskatchewan, Saskatoon, Canada.

Labi, S., and Sinha, K.C. (2004). "Effectiveness of Highway Pavement Seal Coating Treatments." ASCE Journal of Transportation Engineering, 130(1) 14-23.

Lamptey, G., Ahmad, M., Labi, S., and Sinha, K.C. (2005). Life Cycle Cost Analysis for INDOT Pavement Design Procedures. Final Report FHWA/IN/JTRP-2004/28. Purdue University, Lafayette, Indiana.

Liautaud, G. 2004. Maintaining Roads: Experience with Output-based Contracts in Argentina. World Bank Report.

Lytton, R. L. (1987). "Concepts of Pavement Performance Prediction and Modeling." Proceedings of $2^{\text {nd }}$ North American Conference on Managing Pavements, Public Roads, Toronto., Vol. 2.

Madanat, S., Mishalami, R., and Ibrahim, W.H. (1995). "Estimation of Infrastructure Transition Probabilities from Condition Rating Data." Journal of Infrastructure Systems, ASCE, 1(2) 120-5.

Mahoney, J. (1990). "Introduction to Prediction Models and Performance Curves." Course Text, FHWA Advanced Course on Pavement Management.

Mbwana, J. R.. (1993). A Decision Support System for Pavement Management. Ph.D. Dissertation . Cornell University.

Mbwana, J. R., and Turnquist M. A. (1996). "Optimization Modeling for an Enhanced Network-Level Pavement Management System." Transportation Research Record 1524, Transportation Research Board, National Research Council, 76-85.

Morcous,G., Lounis Z., and Mirza, M.S. (2002). "Life-Cycle Assessment of Highway Bridges." Proceedings of the Taiwan-Canada Workshop on Bridges, April 8-9, 61-62.

Morcous, G., and Lounis, Z. (2005). "Maintenance Optimization of Infrastructure Networks Using Genetic Algorithms." Journal of Automation in Construction, 14(2005) 129-142.

Moynihan, G., Zhou, H., and Cui, Q., (2009) "Stochastic Modeling for Pavement Warranty Cost Estimation." ASCE Journal of Construction Engineering and Management, 135(5) 352-359. 
Owen, M. (2000). Managing the Risk in a New Performance-based Environment, Technical Report of Transit New Zealand. Wellington. Online at http://www.transit.govt.nz. Accessed on July 12, 2008.

Ozbek, M.E. (2004). Development of Performance Warranties for Performance-based Road Maintenance Contracts, Masters Thesis, Virginia Polytechnic Institute and State University, Blacksburg.

Ozbek, M.E. (2007). Development of a Comprehensive Framework for the Efficiency Measurement of Road Maintenance Strategies using Data Envelopment Analysis, Ph.D. Dissertation, Virginia Polytechnic Institute and State University, Blacksburg.

Parkman, C., Hallet, J., Henning, T., and Tapper, M. (2003). "Pavement Deterioration Modelling in Long Term Performance-based Contracts: How Far Does it Mitigate the Risk for Client and Contractor?" Proceedings of the Twenty First ARRB and REAAA Conference, Cairns, New Zealand. Online at http://www.transit.govt.nz/content_files/news/ConferencePaper34_PDFFile.pdf. Accessed on July 12, 2008.

Pinero, J.C. (2003). A Framework for Monitoring Performance-Based Road Maintenance, Ph.D. Dissertation, Virginia Polytechnic Institute and State University, Blacksburg.

Prozzi, J. A., and Madanat, S. M. (2000). "Using Duration Model to Analyze Experimental Pavement Failure Data.” Transportation Research Record 1699, Transportation Research Board, National Research Council, 87-94.

Queiroz, C. (1999). "Contractual Procedures to Involve the Private Sector in Road Maintenance and Rehabilitation." Transportation Sector Familiarization Program. Online at http://www.worldbank.org/transport/roads/c\&m_docs/ts_499.pdf. Accessed on October 12, 2008.

Rajagopal, A. S., and George, K. P. (1991). "Pavement Maintenance Effectiveness." Transportation Research Record 1276, Transportation Research Board, National Research Council, 62-66.

Stankevich, N., Qureshi, N., Queiroz, C. (2005). "Performance-based Contracting for Preservation and Improvement of Road Assets." Transport Note No. TN-27. The World Bank, Washington, D.C.

Smith, R., Freeman, T., and Pendleton, O. (1993). “Pavement Maintenance Effectiveness.' Strategic Highway Research Program, National Research Council, Washington, D.C.

Transportation Research Board (TRB). (2008). Research Needs Statements. Online at http://rns.trb.org/dproject.asp?n=17080. Accessed on February 05, 2009. 
Transportation Research Circular (TRC) E-C098. (2006). Presentations from the 11th AASHTO- TRB Maintenance Management Conference, July 16-20, Charleston, South Carolina.

Wang, K. C. P., Zaniewski, J., and Way, G. (1994) "Probabilistic Behavior of Pavements." ASCE Journal of Transportation Engineering, 120(3), 358-374.

Winfrey, R. (1967). "Statistical Analysis of Industrial Property Retirements." Revised by H A Cowles.

Wirahadikusumah, R., and Abraham D.M. (2003). "Application of Dynamic Programming and Simulation for Sewer Management." Engineering, Construction and Architectural Management, 10(3) 193-208.

World Bank (2005). "Sample Bidding Document: Output- and Performance-based Road Contract (OPRC)." Online at http://www.worldbank.org/procure/. Accessed on August 2, 2008.

World Bank (2005). "Performance-based Contracting for Preservation and Improvement of Road Assets." Transport Note No. 27. Washington, D.C. Online at http://www.worldbank.org/transport/roads/resource-guide/Docslatest\%20edition/PBC/trn_27_PBC_Eng_final_2005.pdf. Accessed on July 7, 2008.

Zayed, T.M. , and Chang, L.M. (2002). "A Prototype Model for Build Operate Transfer (BOT) Risk Assessment." ASCE Journal of Management in Engineering, 18(1) 7-16.

Zietlow, G.J., and Bull, A. (1999). "Performance Specified Road Maintenance ContractsThe Road to the Future in Latin American Perspective." Proceedings of the Twenty First World Congress, Kuala Lumpur. Online at http://www.zietlow.com/docs/Psmce.htm. Accessed on July 7, 2008.

Zietlow, G.J. (2004). "Implementing Performance-based Road Management and Maintenance Contracts in Developing Countries - An Instrument of German Technical Cooperation." Online at http://www.zietlow.com/docs/PBMMC-GTZ.pdf. Accessed on July 7, 2008. 
APPENDIX A

CONTRACTOR GUARANTEED ASPHALT PAVEMENT CONTRACT (VALUE ADDED ASPHALT PAVEMENT) 


\section{VALUE ADDED ASPHALT PAVEMENT (CONTRACTOR GUARANTEED ASPHALT PAVEMENT CONTRACT-FDOT) \\ 338 VALUE ADDED ASPHALT PAVEMENT \\ (REV 12-26-06) (FA 2-5-07) (7-07)}

\section{SECTION 338 \\ VALUE ADDED ASPHALT PAVEMENT}

\section{8-1 Description.}

Construct Value Added Asphalt Pavement consisting of Asphalt Concrete Structural Course and Asphalt Concrete Friction Course, subject to a three year warranty period. For purposes of this Specification, Warranty" shall mean the Responsible Party, as designated herein, is responsible for performance of the Value Added Asphalt Pavement for a period of three years after final acceptance of the Contract in accordance with 5-11, including continued responsibility for performing all remedial work associated with pavement distresses exceeding threshold values determined in accordance with 338-5, and as to which notice was provided to the Responsible Party within the three-year warranty period.

The work specified in this Section will not be paid for directly, but will be considered as incidental to other asphalt pay items.

\section{8-2 Materials and Construction Requirements.}

Meet the requirements of the following:

Hot Bituminous Mixtures - Plant, Methods and

Equipment ..................................................Section 320

Hot Bituminous Mixtures - General Construction

Requirements .................................................Section 330

Superpave Asphalt Concrete............................Section 334

Asphalt Concrete Friction Courses ....................Section 337

\section{8-3 Responsible Party.}

Prior to any Value Added Asphalt Pavement being placed on the project, the Contractor shall designate a Responsible Party to accept responsibility for maintaining the Value Added Asphalt Pavement, when remedial work is required. When the scope of the asphalt work is only milling and resurfacing, and there is no construction of the embankment, subgrade or base below the pavement included in the Contract, the Responsible Party may be either the Contractor or the Department approved subcontractor performing the Value Added Asphalt Pavement work. When the construction of the embankment, subgrade or base below the pavement is included in the Contract, in addition to the construction of the Asphalt Concrete Structural Course and Asphalt Concrete Friction Course, the Contractor shall be considered as the Responsible Party. 
When the Responsible Party is a subcontractor, the subcontractor must be prequalified with the Department in the category of asphalt, and such designation must be made to the Department by the Contractor. The proposed subcontractor must execute and deliver to the Department a form, provided by the Department, prior to or concurrent with the Contractor's request to sublet any Value Added Asphalt Pavement work, stipulating that the subcontractor assumes all responsibility as the Responsible Party for the Value Added Asphalt Pavement within the three-year warranty period. Failure to timely designate the Responsible Party will result in the Contractor being the Responsible Party unless otherwise agreed to in writing by the Department.

Upon final acceptance of the Contract in accordance with 5-11, the Contractor's responsibility for maintenance of all the work or facilities within the project limits of the Contract will terminate in accordance with 5-11; with the sole exception that the obligations set forth in this Section for Value Added Asphalt Pavement will continue thereafter to be the responsibility of the Responsible Party as otherwise provided in this Section.

\section{8-4 Statewide Disputes Review Board.}

The Statewide Disputes Review Board in effect for this Contract will resolve any and all disputes that may arise involving administration and enforcement of this Specification. The Responsible Party and the Department acknowledge that use of the Statewide Disputes Review Board is required, and the determinations of the Statewide Disputes Review Board for disputes arising out of this Specification will be binding on both the Responsible Party and the Department, with no right of appeal by either party.

Meet the requirements of 8-3.

\section{8-5 Pavement Evaluation and Remedial Work.}

338-5.1 General: The Department's Flexible Pavement Condition Survey Program, along with observations by the Engineer, will be used as the basis for determining the extent and the magnitude of the pavement distresses occurring on the project. The Department will continuously monitor the pavement and may require remedial action at any time. For evaluation purposes, the project will be subdivided into LOTs of 0.1 mile per lane. When the segment is less than 0.1 mile, the segment will be called a partial LOT. The Department may conduct a Pavement Condition Survey of the value added pavement following the final acceptance of the project, and at intermediate times throughout the warranty period. The final survey, if determined by the Engineer to be necessary, will be conducted no later than 45 calendar days before the end of warranty period. The Department will be responsible for all costs associated with the surveys.

The Responsible Party will be advised if/when the Department believes remedial action is required. If the survey findings, intermediate or final, are to be disputed by the Responsible Party, written notification must be provided to the Engineer within 30 calendar days of the date of receipt of the survey. During the warranty period, the Responsible Party may monitor the project using nondestructive procedures. The 
Responsible Party shall not conduct any coring, milling or other destructive procedures without prior approval by the Engineer.

338-5.2 Category 1 Pavement: For purposes of this Specification, "Category 1

Pavement" is defined as mainline roadways, access roads and frontage roads with a design speed $50 \mathrm{mph}$ and greater.

Threshold values and associated remedial work for Category 1 Value Added Asphalt Pavement are specified in Table 3381.

\begin{tabular}{|c|c|c|c|}
\hline \multicolumn{4}{|c|}{$\begin{array}{c}\text { TABLE 338-1 } \\
\text { Category } 1 \text { Pavements }\end{array}$} \\
\hline Type of Distress & $\begin{array}{l}\text { Type of } \\
\text { Survey }\end{array}$ & $\begin{array}{l}\text { Threshold Values } \\
\text { for Each LOT ( } 0.1 \\
\text { Mile) per Lane. }\end{array}$ & Remedial Work \\
\hline \multirow{2}{*}{ Rutting (1) } & \multirow{2}{*}{ Any Survey } & Depth $\leq 0.25$ inch & None required \\
\hline & & Depth $>0.25$ inch & $\begin{array}{l}\text { Remove and replace } \\
\text { the distressed } \\
\text { LOT(s) to the full } \\
\text { depth of all layers, } \\
\text { and to the full lane } \\
\text { width (2) }\end{array}$ \\
\hline Ride (3) & Any Survey & $\mathrm{RN}<3.5$ & $\begin{array}{l}\text { Remove and replace } \\
\text { the friction } \\
\text { course for the full } \\
\text { length and the full } \\
\text { lane width of the } \\
\text { distressed LOT(s) }\end{array}$ \\
\hline Settlement/Depression(3A) & Any Survey & Depth $\geq 1 / 2$ inch & $\begin{array}{l}\text { Propose the method of } \\
\text { correction to } \\
\text { the Engineer for } \\
\text { approval prior to } \\
\text { beginning remedial } \\
\text { work }\end{array}$ \\
\hline Cracking (4) & Any Survey & $\begin{array}{l}\text { Cumulative length } \\
\text { of cracking }> \\
30 \text { feet for Cracks } \\
> \\
1 / 8 \text { inch }\end{array}$ & $\begin{array}{l}\text { Remove and replace } \\
\text { the distressed } \\
\text { LOT(s) to the full } \\
\text { depth of all layers, } \\
\text { and to the full lane } \\
\text { width (5) }\end{array}$ \\
\hline $\begin{array}{l}\text { Raveling and/or end } \\
\text { Delamination affecting } \\
\text { the Friction Course (6) }\end{array}$ & Any Survey & $\begin{array}{l}\text { Individual length } \\
\geq 10 \text { feet. }\end{array}$ & $\begin{array}{l}\text { Remove and replace } \\
\text { the distressed } \\
\text { area(s) to the full } \\
\text { distressed depth }\end{array}$ \\
\hline
\end{tabular}




\begin{tabular}{|c|c|c|c|}
\hline & & & $\begin{array}{l}\text { and the full lane width, } \\
\text { for the full } \\
\text { distressed length plus } \\
50 \text { ' on each } \\
\text { end }\end{array}$ \\
\hline & & $\begin{array}{l}\text { Individual length }< \\
10 \text { feet. }\end{array}$ & $\begin{array}{l}\text { Patch the distressed } \\
\text { area(s) to the } \\
\text { full distressed depth } \\
\text { and to a } \\
\text { minimum surface area } \\
\text { of } 150 \% \text { of } \\
\text { each distressed area, } \\
\text { subject to } \\
\text { performance at final } \\
\text { survey (7) }\end{array}$ \\
\hline $\begin{array}{l}\text { Pot holes and Slippage } \\
\text { Area(s) (6) }\end{array}$ & Any Survey & $\begin{array}{l}\text { Observation by } \\
\text { Engineer }\end{array}$ & $\begin{array}{l}\text { Remove and replace } \\
\text { the distressed } \\
\text { area(s) to the full } \\
\text { distressed depth, } \\
\text { and to a minimum } \\
\text { surface area of } \\
150 \% \text { of each } \\
\text { distressed area OR } \\
\text { temporarily patch the } \\
\text { distressed } \\
\text { area(s) AND, prior to } \\
\text { the final } \\
\text { survey, remove and } \\
\text { replace the } \\
\text { distressed area(s) to } \\
\text { the full } \\
\text { distressed depth, and } \\
\text { to a minimum } \\
\text { surface area of } 150 \% \\
\text { of each } \\
\text { distressed area }\end{array}$ \\
\hline Bleeding (8) & Any Survey & $\begin{array}{l}\text { Loss of surface } \\
\text { texture due to } \\
\text { excess asphalt, } \\
\text { individual length } \\
\geq 10 \text { feet and } \\
\geq 1 \text { foot. in width. }\end{array}$ & $\begin{array}{l}\text { Remove and replace } \\
\text { the distressed } \\
\text { area(s) to the full } \\
\text { distressed depth, } \\
\text { and to a minimum } \\
\text { surface area of } \\
150 \% \text { of each } \\
\text { distressed area }\end{array}$ \\
\hline
\end{tabular}


(1) Rutting: Rut depth to be determined by Laser Profiler in accordance with the Flexible Pavement Condition Survey Handbook.

For any LOT that cannot be surveyed by Laser Profiler, rut depth to be determined manually in accordance with the Flexible Pavement Condition Survey Handbook, with the exception that the number of readings per LOT will be one every 50 feet. For a partial LOT, a minimum of three measurements not exceeding 50 feet apart will be made. When the average of the measurements by manual straightedge exceeds a 0.30 inch threshold value, the remedial work is needed. (2) Remedial Work for Rutting: The Contractor may propose removal and replacement of less than the full depth of all layers by preparation and submittal of a signed and sealed engineering analysis report, demonstrating the actual extent of the distressed area(s). Remedial work must be performed in accordance with Table 338-1 unless the Engineer approves the proposal.

(3) Ride: Ride Number (RN) to be established by Laser Profiler in accordance with FM 5-549. As a condition of project final acceptance in accordance with 5-11, correct all deficiencies in accordance with acceptance criteria for pavement smoothness in accordance with 330-12.6.

(3a)Settlement/Depression: Depth of the settlement/depression to be determined by a 6 foot manual straightedge. (4) Cracking: Beginning and ending of 1/8 inch cracking will be determined as the average of three measurements taken at one foot intervals. The longitudinal construction joint at the lane line will not be considered as a crack. (5) Remedial Work for Cracking: The Contractor may propose removal and replacement of less than the full depth of all layers by

preparation and submittal of a signed and sealed engineering analysis report, demonstrating the actual extent of the distressed area(s). Remedial work must be performed in accordance with Table 338-1 unless the Engineer approves the proposal.

(6) Raveling, Delamination, Pot holes, Slippage: As defined and determined by the Engineer in accordance with the examples displayed at the following URL: www.dot.state.fl.us/specificationsoffice/pavement.htm

(7) Patched Areas: At the time of final survey, patched areas must be performing to the satisfaction of the Engineer. If the Engineer determines patched areas are not performing satisfactorily, remove and replace the distressed area(s) to the full distressed depth, and to a minimum surface area of $150 \%$ of each distressed area.

(8) Bleeding: Bleeding to be determined as defined and determined by the Engineer in accordance with the examples displayed at the following URL: www.dot.state.fl.us/specificationsoffice/pavement.htm

338-5.5 Remedial Work: During the warranty period, the Responsible Party will perform all necessary remedial work described within this Section at no cost to the Department. Should an impasse develop in any regard as to the need for remedial work or the extent required, the Statewide Disputes Review Board will render a final decision by majority vote.

Remedial work will not apply if any one of the following factors is found to be beyond the scope of the Contract:

a. Determination that the pavement thickness design is deficient. The Department will make available a copy of the original pavement thickness design package and design traffic report to the Responsible Party upon request.

\section{b. Determination that the Accumulated ESALs (Number of 18 Kip}

Equivalent Single Axle Loads in the design lane) have increased by $25 \%$ or more over the Accumulated ESALs used by the Department for design purposes for the warranty period. In calculating ESALs, the Average Annual Daily Traffic (AADT) will be obtained from the Department's traffic count data and the T24 (Percent Heavy Trucks during a 24 hour period) will be obtained from the Department's traffic classification survey data.

c. Determination that the deficiency was due to the failure of the existing underlying layers that were not part of the Contract work. 
d. Determination that the deficiency was the responsibility of a third party or its actions, unless the third party was performing work included in the Contract. If a measured distress value indicates remedial action is required per Table 338-1, Table 3382 and/or Table 338-3, the Responsible Party must begin remedial work within 45 calendar days of notification by the Department or a ruling of the Statewide Disputes Review Board. The Disputes Review Board will determine the allowable duration for the completion of the remedial work, but not to exceed 6 months.

In the event remedial action is necessary and forensic information is required to determine the source of the distress, the Department may core and/or trench the pavement. The Responsible Party will not be responsible for damages to the pavement as a result of any forensic activities conducted by the Department.

As applicable to distress criteria for rutting, ride and cracking for Category 1 and Category 2 pavements, when two LOTs requiring remedial action are not separated by three or more LOTs that otherwise require no remedial action, the remedial work shall be required for the total length of all such contiguous LOTs, including the intermediate LOTs otherwise requiring no remedial action.

Additionally, for Category 1 and Category 2 pavements, where the limits of remedial action are defined as $150 \%$ of the distressed area, and where such areas of remedial action required due to rutting, raveling, cracking, slippage or bleeding are not separated by 1,000 feet, the remedial work will be required for the entire area contiguous to the distressed areas, including intermediate areas otherwise requiring no remedial action.

The Responsible Party has the first option to perform all remedial work that is determined by the Department to be their responsibility. If, in the opinion of the Engineer, the problem poses an immediate danger to the traveling public and the Responsible Party cannot begin remedial work within 72 hours of written notification, the Engineer has the authority to have the remedial work performed by other forces. The Responsible Party is responsible for all incurred costs of the work performed by other forces should the problem (remedial work) be determined to be the responsibility of the Responsible Party. Remedial work performed by other forces does not alter any of the requirements, responsibilities or obligations of the Responsible Party.

The Responsible Party must complete all remedial work to the satisfaction of the Engineer. Any disputes regarding the adequacy of the remedial work will be resolved by the Statewide Disputes Review Board. Approval of remedial work does not relieve the Responsible Party from continuing responsibility under the provisions of this Specification.

Notify the Engineer in writing prior to beginning any remedial work. Meet the requirements of the Department's Standard Specifications for Road and Bridge Construction and implemented modifications thereto when performing any remedial work. Perform all signing and traffic control in accordance with the current edition of the 
Department's Design Standards for Design, Construction, Maintenance and Utility Operations on the State Highway System. Provide Maintenance of Traffic during remedial work at no additional cost to the Department. Lane closure restrictions listed in the original Contract will apply to remedial work. Written request(s) to obtain permission for lane closure(s) for either forensic investigation or remedial work must be made to the Engineer 48 hours in advance of any lane closures. Do not perform any lane closures until written permission is given by the Engineer. If remedial work necessitates a corrective action to overlying asphalt layers, pavement markings, signal loops, adjacent lane(s), roadway shoulders, or other affected Contract work, perform these corrective actions using similar products at no additional cost to the Department.

\section{8-6 Responsible Party's Failure to Perform.}

Should the Responsible Party fail to timely submit any dispute to the Statewide Disputes Review Board, fail to satisfactorily perform any remedial work, or fail to compensate the Department for any remedial work performed by the Department and determined to be the Responsible Party's responsibility in accordance with this Specification, the Department will suspend, revoke or deny the Responsible Party's certificate of qualification under the terms of Section 337.16(d)(2), Florida Statutes, for a minimum of 6 months or until the remedial work has been satisfactorily performed (or full and complete payment for remedial work performed by others made to the Department), whichever is longer. Should the Responsible Party choose to challenge the Department's notification of intent for suspension, revocation or denial of qualification and the Department's action is upheld, the Responsible Party will have its qualification suspended for an additional minimum of 6 months. The remedial work is not an obligation of the Contractor's bond required by Section 337.18, Florida Statutes. 
APPENDIX B

PAVEMENT CONDITION RATING SURVEY -FDOT 


\begin{tabular}{|c|c|c|c|c|c|c|c|c|c|c|c|c|c|c|c|c|c|c|c|c|c|c|c|c|c|c|c|c|c|c|c|c|c|c|}
\hline \multicolumn{35}{|c|}{ Table B1: Pavement Condition Rating for SR 836 (Dolphin Expressway) } \\
\hline RDWYID & BMP & EMP & & SYS & TYP & SPD & DISTRESS & SURVEYED & YEAR $\mathrm{F}$ & FUTURE & & & & & & & & & & & & & & & & & & & & & & & & \\
\hline SR & US & G_BMP $\quad$ G_ & EMP & LN & $\% \mathrm{~T}$ & AADT & RATINGS & 1983 & 1984 & 1985 & 1986 & 1987198 & 1988 & 1989 & 1990 & 1991 & 1992 & 1993 & 1994 & 1995 & 1996 & 19971 & 19981 & 19992 & 2000 & 2001 & 2002 & 2003 & 2004 & 20052 & 2006 & 20072 & 200820 & 2013 \\
\hline INTERSECT & AT & $(M P|S| D E) \quad S U$ & JRFTYPE & ==-==-== & & & & & & & & & & & & & & & & & & & & & & & & & & & & & & \\
\hline ITMSEG-P & W_BMP V & W_EMP $\quad$ RV & N & FY-P & WKMX- & & & & & & & & & & & & & & & & & & & & & & & & & & & & & \\
\hline CONTRACTOR & (AGE_ONE Y & YEAR) & STYPE & & & & & & & & & & & & & & & & & & & & & & & & & & & & & & & \\
\hline ITMSEG-F W W & W_BMP $\quad V$ & W_EMP $\quad$ RW & & FY-F & WKMX- & (REG) & & & & & & & & & & & & & & & & & & & & & & & & & & & & \\
\hline 87200000 & 0 & $0.445 \mathrm{R}$ & & & 1 & 1 & 45 CRACKING & 9.4 & & & 9.4 & 9.4 & 9.4 & 9.4 & 10 & 10 & 10 & 10 & 10 & 10 & 10 & 10 & 10 & 10 & 10 & 10 & 10 & 10 & 10 & 10 & 10 & 9.5 & 8 & 8 \\
\hline 836 & 3 & 4 & 113000 & & & & RIDE & 8.9 & & & 9.2 & 9.1 & 8.8 & 9.2 & 9.3 & 8.8 & 8.7 & 8.1 & 8.1 & 8 & 8.8 & 8.7 & 8.9 & 8 & 8.2 & 8.2 & 8.5 & 8.3 & 7.7 & 7.6 & 7.5 & 7.8 & 8 & 7.1 \\
\hline & & & & & & & RUTTING & 8 & & & 9 & 9 & 9 & 8 & 8 & 8 & 9 & 9 & 9 & 9 & 10 & 10 & 10 & 10 & 10 & 9 & 10 & 9 & 9 & 9 & 9 & 9 & 9 & 8 \\
\hline 87200000 & 0 & $0.445 R$ & & & 1 & 1 & 45 CRACKING & & & & & & & & & & & & & & & & & & & & & & & & & & & \\
\hline 87200000 & 0 & $0.445 R$ & & & 1 & 1 & 45 RIDE & & & & & & & & & & & & & & & & & & & & & & & & & & & \\
\hline 836 & 3 & 4 & 113000 & & & & RUTTING & & & & & & & & & & & & & & & & & & & & & & & & & & & \\
\hline HEFT( & $0.0 \mathrm{R})$ & & & & & & & & & & & & & & & & & & & & & & & & & & & & & & & & & \\
\hline 2499261 & 0 & $1.065 \mathrm{C}$ & & 1993 & & 12 & & & & & & & & & & & & & & & & & & & & & & & & & & & & \\
\hline BREWER $\quad C C$ & co & OF & ORIDA & INC & -19 & & & & & & & & & & & & & & & & & & & & & & & & & & & & & \\
\hline 87200000 & 0.445 & $2.98 \mathrm{R}$ & & & 1 & 7 & 45 CRACKING & 9.4 & & & 9.4 & 9.4 & 9.4 & 9.4 & 9.4 & 10 & 10 & 10 & 9.5 & 9.5 & 8 & 8 & 76.0 & $6.0^{*} \quad 6.6$ & $6.0 * \quad 6$. & $6.0^{*}$ & 10 & 10 & 10 & 10 & 10 & 10 & & \\
\hline 836 & 3 & 4.7 & 157000 & & & & RIDE & 8.9 & & & 9.2 & 9.1 & 8.8 & 9.2 & 9.4 & 8.4 & 8.3 & 8.3 & 8.6 & 8.4 & 8.6 & 8.4 & 8.7 & 8.7 & 8.7 & 8.6 & 9 & 8.9 & 8.3 & 8.5 & 8.4 & 7.6 & & \\
\hline & & & & & & & RUTTING & 8 & & & 9 & 9 & 9 & 8 & 8 & 8 & 9 & 9 & 9 & 9 & 9 & 9 & 9 & 8 & 8 & 8 & 10 & 10 & 10 & 10 & 10 & 9 & & \\
\hline & & & & & & & CRACKING & & & & & & & & & & & & & & & & & & & & & & & & & & & \\
\hline-2008 & & & & & & & $\begin{array}{l}\text { RIDE } \\
\text { RUTTING }\end{array}$ & & & & & & & & & & & & & & & & & & & & & & & & & & & \\
\hline 87200000 & 5.199 & $6.195 \mathrm{R}$ & & & 1 & 1 & 55 CRACKING & 9.4 & & & 9.4 & 9.4 & 9.4 & 9.4 & 9.4 & 10 & 10 & 10 & 9.5 & 9.5 & 8 & 8 & 76.0 & $6.0^{*} \quad 6.6$ & $5.0^{*} \quad 6$. & $6.0^{*}$ & 10 & 10 & 10 & 10 & 10 & 10 & 9.5 & 9.5 \\
\hline 836 & 3 & 4 & 207000 & & & & RIDE & 8.1 & & & 8.2 & 8.4 & 7.9 & 8.3 & 8.6 & 8.4 & 8.3 & 8.3 & 8.6 & 8.4 & 8.6 & 8.4 & 8.7 & 8.7 & 8.7 & 8.6 & 9.1 & 9 & 8.6 & 8.8 & 8.7 & 8.7 & 8.1 & 7.7 \\
\hline & & & & & & & RUTTING & 8 & 9 & 8 & 8 & 9 & 8 & 8 & 9 & 9 & 9 & 9 & & & 9 & 9 & 9 & 8 & 8 & 8 & 10 & 10 & 10 & 9 & 9 & 9 & 9 & 8 \\
\hline & & & & & & & CRACKING & & & & & & & & & & & & & & & & & & & & & & & & & & & \\
\hline-2002 & & & & & & & $\begin{array}{l}\text { RIDE } \\
\text { RUTTING }\end{array}$ & & & & & & & & & & & & & & & & & & & & & & & & & & & \\
\hline 87200000 & 8.002 & $8.527 \mathrm{R}$ & & & 1 & 1 & 55 CRACKING & 9.4 & & & 10 & 9.4 & 9.4 & 9.4 & 9.4 & 10 & 10 & 10 & 9.5 & 9.5 & 9.5 & 9.5 & 9.5 & 9.5 & 9.5 & 9.5 & 9.5 & 9.5 & 9.5 & 9.5 & 8 & 7.5 & 6.5 & 6.5 \\
\hline 836 & 3 & 4 & 154000 & & & & RIDE & 8.2 & & & 8.3 & 8.4 & 7.6 & 8.3 & 8.8 & 8.4 & 8.3 & 8.3 & 8.6 & 8.4 & 8.6 & 8.5 & 8.5 & 8.6 & 8.6 & 8.6 & 8.5 & 8.5 & 7.9 & 8 & 7.8 & 7.8 & 7.5 & 7.5 \\
\hline & & & & & & & RUTTING & 8 & 9 & 9 & 9 & 9 & 9 & 8 & 9 & 9 & 9 & 9 & & & 8 & 8 & 8 & 8 & 8 & 8 & 8 & 8 & 8 & 8 & 8 & 7 & 7 & 7 \\
\hline-1978 & & & & & & & $\begin{array}{l}\text { RIDE } \\
\text { RUTTING }\end{array}$ & & & & & & & & & & & & & & & & & & & & & & & & & & & \\
\hline 87200000 & 8.527 & $9.144 R$ & & & 1 & 1 & 55 CRACKING & 9.4 & & & 10 & 9.4 & 9.4 & 9.4 & 9.4 & 10 & 10 & 10 & 9.5 & 9.5 & 8 & 6.54 .0 & $.0 * \quad 4.0$ & $4.0^{*} \quad 4.6$ & $\begin{array}{l}4.0^{*} \quad 4 . \\
.\end{array}$ & $4.0^{*}$ & 10 & 10 & 10 & 10 & 10 & 9.5 & 7 & 6.5 \\
\hline 836 & 3 & 4 & 170500 & & & & RIDE & 8.2 & & & 8.3 & 8.4 & 7.6 & 8.3 & 8.8 & 8.4 & 8.3 & 8.3 & 8.6 & 8.4 & 8.4 & 8.3 & 8.3 & 7.9 & 7.8 & 7.4 & 8.4 & 8.4 & 7.7 & 7.3 & 7 & 7.7 & 7.36 .1 & \\
\hline & & & & & & & $\begin{array}{l}\text { RUTTING } \\
\text { CRACKING }\end{array}$ & 8 & & & 9 & 9 & 9 & 9 & 9 & 8 & 9 & 9 & 9 & 9 & 9 & 8 & 8 & 8 & 8 & 8 & 10 & 9 & 10 & 9 & 9 & 9 & 9 & 8 \\
\hline-2002 & & & & & & & $\begin{array}{l}\text { RIDE } \\
\text { RUTTING }\end{array}$ & & & & & & & & & & & & & & & & & & & & & & & & & & & \\
\hline 87200000 & 9.144 & $9.514 R$ & & & 1 & 1 & 55 CRACKING & 9.4 & & & 10 & $9.4 \quad 9$ & 9.4 & 9.4 & 9.4 & 10 & 10 & 9 & 9 & 9 & 6.5 & & $.0 * \quad 6.0$ & $6.0 * \quad 6.0$ & $6.0^{*} \quad 6$. & $6.0^{*}$ & 10 & 9.5 & 9.5 & 9.5 & 9.5 & 7 & 75.0 & $.0^{*}$ \\
\hline 836 & 3 & 4 & 170500 & & & & RIDE & 7.8 & & & 7.9 & $7.76 .0^{*}$ & & 7.7 & 8.3 & 8.2 & 8.3 & 8.3 & 8.5 & 8.4 & 8.3 & & 7.9 & 7.9 & 7.3 & 7.9 & 7.8 & 7.1 & 6.7 & 6.76. & & $5.7^{*} \quad 5.1$ & $5.1 * \quad 3.2$ & $.2^{*}$ \\
\hline & & & & & & & $\begin{array}{l}\text { RUTTING } \\
\text { CRACKING }\end{array}$ & 8 & & & 9 & 9 & 9 & 9 & 9 & 9 & 10 & 9 & 9 & 9 & 9 & & 9 & 9 & 10 & 9 & 10 & 9 & 9 & 9 & 9 & 9 & 8 & 7 \\
\hline-2002 & & & & & & & RIDE & & & & & & & & & & & & & & & & & & & & & & & & & & & \\
\hline & & & & & & & RUTTING & & & & & & & & & & & & & & & & & & & & & & & 10 & 10 & 10 & 10 & 10 \\
\hline
\end{tabular}




\section{Table B2: Pavement Condition Rating for SR 836 (Dolphin Expressway)}

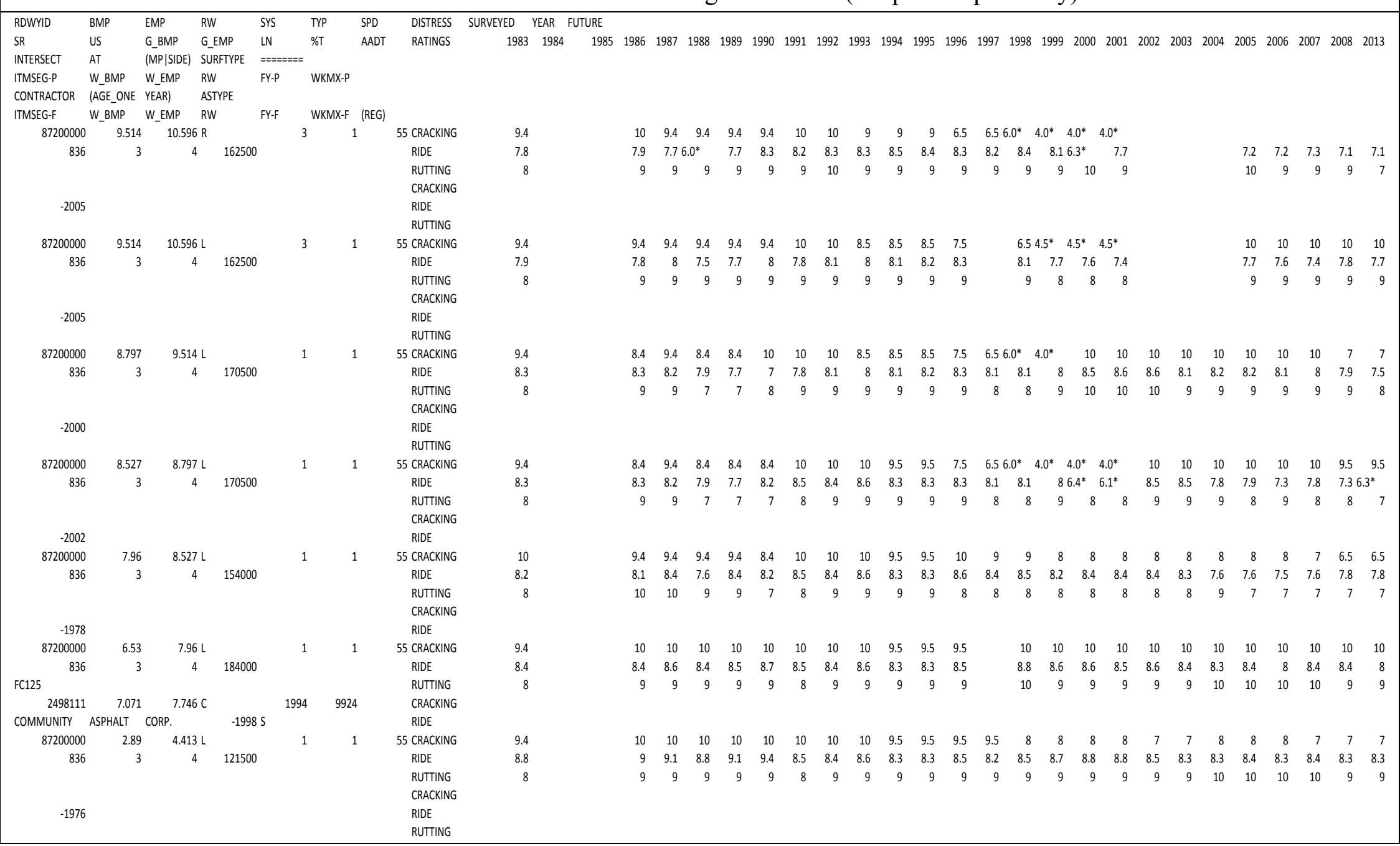




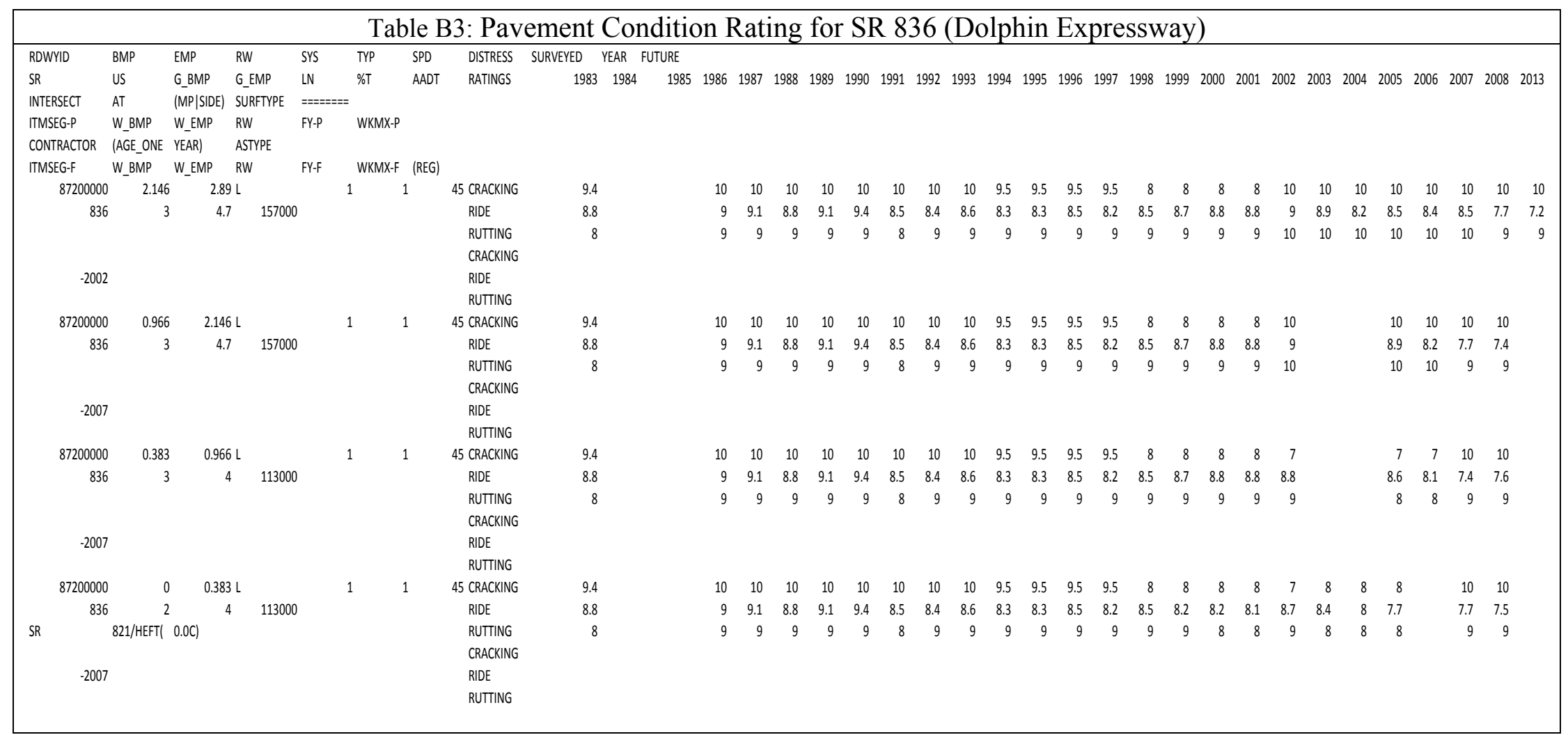


APPENDIX C

SENSITIVITY ANALYSIS RESULTS 
Table C1: Reduced Pavement Performance (5\% More Deterioration)

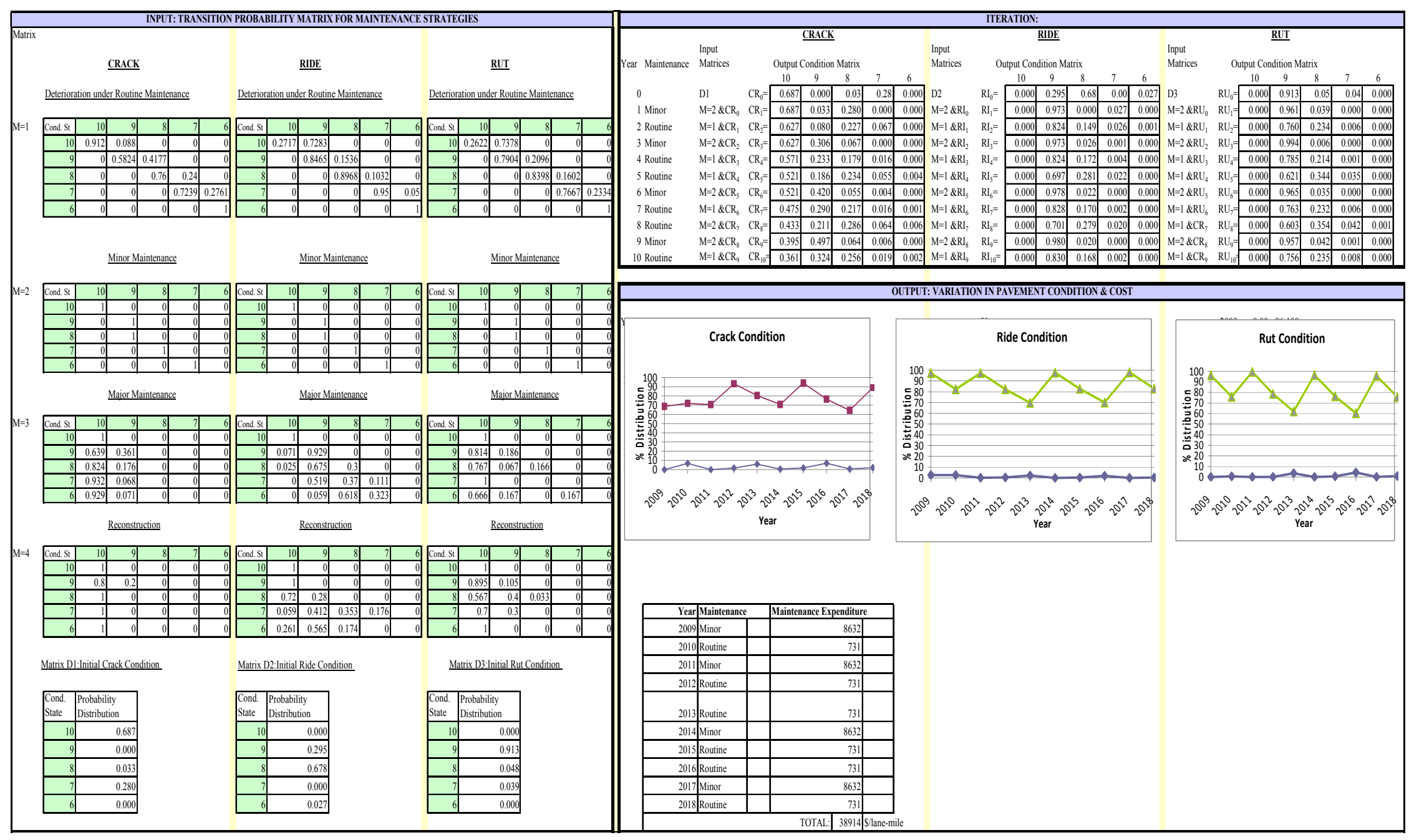


Table C2: Reduced Pavement Performance (10\% More Deterioration)

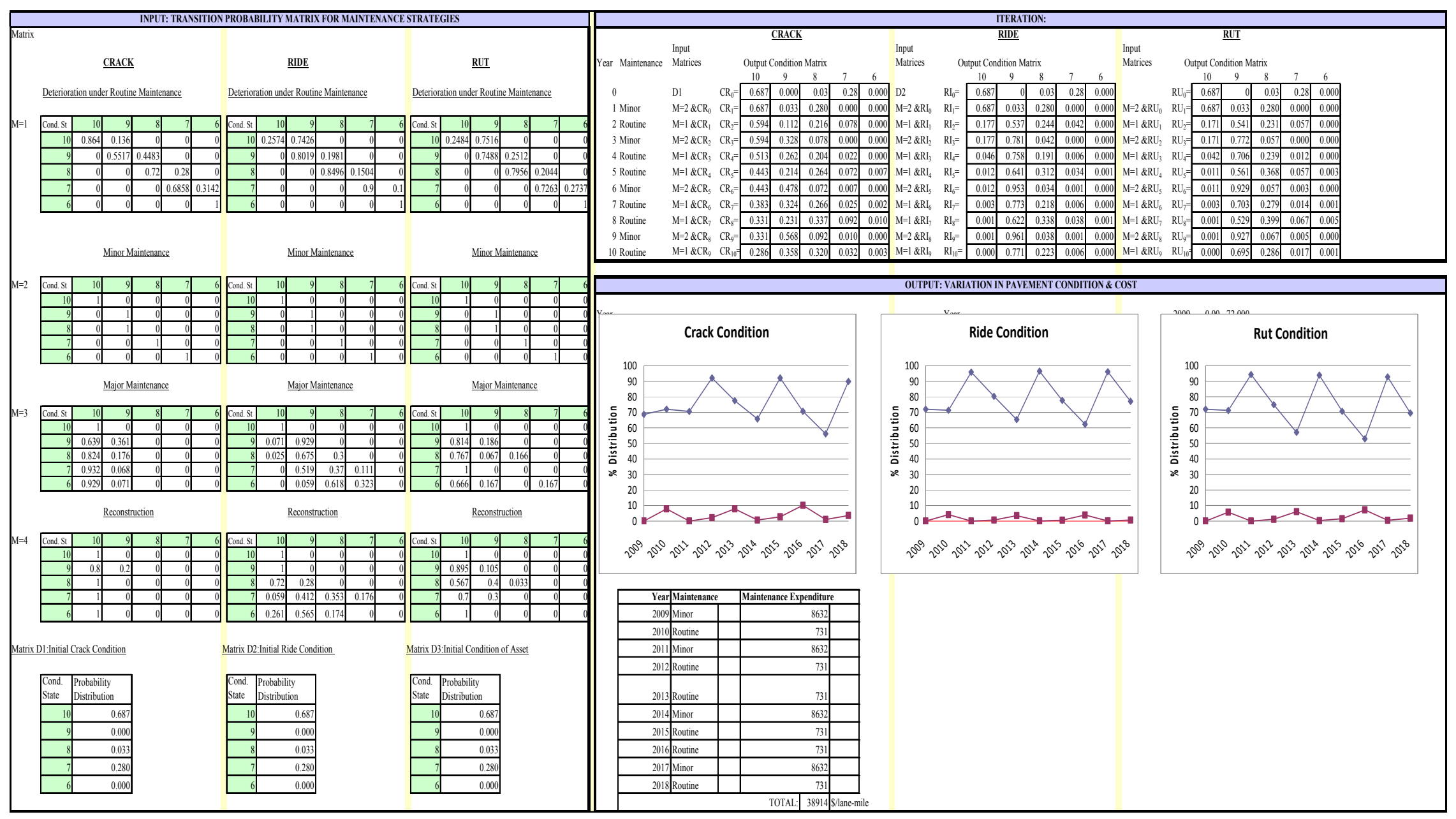


Table C3: Reduced Pavement Performance (15\% More Deterioration)

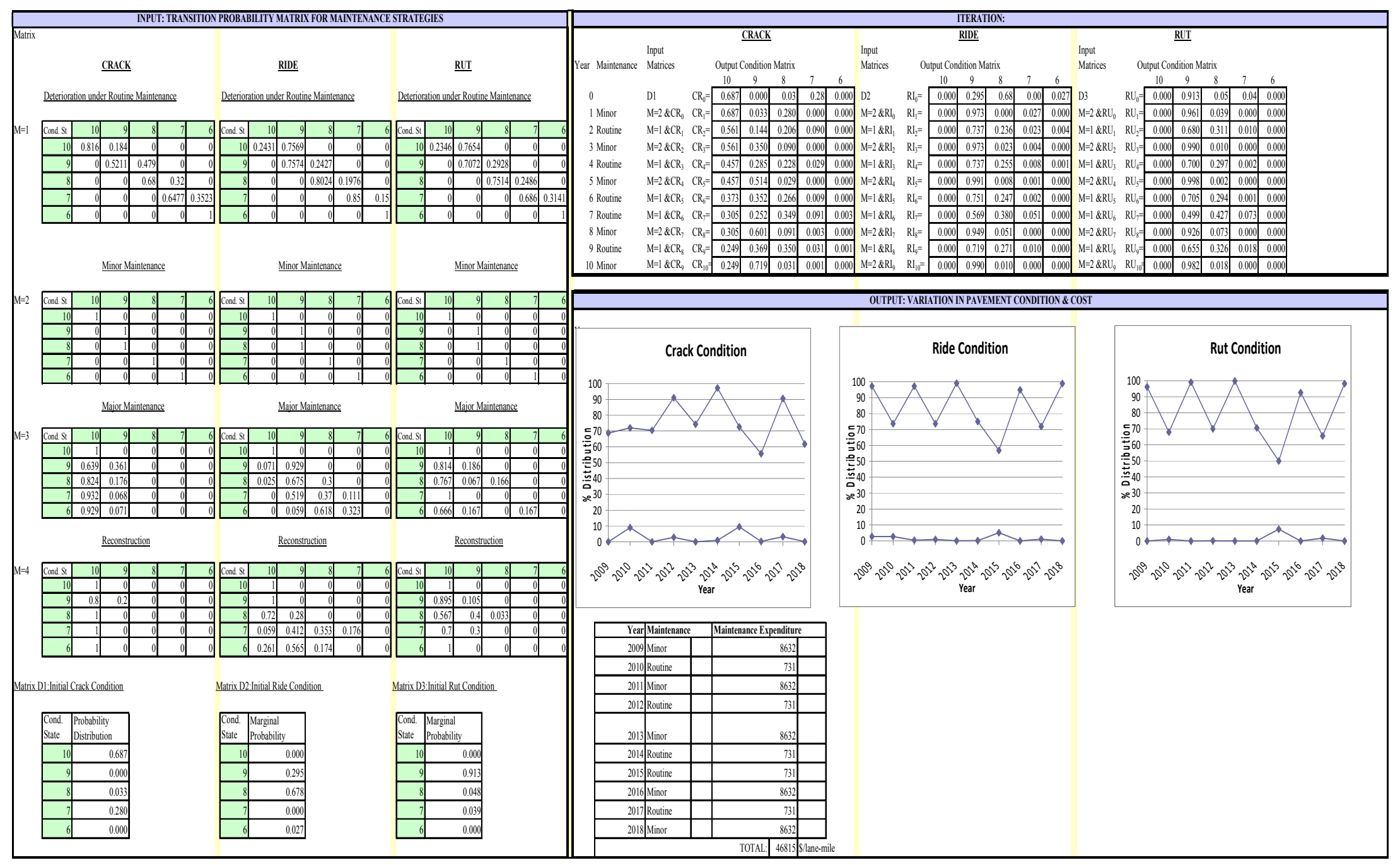


Table C4: Reduced Pavement Performance (20\% More Deterioration)

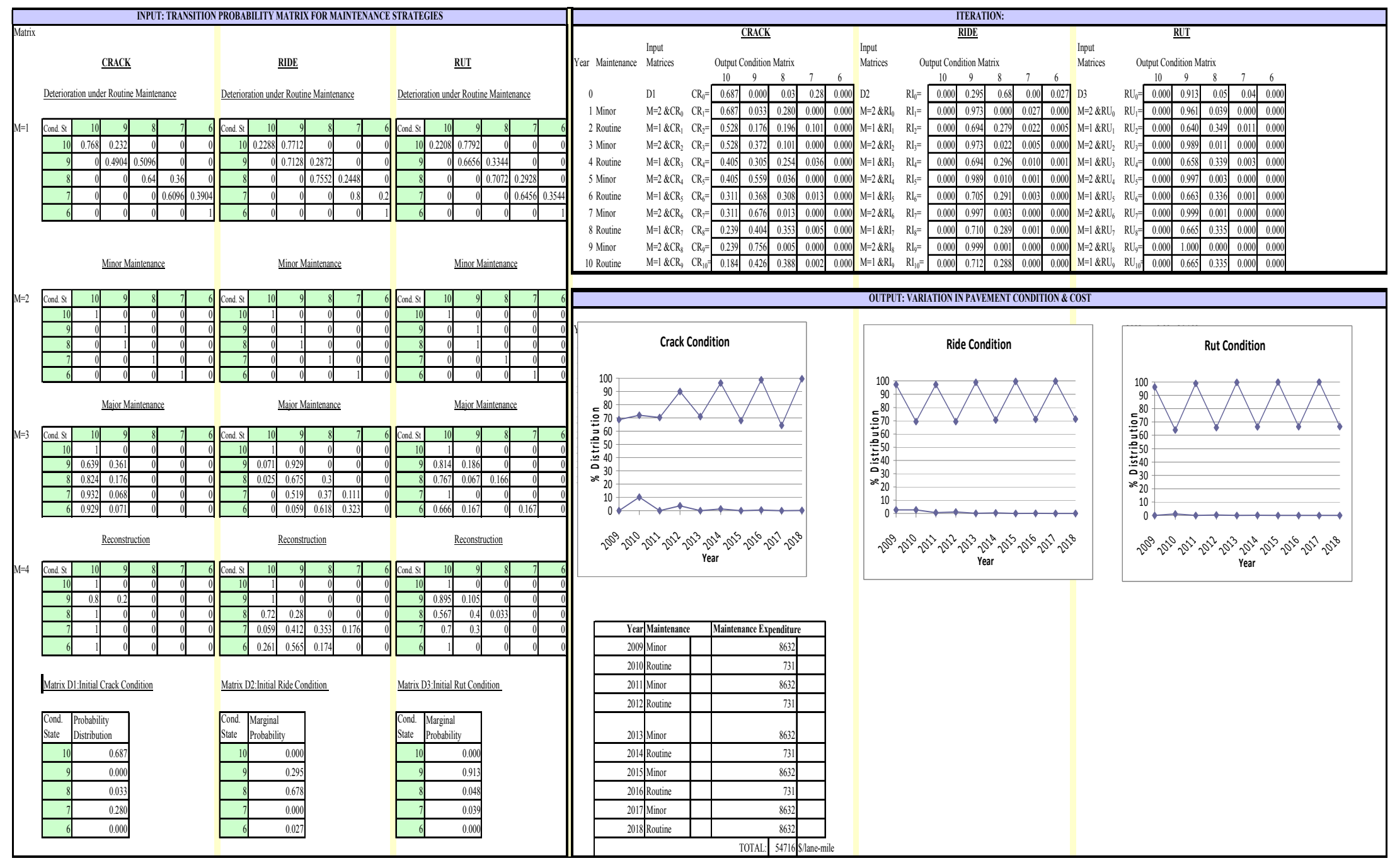


Table C5: Reduced Pavement Performance (25\% More Deterioration)

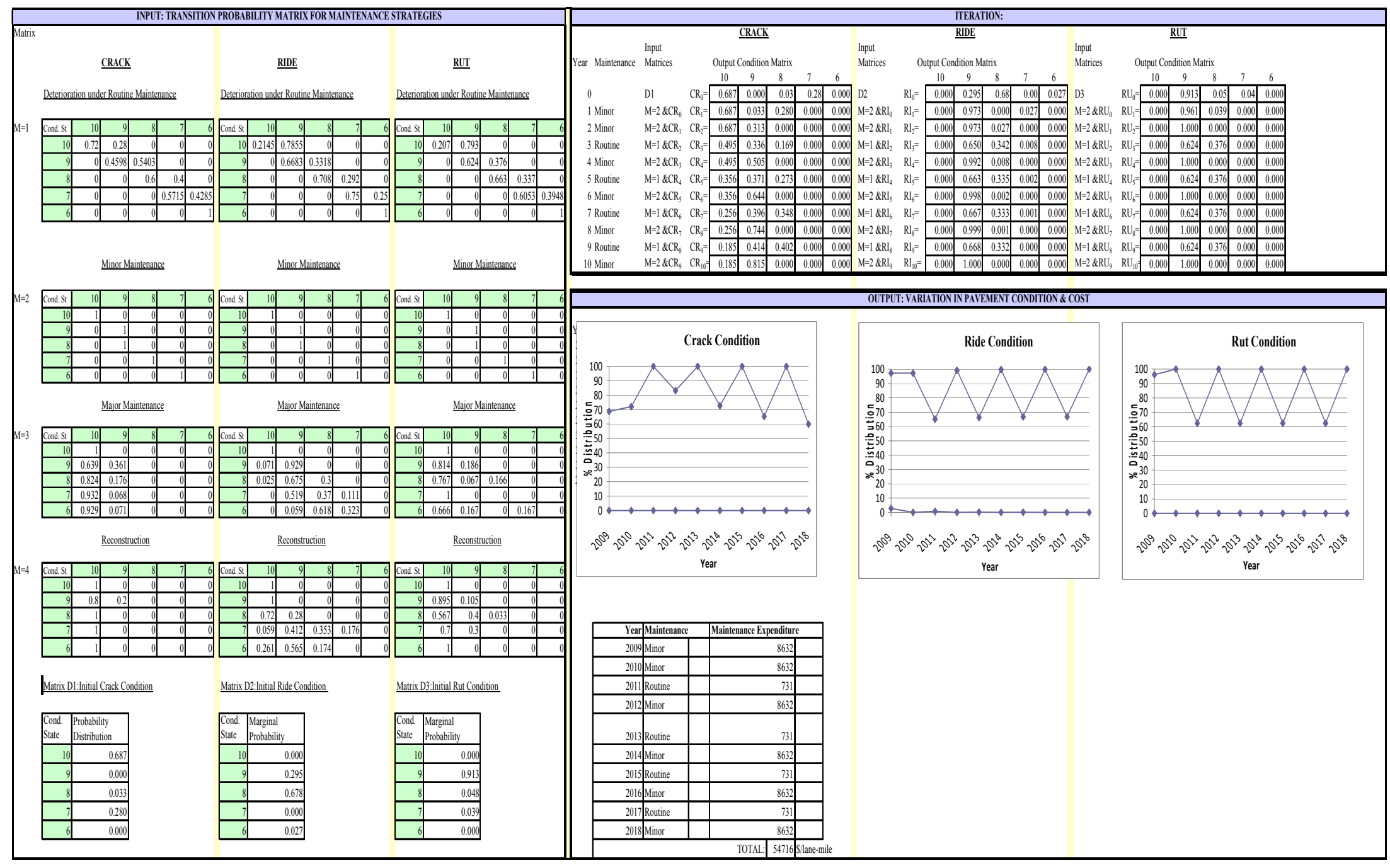


Table C6: Improved Pavement Performance (5\% Less Deterioration)

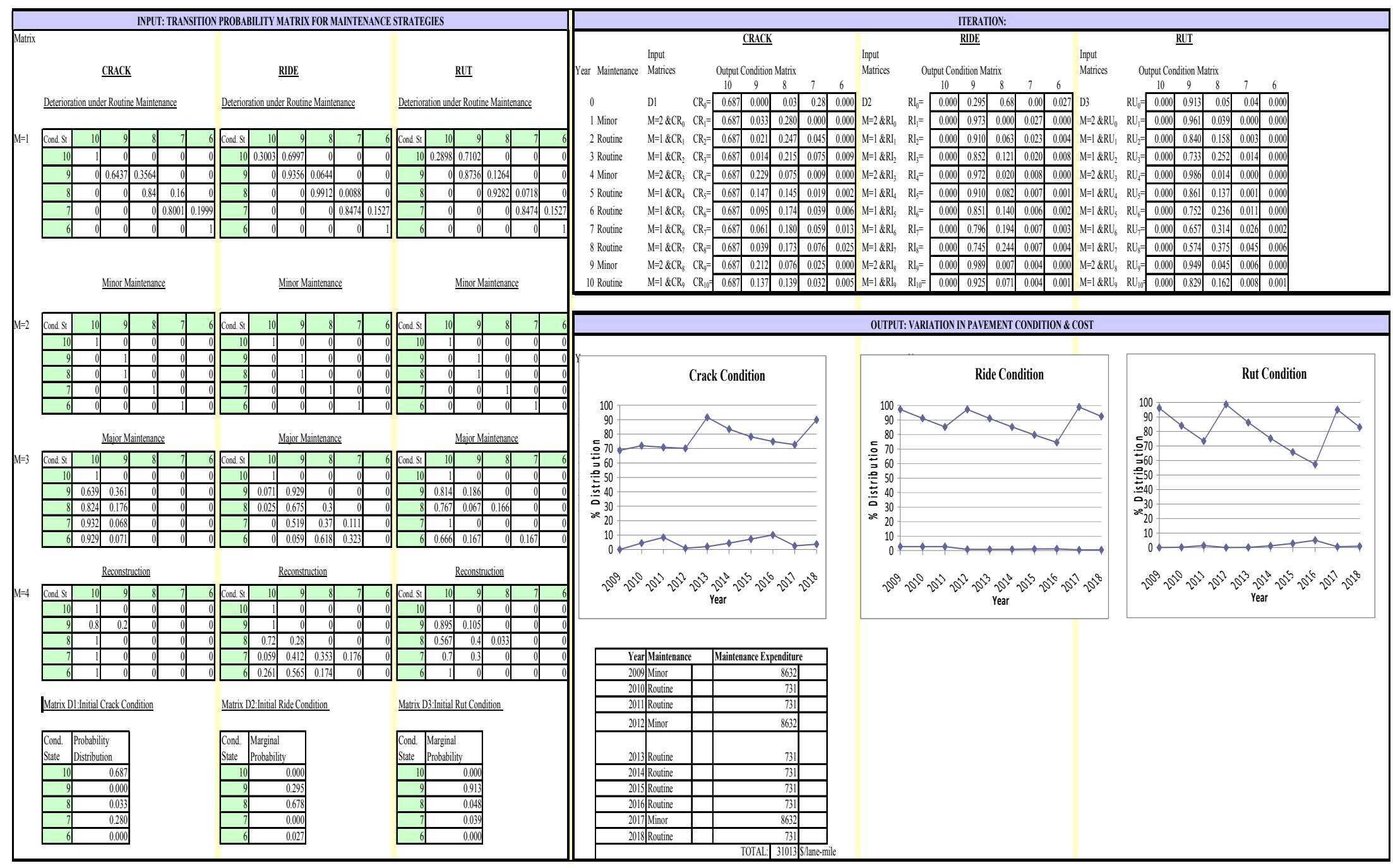


Table C7: Improved Pavement Performance (10\% Less Deterioration)

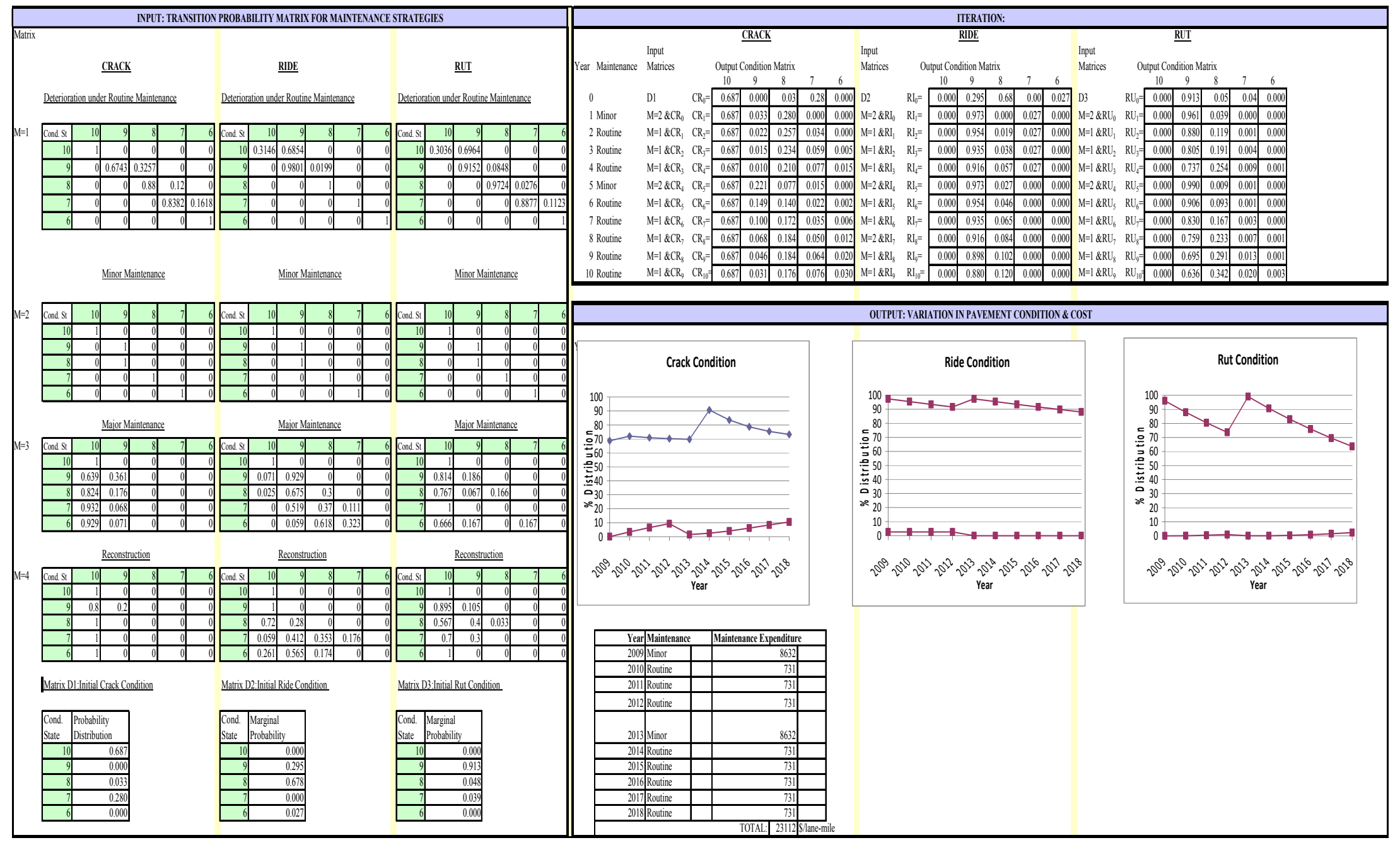


Table C8: Improved Pavement Performance (15\% Less Deterioration)

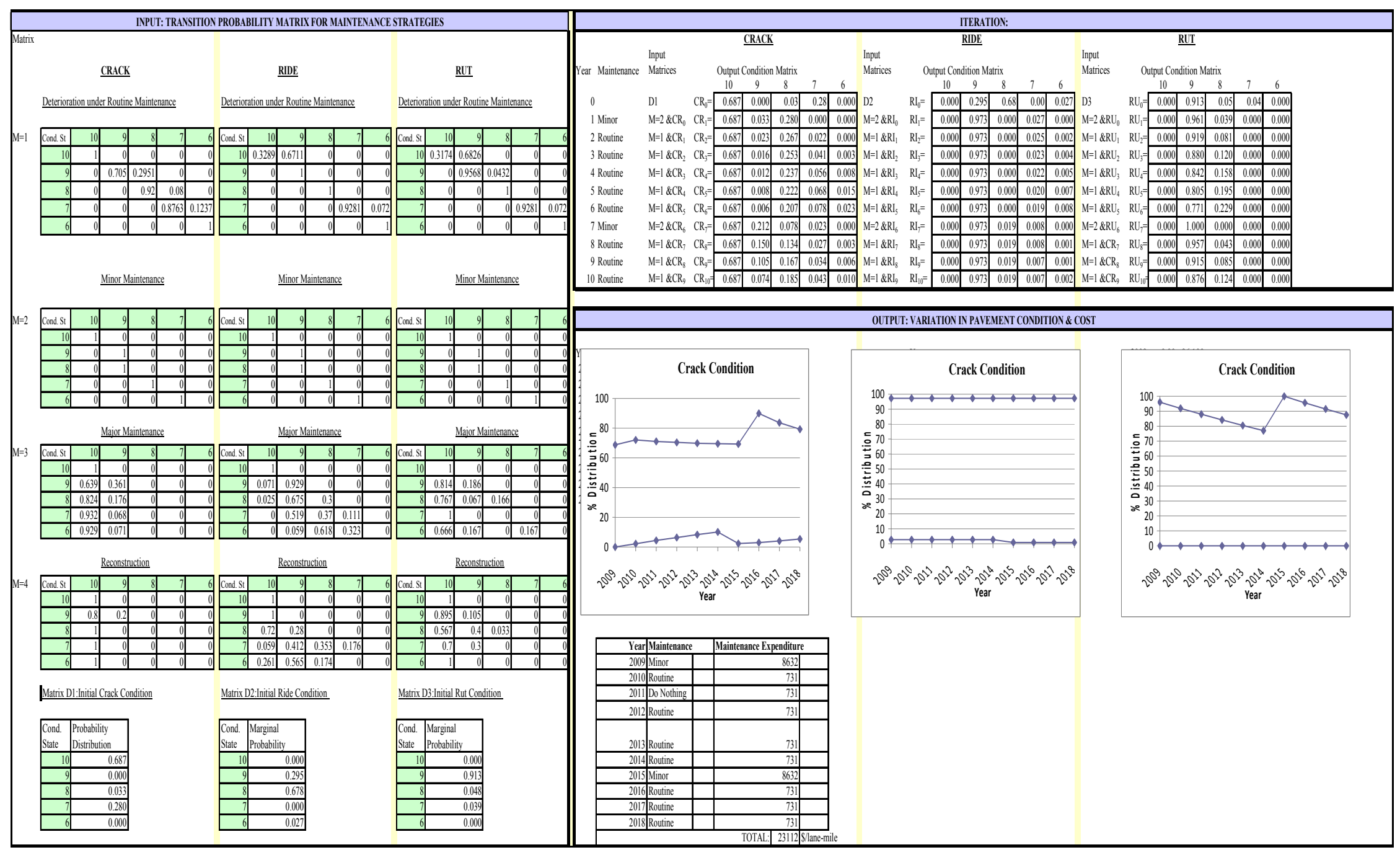


Table C9: Improved Pavement Performance (20\% Less Deterioration)

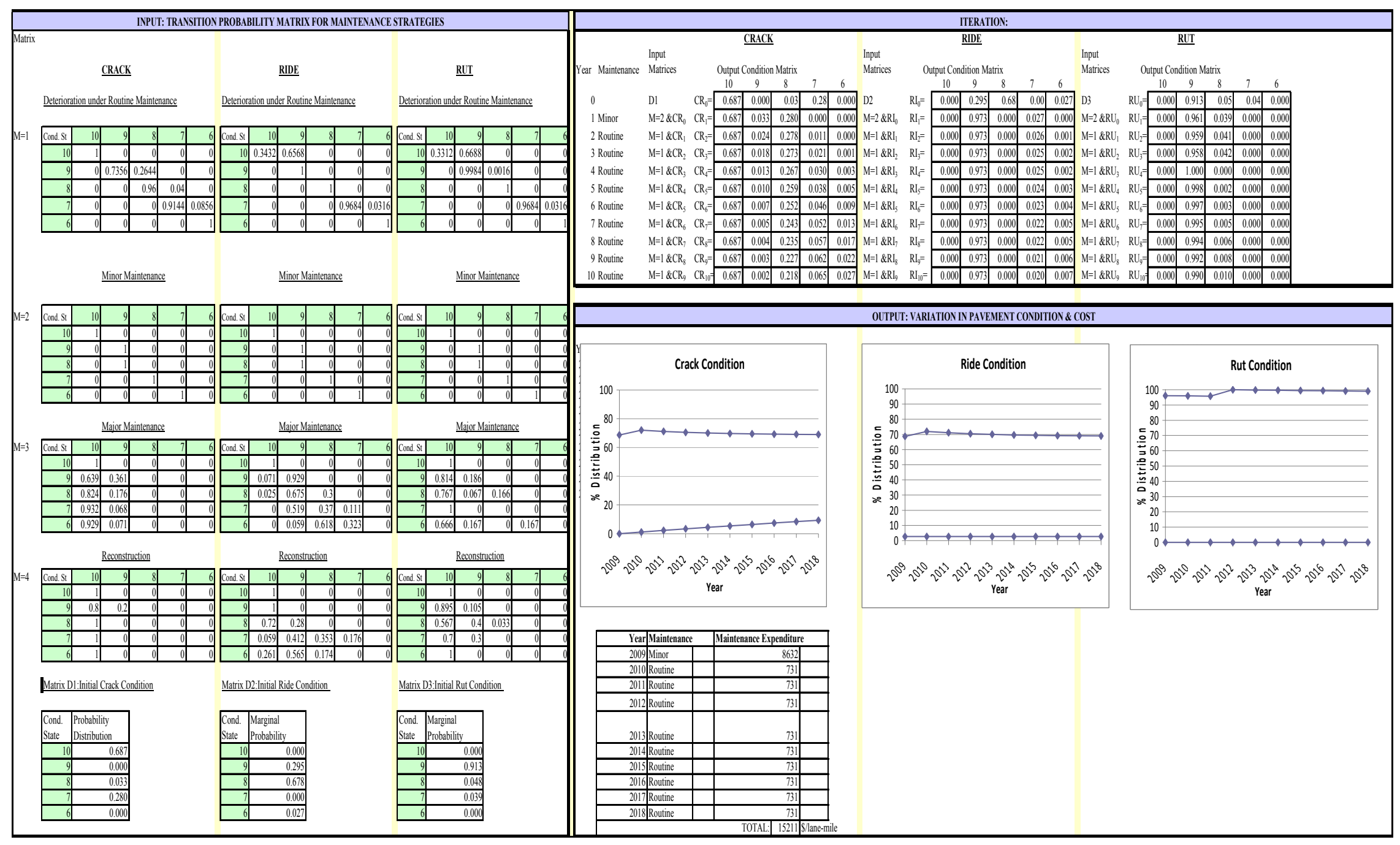


Table C10: Improved Pavement Performance (25\% Less Deterioration)

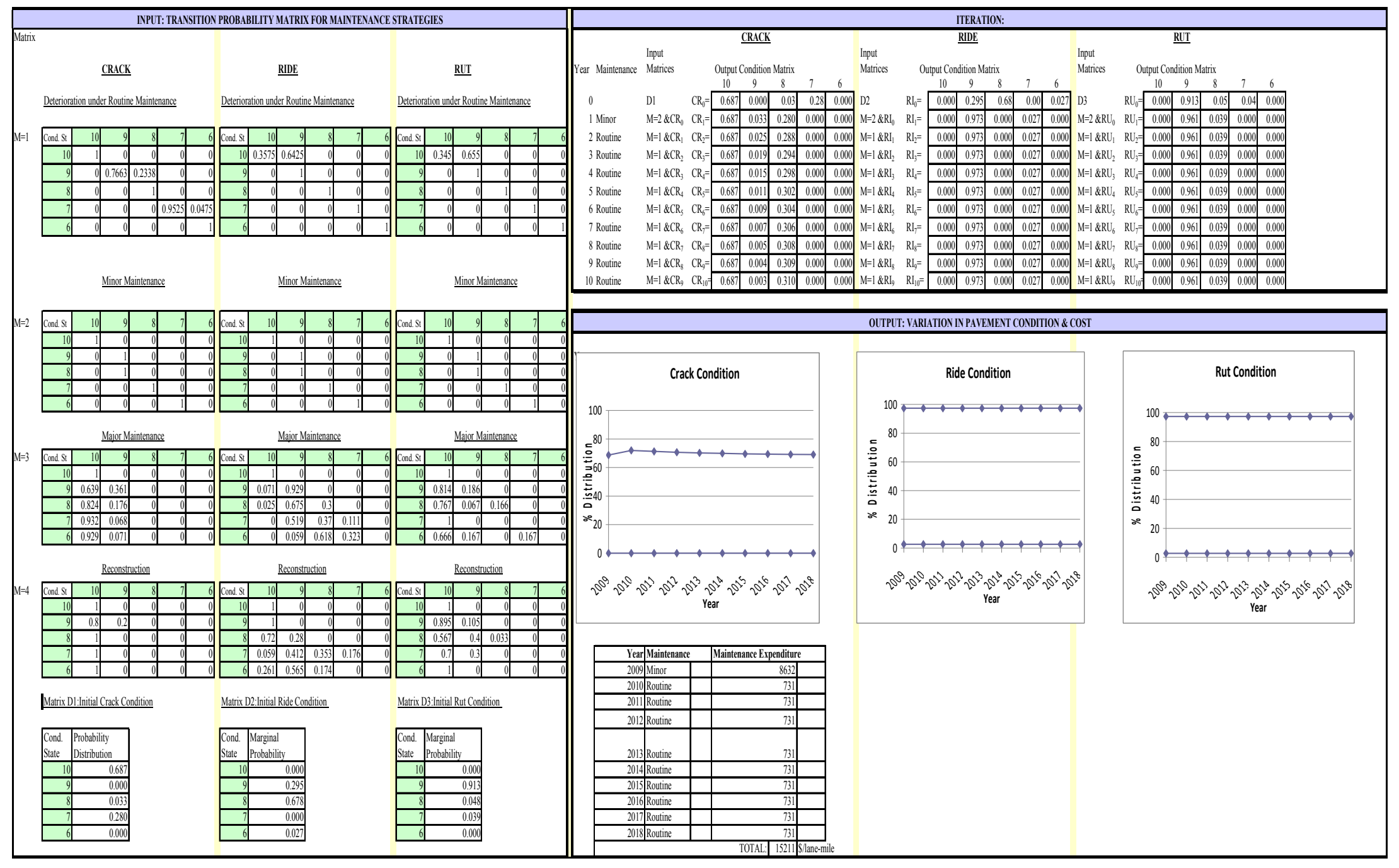


Table C11: Restricting the Proportion of Pavement Under Threshold Limit

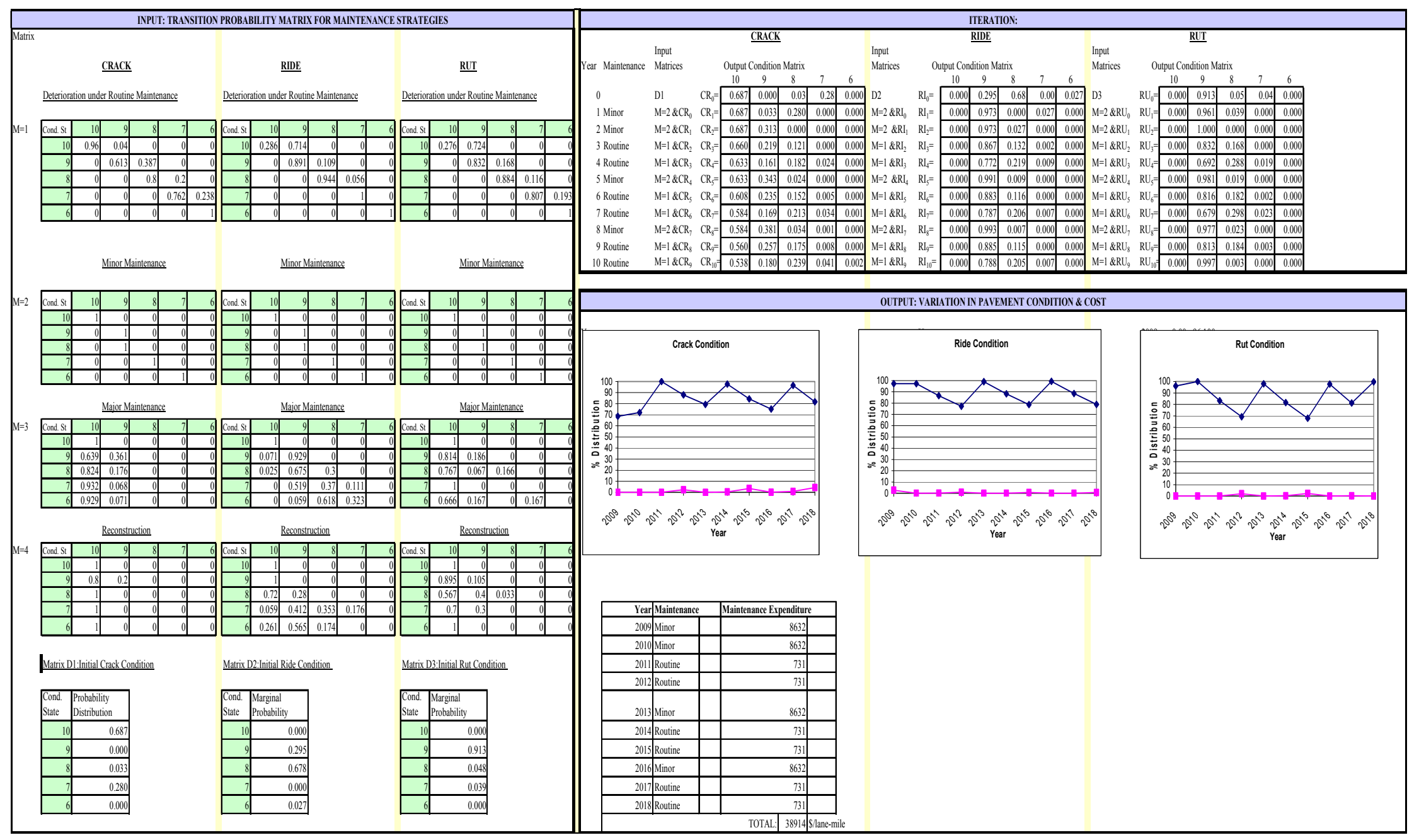


Table C12: Relaxing the Proportion of Pavement Under the Threshold Limit

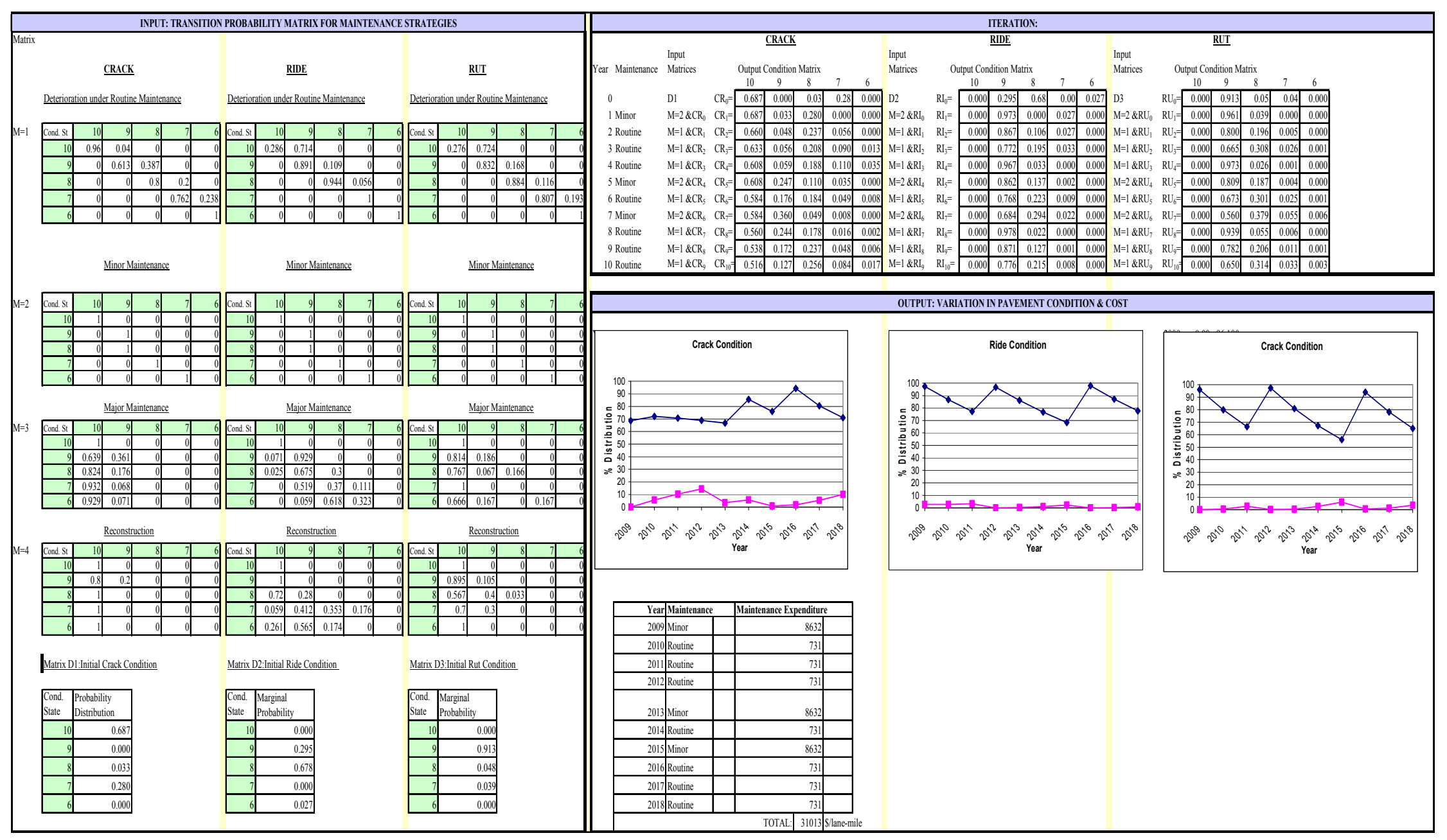


Table C13: Restricting the Performance Constraint (Threshold Level with a Condition Rating of 8)

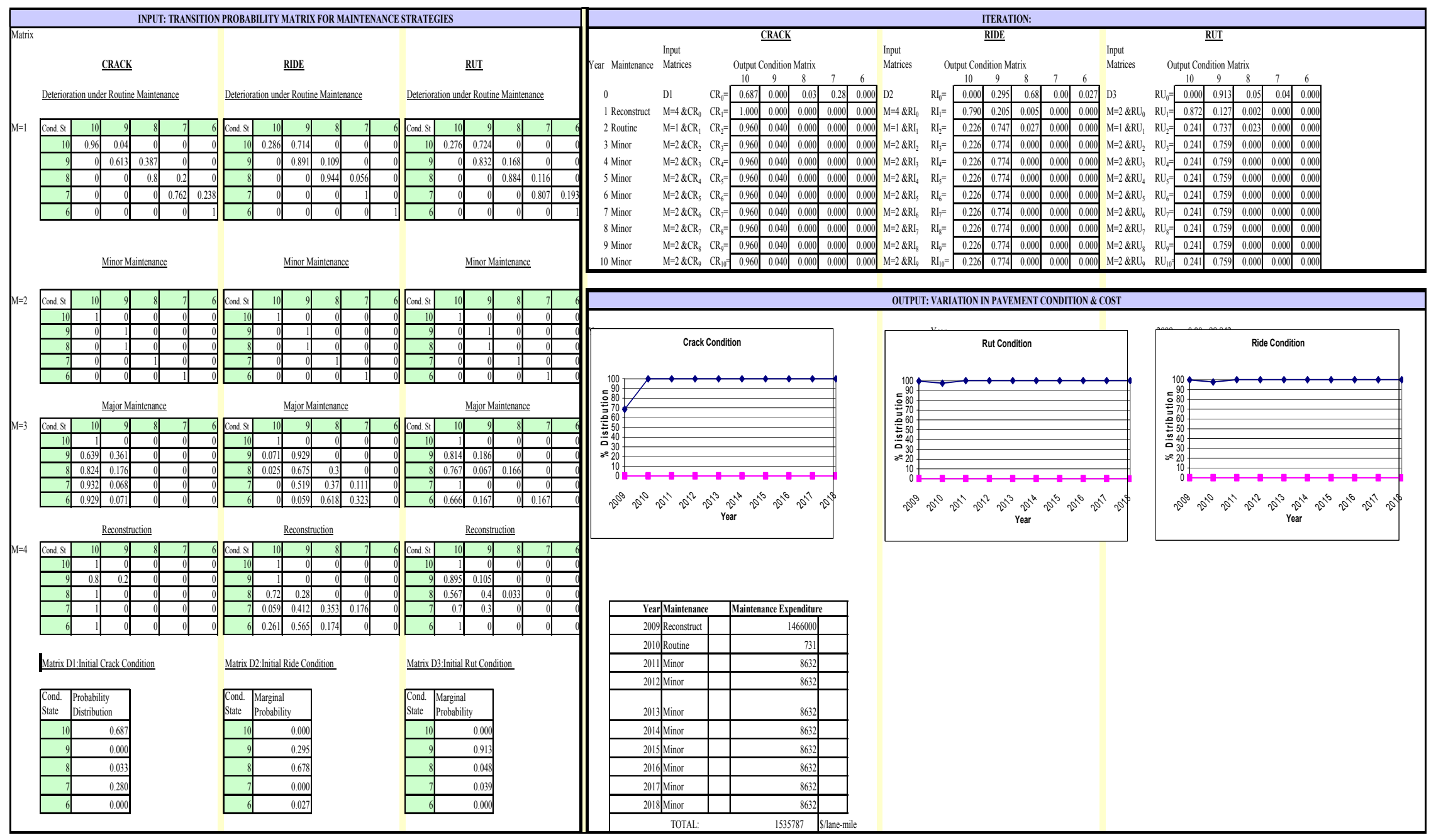


Table C14: Relaxing the Performance Constraint (Threshold Level with a Condition Rating of 6)

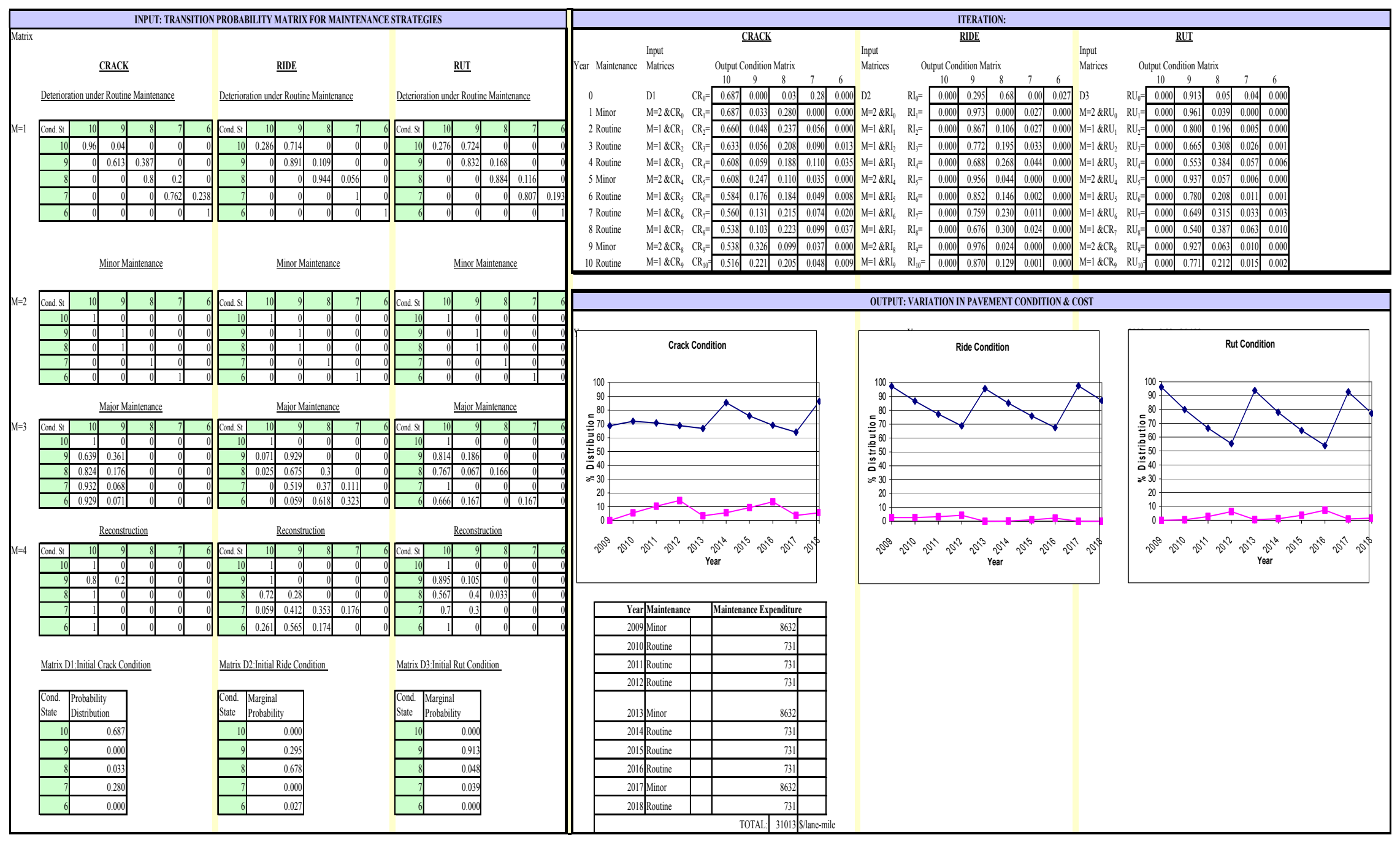


VITA

\section{KAMALESH PANTHI}

1995-1999

B.E. Civil Engineering

Karnataka Regional Engineering College

Surathkal, India

2002-2004 M. Eng. (Construction Engineering Management)

Asian Institute of Technology (AIT)

Bangkok, Thailand

1999-2002 Engineer

Lamjung Electricity Development Company (LEDCO)

Kathmandu, Nepal

2004-2005 Contract Administrator, QA/QC Engineer

Bovis Lend Lease (Thailand) Ltd.

Bangkok, Thailand

2005-2008 Research and Teaching Assistant

Department of Construction Management

Florida International University (FIU), Miami, Florida

\section{PUBLICATIONS}

Panthi, K., Ahmed, S. M., Ogunlana, S.O. (2009) "Contingency Estimation for Construction Projects through Risk Analysis," International Journal of Construction Education and Research, ASC. 5(2) pg. $79-94$.

Panthi, K., Ahmed, S. M, Farooqui R.U. (2009) "Estimating Pavement Maintenance Costs under Performance-based Contracts," Proceedings of the Fifth International Conference on Construction in the 21st Century, Istanbul, Turkey, May 20-22.

Farooqui, R. U., Saqib, M., Ahmed, S. M., Panthi, K., (2009) "Ranking Construction Superintendent Competencies and Attributes Required for Success in Pakistani Construction Industry," Proceedings of the Fifth International Conference on Construction in the 21st Century, Istanbul, Turkey, May 20-22.

Panthi, K., Farooqui R.U., Ahmed, S. M (2009) "An Investigation of the Leadership Style of Construction Managers in South Florida," ASC Proceedings of the $45^{\text {th }}$ Annual Conference, University of Florida, Gainesville, April1-5. 
Panthi, K., Ahmed, S. M., Azhar, S. (2007) "Risk Matrix as a Guide to Develop Risk Response Strategies," ASC Proceedings of the $43^{\text {rd }}$ Annual Conference, Northern Arizona University, Flagstaff, Arizona, April 12-14.

Panthi, K. (2007) "Prioritizing and estimating hydropower project construction risks: a case study of Nyadi hydropower project," Proceedings of the $2^{\text {nd }}$ Annual Himalayan Policy Research Conference, Nepal Study Center, Madison, Wisconsin, October 11.

Farooqui R. U., Ahmed, S. M., Panthi, K., (2007) "Safety in Developing Countries - An assessment of Contractor Safety Practices in Pakistan Construction Industry,"

Proceedings of the Fourth International Conference on Construction in the 21st Century, Gold Coast, Australia, July 11-13.

Panthi, K., Ahmed, S. M., (2008) “Application of Quality Tools to Improve Quality: A Case Study of a Building Remediation Contractor," ASC Proceedings of the $44^{\text {th }}$ Annual Conference, Auburn University, Auburn, Alabama, April 2-5.

Ahmed, S. M., Panthi, K., Farooqui R.U., Abreu, M., (2008) "ISO 9001: 2000 and its Implementation in Dominican Republic Construction Industry," Proceedings of the $6^{\text {th }}$ LACCEI Latin American and Caribbean Conference for Engineering and Technology, Tegucigalpa, Honduras, June 4-6.

Farooqui R.U., Ahmed, S. M., Panthi, K., (2008) "Electrical Safety at Construction Sites: An Exploratory Study of Temporary Power," Proceedings of the $6^{\text {th }}$ LACCEI Latin American and Caribbean Conference for Engineering and Technology, Tegucigalpa, Honduras, June 4-6.

Panthi, K., Bhattarai, S. (2008) "A Framework to Assess Sustainability of Communitybased Water Projects Using Multi-Criteria Analysis," Proceedings of the $1^{\text {st }}$ International Conference on Construction in Developing Countries, Karachi, Pakistan, August 4-5.

Panthi, K., Farooqui R.U., Ahmed, S. M (2008) "Modelling Product Performance Risks faced by Contractors in Performance Specified Road Maintenance Contracts," Proceedings of the $1^{\text {st }}$ International Conference on Construction in Developing Countries, Karachi, Pakistan, August 4-5. 